Aus der Abteilung Gastroenterologie und Endokrinologie

(Prof. Dr. med. Dr. h.c. G. Ramadori)

im Zentrum Innere Medizin

der Medizinischen Fakultät der Universität Göttingen

\title{
siRNA-basierte Studien zu der physiologischen Funktion des Transkriptionsfaktors Runx2 in humanen Osteoblasten
}

\author{
INAUGURAL-DISSERTATION \\ zur Erlangung des Doktorgrades \\ der Medizinischen Fakultät \\ der Georg-August-Universität zu Göttingen
}

vorgelegt von

Kai-Henrik Peiffer

aus

Bad Harzburg

Göttingen 2011 
Dekan:

I. Berichterstatterin:

II. Berichterstatter/in:

III. Berichterstatter/in:

Tag der mündlichen Prüfung:
Prof. Dr. med. Frömmel

Prof. Dr. med. Siggelkow

Prof. Dr. med. Hahn 


\section{Inhaltsverzeichnis}

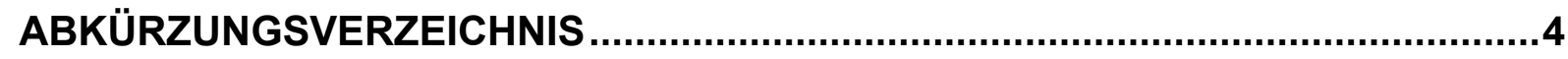

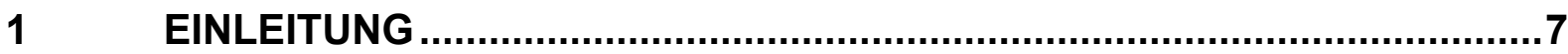

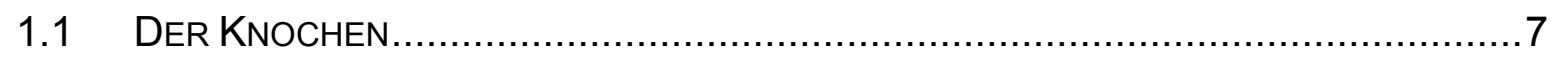

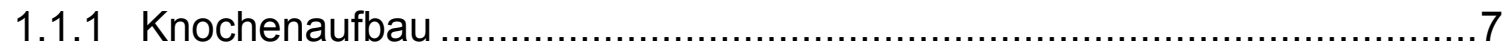

1.1.2 Knochentwicklung und Knochenumbau (Remodelling) ..........................

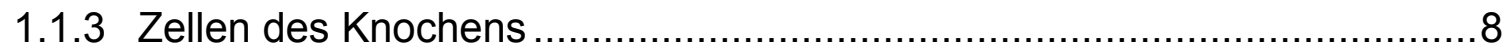

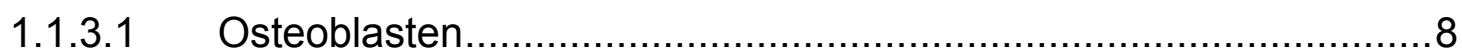

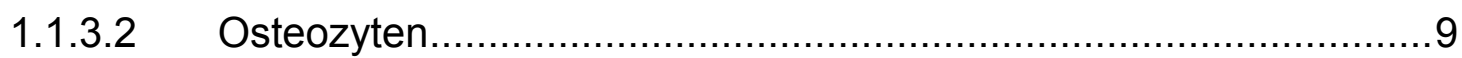

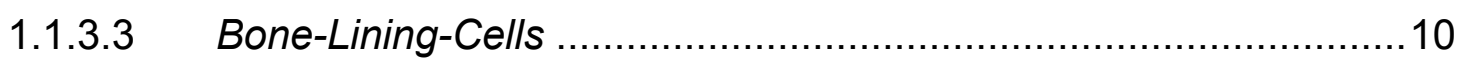

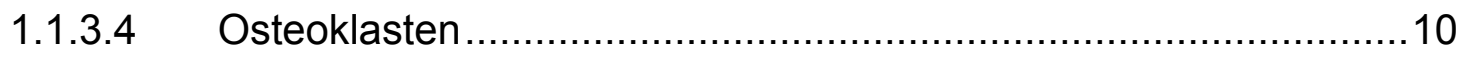

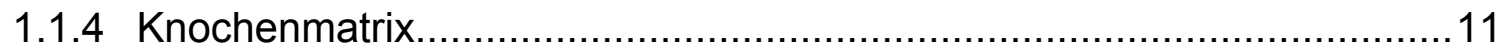

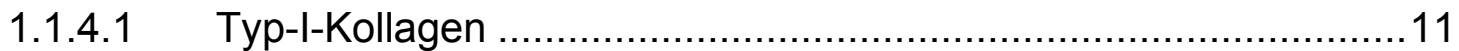

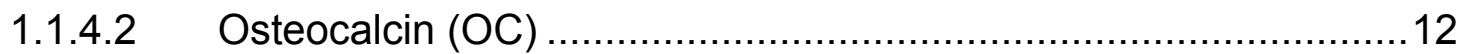

1.1.4.3 Alkalische Phosphatase (AP) .............................................12

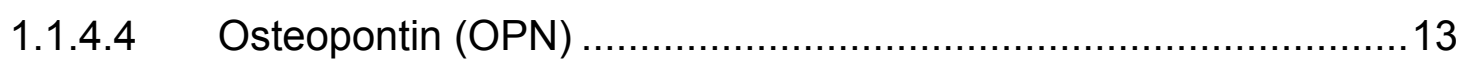

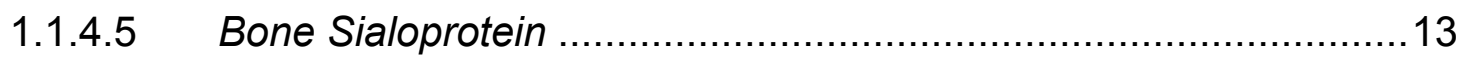

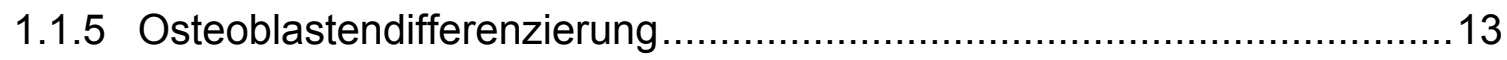

1.1.5.1 Runt-related transcription factor-2 (Runx2) ..............................15

1.1.5.2 Der canonical Wnt-Signalweg und Beta-Catenin ( $\beta$-Catenin) .......17

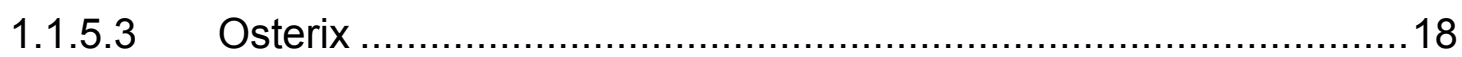

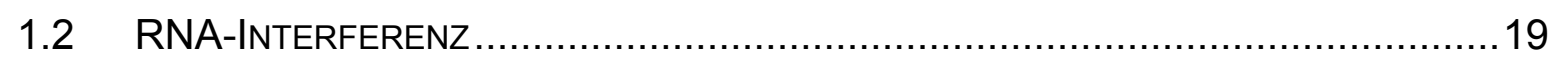

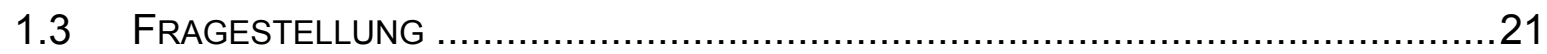

2 MATERIAL UND METHODEN

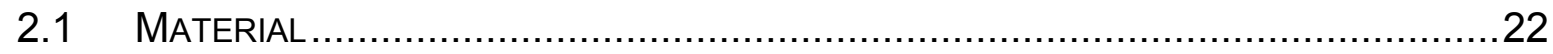

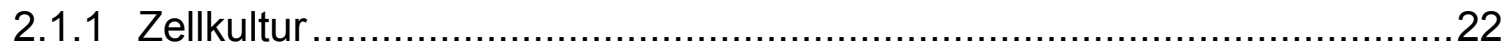

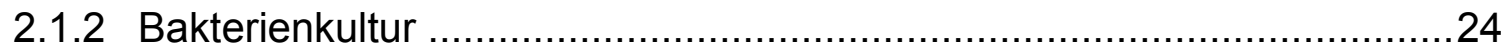

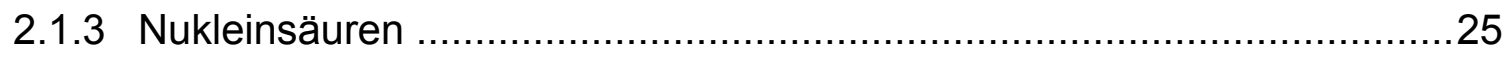

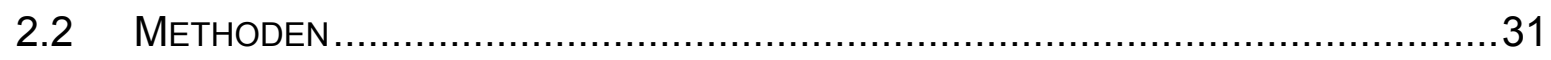

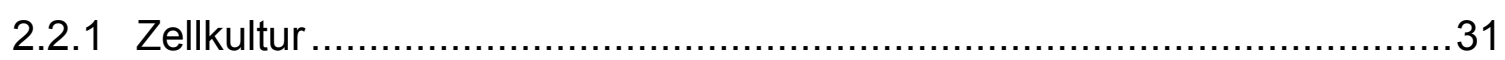

2.2.1.1 Gewinnung von primären humanen Osteoblasten ........................31

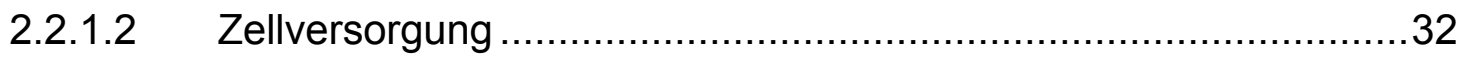




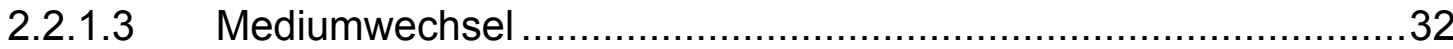

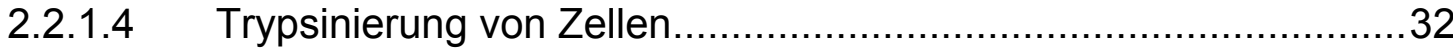

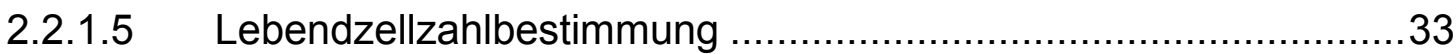

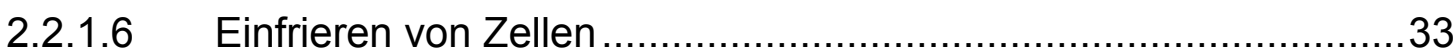

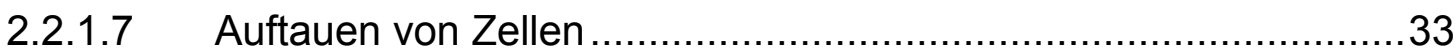

2.2.1.8 Isolierung von Gesamt-RNA ................................................... 34

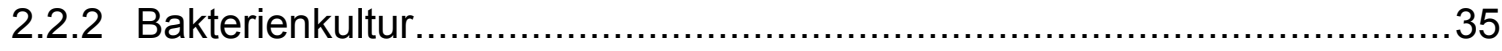

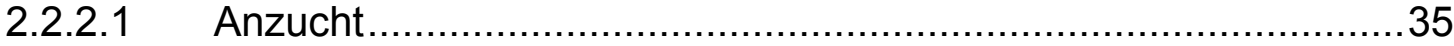

2.2.2.2 Präparation chemisch kompetenter E.coli.................................35

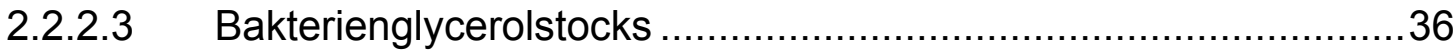

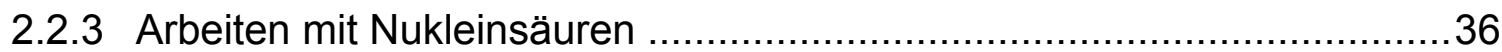

2.2.3.1 Photometrische Konzentrationsmessung..................................36

2.2.3.2 Agarose-Gelelektrophorese ....................................................

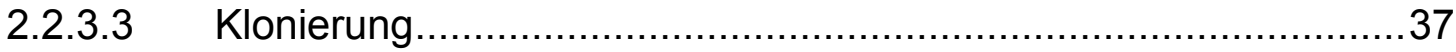

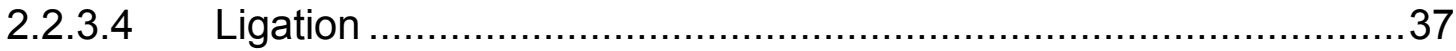

2.2.3.5 Transformation in chemisch kompetente E. coli .........................38

2.2.3.6 Analytische Plasmidisolierung (Miniprep) …..............................38

2.2.3.7 Präparative Plasmidisolierung (Maxiprep) ……...........................39

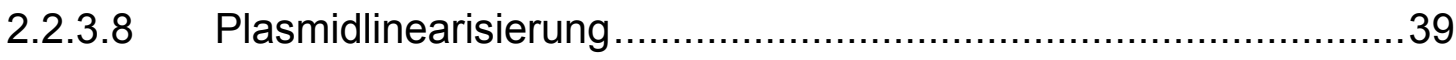

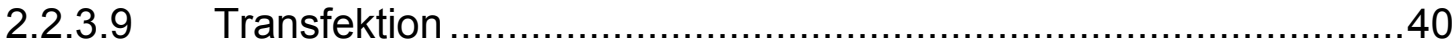

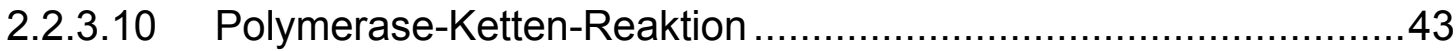

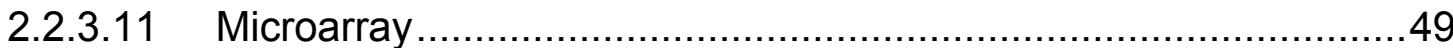

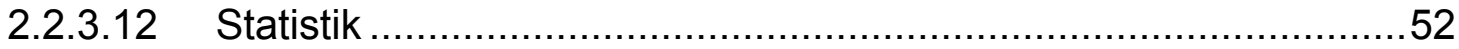

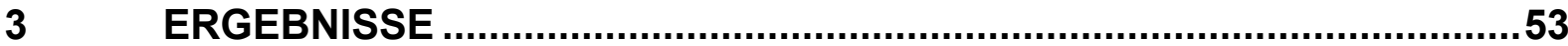

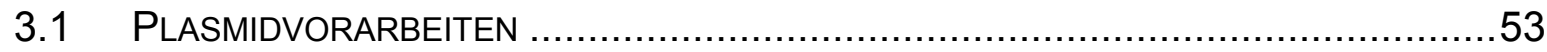

3.1.1 Templatedesign, Klonierung, Sequenzierung.....................................53

3.1.2 Glycerolstock, Maxiprep, Plasmidlinearisierung …................................53

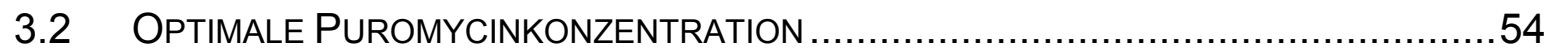

3.3 TRANSIENTE TRANSFEKTION IN HUMANER OSTEOSARKOMZELLLINIE 58 ..............55

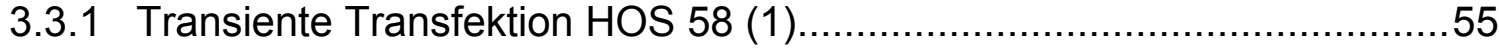

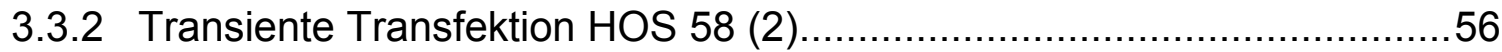

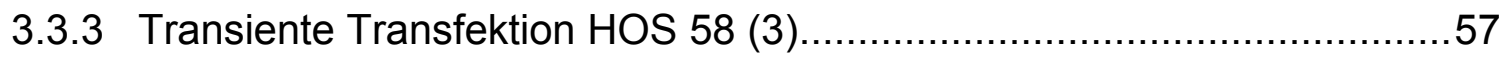

3.4 TRANSIENTE TRANSFEKTION IN PRIMÄREN HUMANEN OSTEOBLASTEN.................58

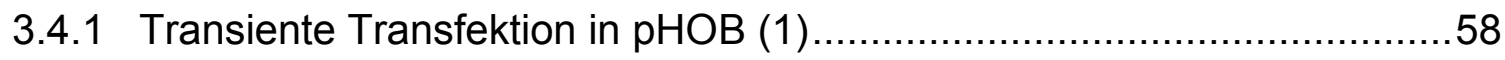




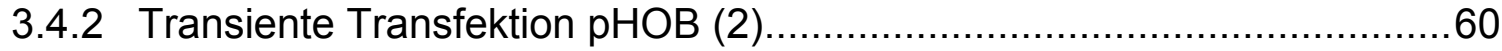

3.4.3 Transfektionseffizienz.............................................................. 61

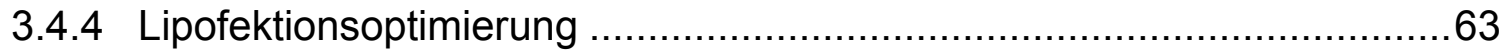

3.4.5 Alternatives Transfektionssystem (1) .......................................65

3.4.6 Alternatives Transfektionssystem (2) ........................................65

3.4.7 Transiente Transfektion mit kurzzeitiger Puromycinselektion .................66

3.4.8 Transiente Transfektion pHOB zur Analyse mittels RNA-Microarray ......67

3.4.9 Vergleich der verschiedenen Transfektionssysteme ...........................69

3.4.10 RNA-Microarray one-color..................................................... 70

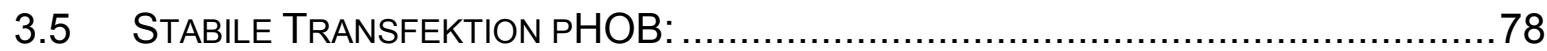

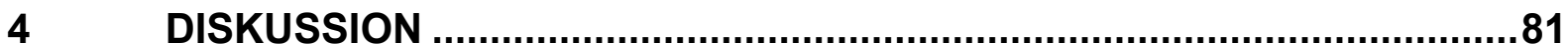

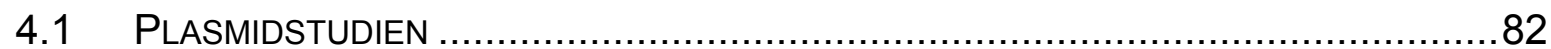

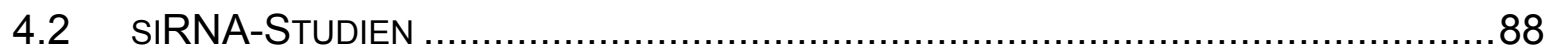

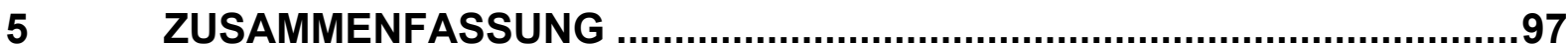

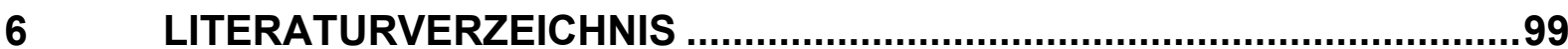




\section{Abkürzungsverzeichnis}

\begin{tabular}{|c|c|}
\hline A & Adenin \\
\hline Abb. & Abbildung \\
\hline$\alpha$ & Alpha \\
\hline AML & Akute myeloische Leukämie \\
\hline AP & Alkalische Phosphatase \\
\hline$\beta$ & Beta \\
\hline$\beta$-Catenin & Beta-Catenin \\
\hline BMP & bone morphogenetic protein \\
\hline BMU & basic multicellular units \\
\hline $\mathrm{bp}$ & Basenpaare \\
\hline bzw. & beziehungsweise \\
\hline $\mathrm{C}$ & Cytosin \\
\hline ca. & circa \\
\hline $\mathrm{CaCl}_{2}$ & Kalziumchlorid \\
\hline CBFA1 & core-binding factor 1 \\
\hline${ }^{\circ} \mathrm{C}$ & Grad Celsius \\
\hline $\mathrm{cm}$ & Zentimeter \\
\hline $\mathrm{cm}^{2}$ & Quadratzentimeter \\
\hline $\mathrm{CO}_{2}$ & Kohlendioxid \\
\hline Ct-Wert & Cycle threshold- Wert \\
\hline$d$ & Tag \\
\hline $\mathrm{dl}$ & Deziliter \\
\hline DMEM & Dulbecco`s MEM-Modifikation \\
\hline DMSO & Dimethylsulfoxid \\
\hline DNA & Desoxyribonuleic acid (Desoxyribonukleinsäure) \\
\hline dNTP & desoxyribonukleosidtriphosphate \\
\hline DOPE & Dioleoylphosphatidylethanolamin \\
\hline DTT & Dithiothreitol \\
\hline EDTA & Ethylendiamintriphosphat \\
\hline et al. & et alii \\
\hline FCS & fetal calf serum (fetales Kälberserum) \\
\hline FZD6 & frizzled homolog 6 \\
\hline$\gamma$ & Gamma \\
\hline g & Gramm \\
\hline
\end{tabular}




\begin{tabular}{|c|c|}
\hline G & Guanin \\
\hline $\mathrm{h}$ & Stunde \\
\hline $\mathrm{HOB}$ & humane Osteoblasten \\
\hline i.R. & im Rahmen \\
\hline$\kappa$ & Kappa \\
\hline I & Liter \\
\hline LRP5 & low-density lipoprotein (LDL)-receptor-related protein 5 \\
\hline Lsg. & Lösung \\
\hline M & Molar \\
\hline mCSF & macrophage colony-stimulating factor \\
\hline $\mathrm{mg}$ & Milligramm \\
\hline $\mathrm{MgCl}_{2}$ & Magnesiumchlorid \\
\hline $\min$ & Minute \\
\hline $\mathrm{ml}$ & Milliliter \\
\hline $\mathrm{mM}$ & Millimolar \\
\hline $\mathrm{mm}$ & Millimeter \\
\hline $\mathrm{mm}^{3}$ & Kubikmillimeter \\
\hline M-MLV & Moloney-Mäuseleukämievirus \\
\hline mRNA & messenger RNA \\
\hline MSC & mesenchymale Stammzelle \\
\hline $\mathrm{n}$ & Anzahl \\
\hline $\mathrm{NaCl}$ & Natriumchlorid \\
\hline NFATC $_{1}$ & nuclear factor of activated T-cells \\
\hline ng & Nanogramm \\
\hline $\mathrm{nm}$ & Nanometer \\
\hline $\mathrm{OC}$ & Osteocalcin \\
\hline OD & optische Dichte \\
\hline OPG & Osteoprotegerin \\
\hline OPN & Osteopontin \\
\hline OSF & osteoblastic-specific transcription factor \\
\hline $\mathrm{p}$ & Irrtumswahrscheinlichkeit \\
\hline PBS & phosphatgepufferte Salzlösung \\
\hline PCR & Polymerase-Ketten-Reaktion \\
\hline PEG & Polyethylenglykol \\
\hline Pen/Strep & Penicillin/ Streptomycin \\
\hline $\mathrm{pH}$ & $-\log [H+]$ \\
\hline $\mathrm{pHOB}$ & primäre humane Osteoblasten \\
\hline
\end{tabular}




\begin{tabular}{|c|c|}
\hline PPAR $\gamma 2$ & peroxisome proliferator activated receptor gamma 2 \\
\hline RANKL & receptor for activation of nuclear factor kappa B-Ligand \\
\hline RNA & Ribonukleinsäure \\
\hline RT & Raumtemperatur \\
\hline RT-PCR & Reverse-Transkriptase-Polymerase-Ketten-Reaktion \\
\hline Runx & runt-related transcription factor \\
\hline sec & Sekunde \\
\hline SEM & Standardfehler \\
\hline SFRP1 & secreted frizzled-related protein-1 \\
\hline shRNA & short hairpin RNA \\
\hline siRNA & short interfering RNA \\
\hline $\mathrm{T}$ & Thymin \\
\hline Tab. & Tabelle \\
\hline TGF $\beta$ & tumor growth factor $\beta$ \\
\hline$U$ & unit \\
\hline UV & Ultraviolett \\
\hline$\mu g$ & Mikrogramm \\
\hline$\mu l$ & Mikroliter \\
\hline$\mu \mathrm{M}$ & Mikromolar \\
\hline V & Volt \\
\hline Vol. & Volumen \\
\hline vsn & variance stabilization and normalization \\
\hline WIF1 & Wnt inhibitory factor 1 \\
\hline z.B. & zum Beispiel \\
\hline
\end{tabular}




\section{$1 \quad$ Einleitung}

\subsection{Der Knochen}

Der Knochen, als spezifische Gewebeart der Vertebraten, ist ein besonders hartes und widerstandsfähiges Gewebe, welches einerseits für den Körper als Skelettbildner multiple mechanische Funktionen, wie Trage-, Stütze-, Halte- und Schutzfunktion erfüllt, andererseits als Mineralienreservoir ein zentrales Element im Kalzium- und Phosphatstoffwechsel darstellt. Als dynamisches Gewebe erfährt der Knochen lebenslang Umbau- und Reparaturvorgänge. Dementsprechend ist die Knochenentwicklung und der Knochenstoffwechsel ein Produkt vielfältiger und komplexer Regulationsvorgänge, deren Mechanismen Gegenstand intensiver und aktueller Forschung sind. Die in den Knochenstoffwechsel involvierten Zellen nehmen hierbei eine zentrale Rolle ein.

\subsubsection{Knochenaufbau}

Von den verschiedenen Knochenarten können z.B. die langen Röhrenknochen von den platten und kurzen Knochen unterschieden werden.

Makroskopisch werden die langen Röhrenknochen in drei Abschnitte unterteilt. Während die Epiphyse dem Knochen jeweils am Ende aufsitzt, erstreckt sich die Diaphyse als Mittelteil zwischen den beiden Epiphysen. Als Bindeglied zwischen diesen beiden Abschnitten fungiert die Metaphyse.

Histologisch kann grundsätzlich der trabekuläre (spongiöse) von dem kortikalen (kompakten) Knochen unterschieden werden. Der trabekuläre Knochen bildet als Substantia spongiosa ein schwammartiges Gerüstwerk feiner Knochenbälkchen, welches von dem schützenden kortikalen Knochen als Substantia corticalis umgeben ist. Diese wird in der Diaphyse langer Röhrenknochen aufgrund ihres Durchmessers auch als Substantia compacta bezeichnet. Im Lamellenknochen können in dieser Schicht Osteome gefunden werden, die aus dem Blutgefäße enthaltenden Haverschen Kanal und lamellenartig um diesen herum angeordneter Knochengrundsubstanz bestehen.

Im Inneren langer Knochen ist zudem die Markhöhle (Cavum medullare) lokalisiert, die das blutbildende Knochenmark (Medulla ossium) beinhaltet, welches im Laufe des Lebens in den meisten Knochen durch Fettgewebe ersetzt wird.

Während die Knochenbinnenräume durch das bindegewebige Endost ausgekleidet werden, wird der äußere Knochen an nicht überknorpelten Stellen durch die bindegewebige Knochenhaut, das Periost, überzogen (Lüllmann-Rauch 2003). 


\subsubsection{Knochentwicklung und Knochenumbau (Remodelling)}

In der Knochenentstehung (Ossifikation) können grundsätzlich zwei Arten unterschieden werden. Während sich in der desmalen Ossifikation die Knochensubstanz aus einem bindegewebigen Gerüst entwickelt, entsteht der Knochen bei der chondralen Ossifikation aus einem Grundgerüst hyalinen Knorpels. Mit Ausnahmen der Knochen des Schädeldaches, des Gesichtes und eines Teils des Schüsselbeins, entsteht die überwiegende Mehrzahl der Knochen durch die chondrale Ossifikation.

Unter dem Begriff Remodelling versteht man den Umbau bereits bestehenden Knochens durch Resorption und nachfolgendem Ersatz des abgebauten Materials. So wird beispielsweise in dem spongiösen Knochen 28\% der Knochensubstanz jährlich umgebaut (Lüllmann-Rauch 2003). Diese Umbaumaßnahmen werden durch ein als basic multicellular units (BMU) bezeichnetes Kollektiv verschiedener Zelltypen mit Osteoklasten und Osteoblasten ausgeführt (Parfitt 1994).

Ausgelöst werden diese Vorgänge durch eine Vielzahl hormoneller, lokaler und mechanischer Stimuli (Robling et al. 2006).

\subsubsection{Zellen des Knochens}

Vier verschiedene Hauptzelltypen werden im Knochen unterschieden: Osteoblasten, Osteozyten, Bone-Lining-Cells und Osteoklasten. Aufgrund ihrer Entwicklung aus den aus mesenchymalen Vorläuferzellen abstammenden Osteoprogenitorzellen werden die drei erst genannten Zelltypen den sich aus hämatopoetischen Vorläuferzellen differenzierenden Osteoklasten gegenübergestellt.

Diese Zelltypen werden nachfolgend im Detail vorgestellt.

\subsubsection{Osteoblasten}

Osteoblasten sind einkernige spezialisierte Zellen mesenchymalen Ursprungs, die in vivo unter dem Periost, dem Endost sowie in den Haverschen Kanälen an der Knochenoberfläche lokalisiert und hauptsächlich für die Knochenbildung zuständig sind. Ihren Ursprung finden Osteoblasten in mesenchymalen Stammzellen (MSCs) des lokalen Stromagewebes, die sich zu Knochenprogenitorzellen entwickeln. Aus den Knochenprogenitorzellen differenzieren sich im nächsten Entwicklungsschritt Präosteoblasten, aus welchen schließlich die Osteoblasten hervorgehen. Auf Einzelheiten der Osteoblastendifferenzierung wird weiter unten näher eingegangen.

In Zellkultur haben diese fibroblastenähnlichen Zellen eine kuboidale Form und zeichnen sich durch eine große Menge rauen endoplasmatischen Retikulums und einen großen GolgiApparat aus (Marks und Popoff 1988). Spezifische Genprodukte, welche die Osteoblasten 
von den Fibroblasten unterscheiden, sind das nicht kollagene Protein Osteocalcin sowie die essentiellen Transkriptionsfaktoren Runx2 und Osterix (Ducy et al. 1997, Ducy et al. 2000, Nakashima et al. 2002).

$\mathrm{Zu}$ ihren Hauptaufgaben zählen die Sekretion von Knochenmatrixbestandteilen und die Kalzifizierung der Knochenmatrix. So synthetisieren und sezernieren diese Zellen vor allem Typ-I-Kollagen, aber auch Alkalische Phosphatase (AP), Osteocalcin (OC), Osteopontin (OPN), Bone Sialoprotein (BSP), sowie Wachstumsfaktoren wie BMP und TGF $\beta$ (Ross und Christiano 2006).

Auch in der Knochenresorption spielen die Osteoblasten eine Rolle, indem sie beispielsweise die für die Osteoklastenentwicklung wichtigen Faktoren mCSF (Makrophagenkolonie stimulierender Faktor), RANKL (receptor for activation of nuclear factor kappa B-Ligand) und OPG (Osteoprotegerin) synthetisieren (Gori et al. 2000, Pixley und Stanley 2004).

Reguliert werden die Osteoblasten in ihrer Differenzierung und Funktion endokrin, lokal und mechanisch (Drissi et al. 2002, Kang et al. 2005, Salingcarnboriboon et al. 2006).

\subsubsection{Osteozyten}

Die Osteozyten stellen zahlenmäßig die größte Gruppe Zellen innerhalb des Knochens dar. Mit einer Lebenserwartung von 1-50 Jahren gibt es schätzungsweise zehnmal mehr Osteozyten als z.B. Osteoblasten im menschlichen Knochen (Boskey et Coleman 2010, Parfitt 1977).

Osteozyten entwickeln sich aus Osteoblasten, indem diese hinter der Knochenformationsfront zurückbleiben und sich selbst mit Knochenmatrix ummauern.

Nach und nach verliert der sich differenzierende Osteozyt einen Großteil seiner Zellorganellen sowie des Zytoplasmas und beginnt mit der Expression von E11, einem frühen osteozytären Marker (Palumbo 1986, Wetterwald et al. 1996).

Im Gegenzug dazu bilden sich durch Knochenkanälchen lange Fortsätze, mit denen der Osteozyt über gap junctions mit anderen Osteozyten und den der Knochenoberfläche anliegenden Osteoblasten in Verbindung steht (Doty 1981).

Während nur eine geringe Matrixsyntheseleistung des reifen Osteozyten angenommen wird, besteht über die Funktion dieser Zellen Unklarheit (Gartland et al. 2004). So wird neben einer Rolle im lonentransport vor allem eine mechanorezeptive Funktion des Osteozyten diskutiert (Shen et al. 1988). Demnach könnte eine Funktion in der Erkennung sich verändernder mechanischer Beanspruchung des Knochens liegen (You et al. 2004). Bei mechanischer Beanspruchung kommt es zu einem Flüssigkeitsstrom durch das Knochenkanalsystem, was zu veränderten Scherkräften und Membrandeformationen an den Osteozyten führt, wodurch antiapoptotische Faktoren freigesetzt werden (Boskey et Coleman 
2010). Dementsprechend konnte die Apoptose von Osteozyten bei verminderter mechanischer Beansprunchung des Knochens gezeigt werden (Aguirre et al. 2006).

\subsubsection{Bone-Lining-Cells}

Endostale Knochenoberflächen, die nicht aktiv am Remodelling teilnehmen, sind von diesen flachen, elongierten Zellen bedeckt. Ausgezeichnet durch nur wenige Zellorganellen wie Mitochondrien und freien Ribosomen, handelt es sich bei diesen lichtmokroskopisch kaum erkennbaren Zellen vermutlich um ein terminales Differenzierungsstadium von Osteoblasten (Miller und Jee 1987, Parfitt 1994). Über gap junctions sind die Bone-Lining-Cells sowohl untereinander als auch mit Osteozyten und Osteoblasten verbunden (Duncan und Turner 1995).

Die Funktion dieser Zellen ist zurzeit nicht vollständig geklärt. Neben einer Kompartimierungsfunktion als Membran zwischen ossärer und interstitieller Flüssigkeit ist auch eine Verdauungsfunktion von Kollagenen beschrieben, welche von Osteoklasten unverdaut zurück gelassen werden (Everts et al. 2002, Miller und Jee 1987, Raggatt und Partridge 2010).

Es gibt weiterhin Anzeichen dafür, dass die Bone-Lining-Cells im Remodelling eine wesentliche Funktion als regulativer Vermittler besitzen (Hauge et al. 2001, Raggatt und Partridge 2010).

In Ratten konnte zudem eine Dedifferenzierung zu Osteoblasten und eine folgende vermehrte Knochenformation als Antwort auf eine Stimulation mit Parathormon beobachtet werden (Dobnig und Turner 1995). Eine solche Reaktivierung zu Osteoblasten konnte auch nach mechanischer Beanspruchung des Knochens gezeigt werden (Chow et al.1998)

\subsubsection{Osteoklasten}

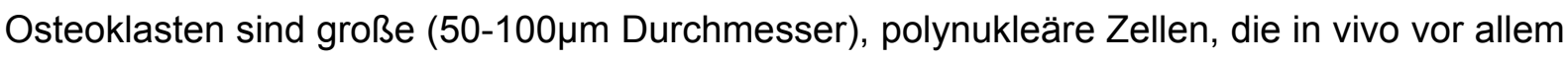
in der Nähe von Gefäßkanälen an der Knochenoberfläche lokalisiert sind und deren Hauptaufgabe in der Resorption von Knochensubstanz besteht (Boskey und Coleman 2010, Marks und Popoff 1988). Sie sind spezialisierte Zellen, die aus der Fusion und Differenzierung mononukleärer Vorläuferzellen der Monozyten/Makrophagen- Zelllinie entstehen (Udagawa et al. 1990). Morphologisch sind die mehrkernigen großen Osteoklasten im aktiven Zustand durch die sogenannte ruffled membrane und die sie umschließende sealing zone gekennzeichnet (Teitelbaum 2000).

Angeheftet an Knochen sezernieren die Osteoklasten Salzsäure, welche zu einer Demineralisierung des Knochens führt. Nach proteolytischem Abbau der organischen Matrix, vor allem durch das Iysosomale Enzym Kathepsin K, werden die Reste endozytiert, sodass 
knochensubstanzfreie Resorptionslakunen, die sogenannten Howship-Lakunen, entstehen (Ross und Christiano 2006).

Interessanterweise sind für diese Entwicklung zwei Substanzen essentiell, die unter der Kontrolle von Osteoblasten stehen. So wird einerseits der Profilerations- und Differenzierungsfaktor mCSF (Makrophagenkolonie stimulierender Faktor) und andererseits der Differenzierungsfaktor RANKL (receptor for activation of nuclear factor kappa B-Ligand) von Osteoblasten synthetisiert und sezerniert (Boskey und Coleman 2010, Lacey et al. 1998, Pixley und Stanley 2004). Des Weiteren sezernieren Osteoblasten als Vertreter der TNFRezeptor-Superfamilie das Glycoprotein Osteoprotegerin, welches aktive RANKL-Moleküle bindet und so zu einer verminderten Osteoklastendifferenzierung führt (Raggatt und Partridge 2010, Simonet et al. 1997). Viele endokrine Wirkungen auf die Osteoklasten, beispielsweise die des Parathormons, werden aufgrund dieser Mechanismen durch die Osteoblasten vermittelt (Lee S-K und Lorenzo 1999, Rodan und Martin 1981)

\subsubsection{Knochenmatrix}

Während 10\% der Knochenmatrix durch Hydratationswasser und 20\% durch organische Stoffe gebildet wird, wird der Hauptteil (70\%) von anorganischen Stoffen bereitgestellt.

Bei den anorganischen Stoffen unterscheidet man kollagene Stoffe, wie z.B. das Typ-I-Kollagen und nicht kollagene Stoffe, wie z.B. Osteocalcin, Osteopontin, Bone Sialoprotein und die alkalische Phosphatase. Diese Stoffe werden weiter unten aufgrund ihrer für den Osteoblasten charakterisierenden Eigenschaften näher beleuchtet.

Die anorganischen Stoffe werden in der Mehrheit durch Hydroxylapatitkristalle repräsentiert. Diese Kalziumphosphatverbindungen stellen den größten Kalziumspeicher des Körpers dar und sind aufgrund ihres Hydratmantels in der Lage an der Kalziumhomöostase teilzunehmen (Boskey und Posner 1984).

\subsubsection{Typ-I-Kollagen}

Dieses im Knochen vorherrschende Kollagen ist zudem auch in anderen Geweben wie z.B. der Haut oder der Kornea zu finden (Seibel 2005). Vom Osteoblasten, Fibroblasten und Odontoblasten als Prä-Prokollagen sezerniert, wird es im extrazellulären Raum enzymatisch gespalten (Seibel 2005). Strukturell besteht das reife Typ-I-Kollagen aus zwei $\alpha 1-K e t t e n$ sowie einer $\alpha 2-K e t t e . ~ K r a n k h e i t e n$ wie das klassische Ehlers-Danlos-Syndrom oder die Osteogenesis imperfecta, bedingt durch Mutationen in Typ-I-Kollagen-Genen, unterstreichen die Wichtigkeit dieses Moleküls für die mechanische Stärke der entsprechenden Gewebe (Kocher und Shapiro. 1998, Nuytinck et al. 2000). 


\subsubsection{Osteocalcin (OC)}

Dieses Hydroxylapatit bindende Protein wird lediglich von Osteoblasten, Odontoblasten und hypertrophen Chondrozyten synthetisiert und dementsprechend als spezifischer osteoblastärer Marker angesehen (Seibel 2005). Da das Osteocalcin zu einem geringen Teil vom Osteoblasten ins Blut abgegeben wird, gilt auch der Serumspiegel von Osteocalcin als Marker für die osteoblastäre Aktivität (Hauschka et al. 1989).

Über die Funktion dieses Proteins ist allerdings nicht viel bekannt. Das in der Osteoblastendifferenzierung späte Auftreten während der Mineralisation legt eine Aufgabe innerhalb dieses Prozesses nahe (Ducy et al. 2000, Siggelkow et al. 2004). Interessanterweise zeigen Versuche am Osteocalcin-knock-out-Mausmodell eine vermehrte Knochenformation bei uneingeschränkter Knochenresorption (Ducy et al. 1996). Dementsprechend scheint Osteocalcin im Knochenstoffwechsel eine Rolle in Form eines inhibitorischen Regulators zu spielen (Seibel et al. 2005).

Heute wird zudem angenommen, dass Osteocalcin die Insulinproduktion im Pankreas und die Insulinsensitivität im peripheren Gewebe beeinflusst und dadurch in den Glukosestoffwechsel involviert ist (Motyl et al. 2010).

\subsubsection{Alkalische Phosphatase (AP)}

Die knochenspezifische alkalische Phosphatase ist ein über Glycosyl-Phosphatidylinositol an die osteoblastäre Membran gebundenes Enzym (Moss 1992). Da die Expression der alkalischen Phosphatase während der osteoblastären Entwicklung einen charakteristischen Verlauf nimmt, wird sie als Marker für die Osteoblastendifferenzierung herangezogen (Owen et al. 1990, Siggelkow et al. 2004).

Die Funktion dieses Enzyms ist bis heute nicht vollständig geklärt. AP-knock-out-Mäuse zeigen einen Defekt der Knochenentwicklung wie bei der infantilen Form der Hypophosphatasie (Wennberg et al. 2000). An Hypophosphatasie erkrankte Patienten weisen verminderte Aktivtäten der gewebeunspezifischen alkalischen Phosphatase auf (Beck et al. 2009). Zudem konnten für diese Störung des Knochenstoffwechsels verschiedene ursächliche Mutationen im Gen für die gewebeunspezifische alkalische Phosphatase identifiziert werden (Orimo et al. 2001).

Durch die Hydrolisierung von anorganischen Pyrophosphaten, welche inhibitorisch in der Kochenmineralisation wirken, und durch die Bereitstellung von für die Knochenmatrixkristallisierung wichtigen anorganischen Phosphaten nimmt die alkalische Phosphatase eine wichtige Rolle in der Knochenmatrixformation ein (Hessle et al. 2002, Millan 2006, Russel 1965). 


\subsubsection{Osteopontin (OPN)}

Osteopontin ist ein negativ geladenes, glykosiliertes Phosphoprotein, welches zur Bindung von Kalzium und extrazellulärer Proteine befähigt ist (Haylock und Nilsson 2006). Es wird von Osteoblasten und Osteoklasten synthetisiert, kann aber auch in anderen Organen wie im Innenohr und im Gehirn gefunden werden (Rodan 1995, Tezukat et al. 1992). Neben einer Beteiligung an multiplen Prozessen wie z.B. Zelladhäsion und Angiogenese konnten Versuche an Osteopontin-knock-out-Mäusen eine regulative Rolle in dem Ausmaß der Osteoklastenaktivität zeigen (Franzen et al. 2008, Haylock und Nilsson 2006).

\subsubsection{Bone Sialoprotein}

Bone Sialoprotein ist ein Hauptstrukturprotein der Knochenmatrix. Es wird von Osteoblasten, Osteozyten, Osteoklasten und hypertrophen Chondrozyten synthetisiert und stellt etwa 12\% der nicht kollagenen Proteine. Es konnte gezeigt werden, dass eine Überexpression in Mäusen zu einer vermehrten Osteoklasten- und zu einer verminderten Osteoblastenaktivität führt, was wiederum in einer Osteopenie resultiert (Valverde et al 2008).

\subsubsection{Osteoblastendifferenzierung}

Als Vorläuferzelle des Osteoblasten ist die mesenchymale Stammzelle zu nennen, die sich als multipotente Progenitorzelle zum Chondrozyten, Myoblasten, Adipozyten oder zum Osteoblasten entwickeln kann (Arnold und Caplan 2005, Bianco und Robey 2000, Jaiswal et al. 1997). Welcher Differenzierungsweg bestritten wird ist abhängig von endokrinen, lokalen und mechanischen Faktoren, die in der Expression spezifischer Transkriptionsfaktoren resultieren. 


\section{Mesenchymale Stammzelle}

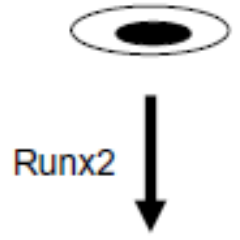

\section{Osteoprogenitor-} Zelle
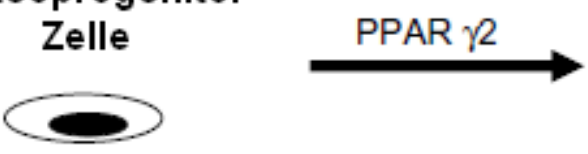

Sox 5, 6, 9
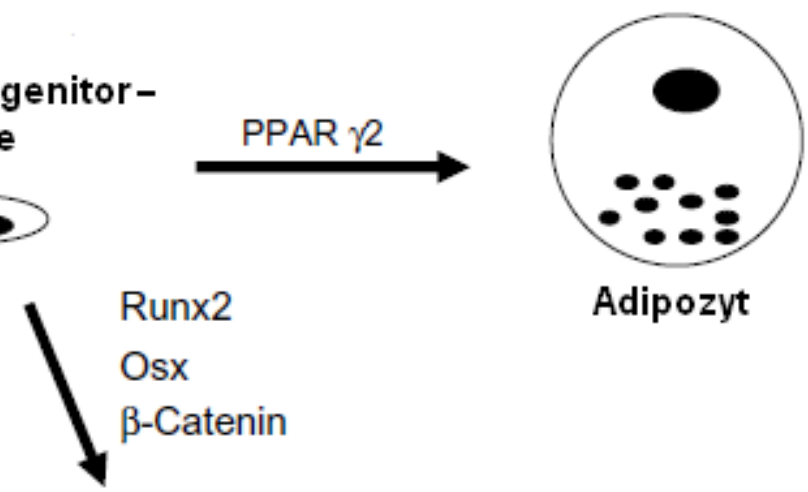

Adipozyt

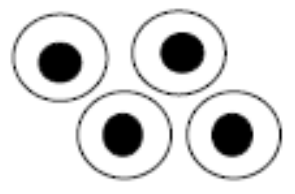

Chondrozyten

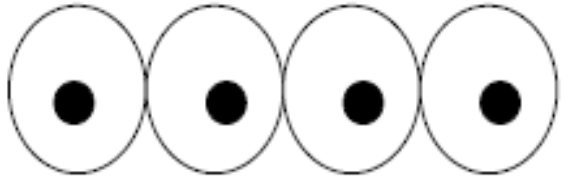

Osteoblasten

Abb. 1: Differenzierung einer mesenchymalen Stammzelle unter dem Einfluss verschiedener Transkriptionsfaktoren: Schematische Darstellung der Differenzierung mesenchymaler Stammzellen zu Osteoprogenitor-Zellen (unter dem Einfluss von Runx2) und dann zu Chondrozyten (unter dem Einfluss der chondrozytären Transkriptionsfaktoren Sox 5, 6 und 9), zu Adipozyten (unter dem Einfluss des adipogenen Transkriptionsfaktors PPAR 2 ) oder zu Osteoblasten (unter dem Einfluss der osteogenen Transkriptionsfaktoren Runx2, Osterix und $\beta$-Catenin). Zu den Einzelheiten der verschiedenen Transkriptionsfaktoren siehe weiter unten (modifiziert nach Marie 2008, S. 99).

Mehrere Zellkulturmodelle sind vorgeschlagen worden, die Einblicke in die genauen Vorgänge der Osteoblastendifferenzierung gegeben haben. So konnte Owen et al. 1990 ein Osteoblastenmodell aus calvarischen Zellen der Ratte entwickeln, welches eine dreiphasige Differenzierung des Osteoblasten nahelegt. Diese Differenzierungschritte konnten z.B. von Quarles et al. 1992 bei calvarian MC3T3-E1-Zellen und von Siggelkow et al. 1999 und 2004 in primären humanen Osteoblasten (pHOBs) bestätigt werden. Demnach durchlaufen Osteoblasten 1) eine Periode der Proliferation, 2) eine Periode der extrazellulären Matrixreifung und 3) eine Periode der Mineralisation.

Die Proliferationsperiode zeichnet sich durch hohe Zellteilungsraten, hohe Expressionraten von Zellzyklus- und Wachstumsgenen und durch die Produktion von Kollagen Typ I und Fibronectin aus.

Die Periode der extrazellulären Matrixreifung ist charakterisiert durch maximale Produktion der alkalischen Phosphatase und einen Anstieg von Osteocalcin zum Ende dieser Periode. 
Die Mineralisationsperiode zeichnet sich durch maximale Produktion von Osteocalcin, Osteopontin und Bone Sialoprotein aus. Diese Periode konnte im pHOB-Modell nur durch Stimulation mit Vitamin D3 erreicht werden.

Bei geänderten Kulturbedingungen konnte, wie bei anderen Zelltypen mesenchymalen Ursprungs, auch für Osteoblasten sowohl ein Dedifferenzierungspotential in frühere Differenzierungsstufen als auch ein Transdifferenzierungspotential in z.B. Adipozyten und Chondrozyten nachgewiesen werden (Nöth et al. 2002, Nuttall et al. 1998, Song und Tuan 2004).

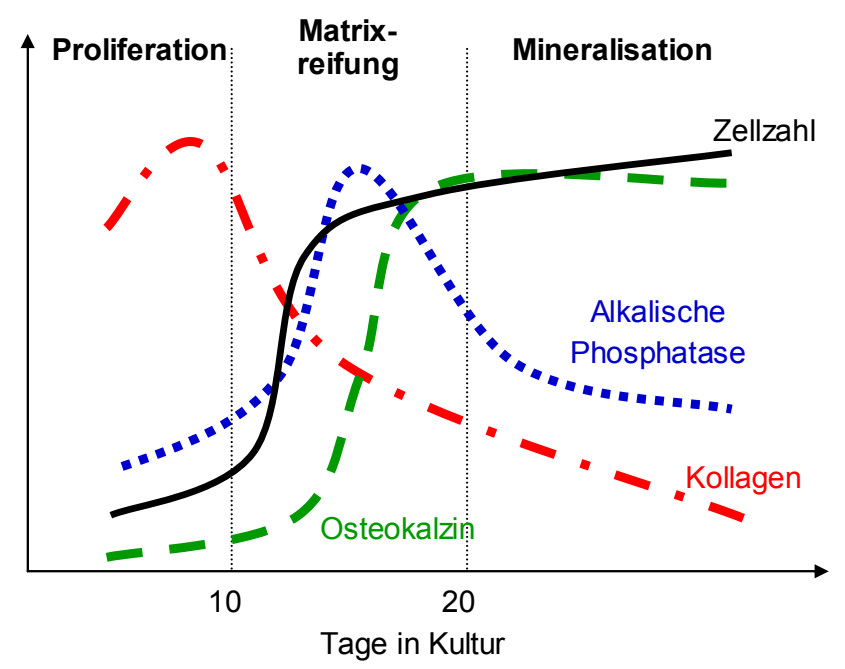

Abb. 2: Differenzierungsmodell primärer Rattenosteoblasten. Abgebildet ist der sequenzielle Ablauf der Differenzierung anhand von Proliferation (Zellzahl) und Genexpression osteoblastencharakteristischer Proteine (Osteocalcin, Typ-I-Kollagen, alkalische Phosphatase) (modifiziert nach Owen et al. 1990, S. 422).

\subsubsection{Runt-related transcription factor-2 (Runx2)}

Der Transkriptionsfaktor Runx2 ist essentiell für die Kondensation mesenchymalen Gewebes und die Differenzierung von Osteoblasten innerhalb einer adäquaten Knochenentwicklung. Das Runx2-Gen, als Mitglied der runt-domain-Genfamilie, welche eine Gruppe von drei Genen einschließt, gleicht sich mit diesen in der Runtdomäne und ist hiermit homolog zum Drosophila-Gen Runt. Diese Gene kodieren für drei Transkriptionsfaktoren: Runx1, Runx2 und Runx3, die zusammen mit dem Cofaktor $\operatorname{Cbf} \beta$ als Heterodimere ihre transkriptionelle Aktivität in verschiedenen Geweben entfalten (Komori 2005).

Runx1 konnte als wichtiger Transkriptionsfaktor in der Differenzierung hämatopoetischer Stammzellen identifiziert werden. Translokationen im Runx1-Gen sind pathophysiologisch im Zusammenhang mit der akuten myeloischen Leukämie (AML) beschrieben (Okada et al. 1998, Schröder et al. 2005).

Runx3 dagegen wurde vor allem in der Wachstumsregulation von gastralen Epithelzellen und in der Neurogenese beobachtet (Levanon et al. 2002, Schröder et al. 2005). Weitere 
Studien zeigen zusätzlich eine Beteiligung in der chondrozytären Differenzierung (Yoshida et al. 2004). Ein pathophysiologischer Zusammenhang zwischen Mutationen im Runx3-Gen und Magenkarzinomen konnte gezeigt werden (Li et al. 2002).

Der allerdings für diese Arbeit wichtige Transkriptionsfaktor Runx2 wurde erstmals 1997 als osteoblast-specific transcription factor (OSF) bzw. als core-binding factor 1 (Cbfa1) beschrieben (Ducy et al. 1997, Komori et al. 1997).

Durch zwei verschiedene Promotoren werden zwei Hauptisoformen von Runx2 (I und II) determiniert, die beide essentielle Funktionen in der Osteoblastendifferenzierung ausüben (Levanon und Groner 2004).

Sowohl transkriptionell als auch posttranslational wird Runx2 durch multiple Faktoren reguliert. Während beispielsweise bone morphogenetics proteins (BMPs) transkriptionell zu einer verstärkten Expression von Runx2 mRNA führen, interagiert der adipogenetische Transkriptionsfaktor PPARy2 auch posttranslational direkt mit dem Runx2-Protein und inhibiert seine transkriptionale Aktivität auf den Osteocalcinpromotor (Gori et al. 1999, Jeon et al. 2003).

Die Funktion von Runx2 konnte in den letzten Jahren durch intensive Forschung näher analysiert werden.

Homozygote Runx2-knock-out-Mäuse waren kleiner als normale Mäuse und starben kurz nach der Geburt durch Versagen des respiratorischen Systems. Weder desmale noch chondrale Ossifikation konnte in diesen Mäusen nachgewiesen werden (Komori et al. 1997). Bereits heterozygote Runx2-knock-out-Mäuse zeigten eine Hypoplasie der Klavikula sowie eine Entwicklungsstörung der kranialen Knochen (Otto et al. 1997). Diese Veränderungen entsprechen dem Symptomkomplex der humanen autosomal dominant vererbten Erbkrankheit kleidokraniale Dysplasie (CCD). Tatsächlich konnte gezeigt werden, dass Mutationen, die ursächlich für heterozygoten Funktionsverlust von Runx2 waren, zu CCD führen (Morava et al. 2002, Mundlos et al. 1997).

Während das chondrozytäre Skelett bei homozygoten Runx2-knock-out-Mäusen fast vollständig vorhanden war, fehlte eine mesenchymale und vaskuläre Zellinvasion perichondral als Voraussetzung für eine adäquate Ossifikation (Komori et al. 1997). Dies zeigt die Wichtigkeit von Runx2 für die mesenchymale Kondensation. Des Weiteren konnten in diesen Mäusen nur wenige unreife Osteoblasten gefunden werden, die zwar schwach alkalische Phosphatase, aber kein Osteopontin und Osteocalcin als osteoblastäre Marker exprimierten (Komori et al. 1997).

Überexpression von Runx2 in murinen nichtosteoblastären Zellen dagegen führt zu einer vermehrten Expression von osteoblastentypischen Genen wie z.B. Osteocalcin, Typ-IKollagen, Bone Sialoprotein und Osteopontin (Ducy et al. 1997). Während in murinen mesenchymalen Stammzellen eine Überexpression von Runx2 zu einer osteoblastären 
Differenzierung führt, bewirkt eine Überexpression in unreifen murinen osteoblastären Zellen auch eine Knochenmatrixbildung (Byers et al. 2002, Byers und Garcia 2004). Demnach ist Runx2 für die Osteoblastendifferenzierung essentiell.

Im in-vivo-Mausmodell bewirkt eine Überexpression von Runx2 interessanterweise eine Osteopenie, die sich durch multiple Frakturen äußert (Geoffroy et al. 2002, Liu W et al. 2001). Diese Osteopenie wird durch vermehrten Knochenabbau und einen verminderten Grad an Mineralisation hervorgerufen. Histologisch konnte eine deutlich verminderte Zahl reifer Osteoblasten, charakterisiert durch starke Osteocalcin-Expression sowie eine verminderte Zahl Osteozyten gefunden werden. Dies lässt darauf schließen, dass Runx2 zwar für die frühe Osteoblastendifferenzierung essentiell ist, die späte Differenzierung in reife Osteoblasten und damit auch die Bildung von Osteozyten allerdings inhibiert.

In murinen Osteoklasten konnte zudem eine Induktion von RANKL und die Suppression von Osteoprotegerin in Osteoklasten durch Runx2 und eine damit verstärkte knochenabbauende Osteoklastentätigkeit gezeigt werden (Enomoto et al. 2003).

Während Runx2 also die terminale Osteoblastendifferenzierung blockiert, beeinflusst es zudem auch fördernd die Osteoklastentätigkeit in diesen Mauszellen.

Runx2-knock-out-Mäuse zeigten weiterhin eine fehlende Hypertrophie von Chondrozyten als terminalen Differenzierungsschritt der Chondrozytogenese. In-vitro-Modelle zeigten sogar eine Transdifferenzierung reifer Chondrozyten in Adipozyten bei Abwesenheit von Runx2 (Inada et al. 1999, Takeda et al. 2001). Diese Transdifferenzierung konnte durch Induktion von Runx2 verhindert werden (Enomoto et al. 2004). Demnach ist Runx2 für die terminale Chondrozytendifferenzierung essentiell und verhindert gleichsam die Adipogenese.

Zusammenfassend ist Runx2 unentbehrlich sowohl für die mesenchymale Kondensation im Rahmen einer adäquaten Ossifikation als auch für die Differenzierung mesenchymaler Voräuferzellen in Osteoblasten. Die terminale Osteoblastendifferenzierung und die Bildung von Osteozyten wird durch Runx2 allerdings gehemmt. Weiterhin spielt Runx2 eine Rolle in der Osteoklastendifferenzierung und damit im Knochenabbau, und ist nicht zuletzt essentiell für die terminale chondrozytäre Differenzierung in hypertrophe Chondrozyten.

\subsubsection{Der canonical Wnt-Signalweg und Beta-Catenin ( $\beta$-Catenin)}

Wnts sind eine Gruppe Glycoproteine, die an membranständige frizzled-Rezeptoren binden und so G-Protein vermittelte Signalwege induzieren (Bodine und Komm 2006). Hiermit sind sie an der Kontrolle multipler physiologischer und pathophysiologischer Prozesse beteiligt.

Der canonical Wnt-Signalweg ist für die Osteoblastendifferenzierung von entscheidender Bedeutung. Dieser Signalweg führt zu einer Inhibition der GSK3-vermittelten Phosphorylierung des zentralen Elements Beta-Catenin ( $\beta$-Catenin). Als Folge akkumuliert $\beta$ Catenin im Zytoplasma und transloziert in den Nukleus, wo es seine transkriptionelle Aktivität entfalten kann. 
Für viele Wnt-Antagonisten wie secreted frizzled related proteins (sFRPs) oder DickkopfProteine (Dkks) konnte ein hemmender Einfluss auf den canonical Wnt-Signalweg demonstriert werden (Ross und Christiano 2006).

An $\beta$-Catenin-knock-out-Mäusen konnte eine essentielle Rolle von $\beta$-Catenin für die Osteoblastogenese und eine Inhibition der Chondrozytogenese gezeigt werden (Day et al. 2005, Hill et al. 2005, Hu et al. 2005).

Ein weiteres Protein, das low-density lipoprotein ( $L D L$ )-receptor-related protein 5 (LRP5) führt durch Interaktionen zu einer Aktivierung des Wnt-Signalweges. Es konnten Mutationen in dem Gen von LRP5 gefunden werden, die zu einer abnorm erhöhten Knochenmasse führen bzw. an der Entstehung der autosomal rezessiven Krankheit osteoporosispseudoglioma syndrome beteiligt sind (Harada und Rodan 2003). Dies zeigt im humanen Modell die Beteiligung des Wnt-Signalweges am Knochenmetabolismus.

Runx2 konnte als Zielgen für den canonical Wnt-Signalweg identifiziert werden. Dementsprechend wird die Expression von Runx2, wahrscheinlich durch $\beta$-Catenin, induziert (Gaur et al. 2005).

Teils über die Aktivierung von Runx2 bewirkt $\beta$-Catenin zudem in Chondrozyten eine erhöhte Expression von Typ-X-Kollagen, als Marker für hypertrophe Chondrozyten (Dong et al 2006). Durch eine Inhibition von PPAR $\gamma 2$, einem essentiellen Transkriptionsfaktor der Adipogenese, und von RANKL hat es weiterhin inhibierenden Effekt auf die Adipogenese und die Osteoklastogenese (Kang et al. 2007, Spencer et al. 2006).

Wnt10b, ein weiteres Wnt-Protein des canonical Wnt-Signalweges, induziert im Mausmodell die Expression von Runx2 und Osterix und inhibiert die Expression von PPAR 2 und führt so zu einer erhöhten Knochensynthese durch eine vermehrte Zahl aktiver Osteoblasten (Bennett et al. 2005, Bennett et al. 2007). Dies unterstreicht zusätzlich die Rolle des canonical Wnt-Signalweges in der Regulation der Osteo- und Adipogenese (Marie 2008).

\subsubsection{Osterix}

Osterix als zinc finger-containing Transkriptionsfaktor ist essentiel für die Differenzierung von Präosteoblasten in etwas differenziertere unreife Osteoblasten (Marie 2008, Nakashima et al. 2002).

Osterix-knock-out-Mäuse zeigen aufgrund des vollständigen Fehlens einer Osteoblastenpopulation weder eine desmale noch eine chondrale Knochenentwicklung. In diesen Mäusen konnte sowohl eine Expression von Runx2 als auch eine chondrozytäre Entwicklung von mesenchymalen Stammzellen beobachtet werden (Nakashima et al. 2002). In Runx2-knock-out-Mäusen dagegen konnten Effekte auf die chondrozytäre Differenzierung sowie keine Osterix-Expression gefunden werden(Inada et al. 1999). 
Dementsprechend wird davon ausgegangen, dass Osterix als Transkriptionsfaktor downstream von Runx2 in der Osteoblastendifferenzierung agiert. Trotz einiger Anzeichen für eine Induktion von Osterix durch Runx2 konnte hierfür noch kein endgültiger Beweis erbracht werden (Marie 2008, Nakashima et al. 2002). Durch eine Überexpression von Osterix konnte weiterhin eine vermehrte Expression von Runx2 induziert werden, wobei die Mechanismen dieser Induktion zunächst noch unbekannt sind (Tai et al. 2004) Intensive Forschung wird zudem in der Frage nach interagierenden Faktoren mit Osterix betrieben. So konnte z.B. durch eine Interaktion mit NFATc1 (nuclear factor of activated Tcells) eine erhöhte Aktivität des Promotors für das Gen der $\alpha 1$-Kette vom Typ-I-Kollagen gezeigt werden (Koga et al. 2005).

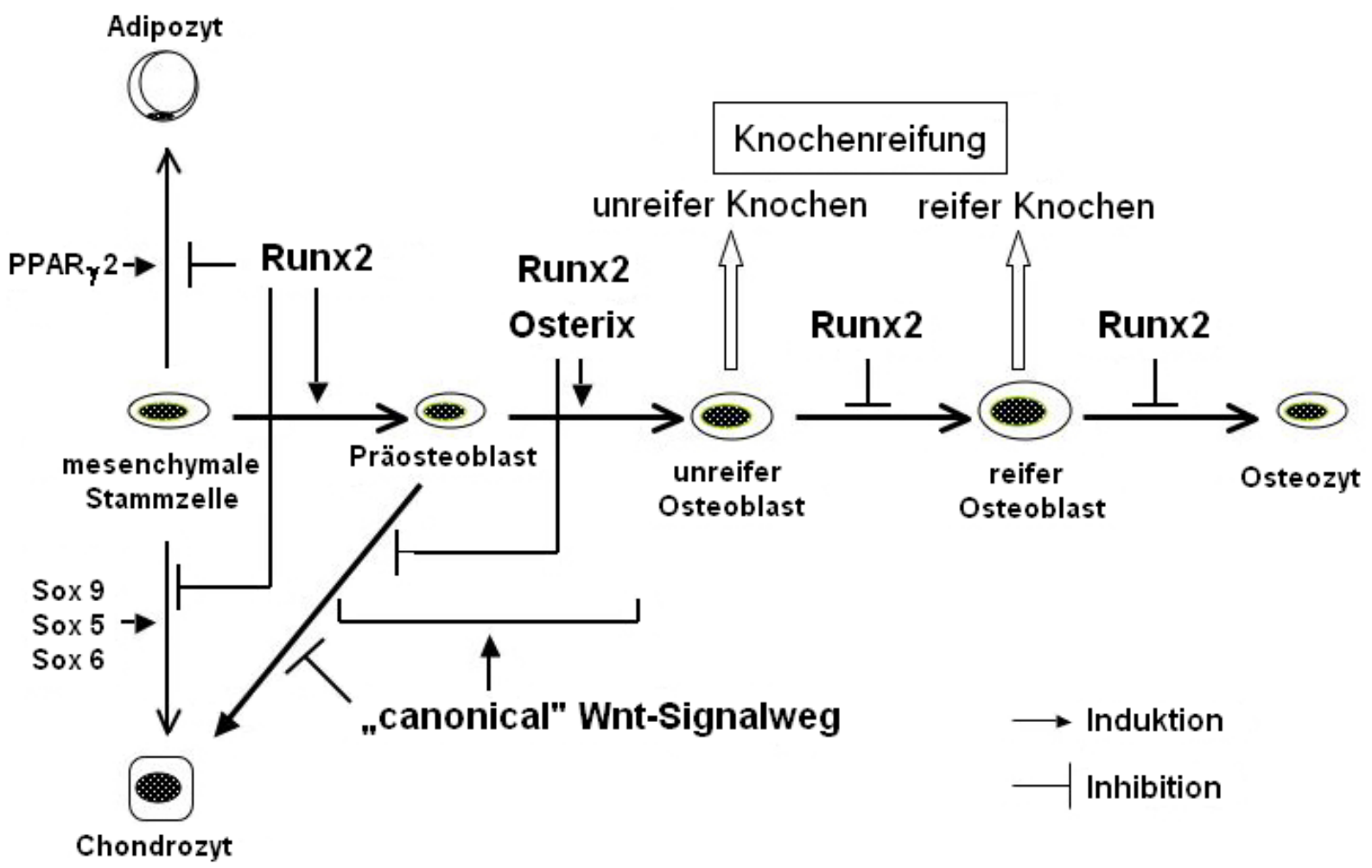

Abb. 3: Transkriptionsfaktoreninteraktionen im Rahmen der Differenzierung mesenchymaler Stammzellen. Dargestellt sind die Interaktionen verschiedener Transkriptionsfaktoren bei der adipogenen, chondrogenen und im Detail osteogenen Differenzierung (modifiziert nach Komori 2010, S. 46).

\subsection{RNA-Interferenz}

Als RNA-Interferenz wird die posttranskriptionelle Suppression einer Genexpression bezeichnet, die durch doppelsträngige RNA-Moleküle (dsRNA) induziert wird. Dieser Mechanismus wurde zuerst von Fire et al. 1998 benutzt, die durch Injektion von dsRNA in den Fadenwurm Caenorhabditis elegans Gensuppressionen beobachten konnten. Für diese Leistung wurde innen 2006 der Nobelpreis verliehen. 
Anhand von Versuchen mit 25bp langen doppelsträngigen RNA-Molekülen erkannten Hamilton und Baulcombe 1999, dass dieser Mechanismus auf der Wechselwirkung zwischen diesen dsRNAs und zu innen homologen mRNAs beruht.

Auch zelleigene kleine RNAs, sogenannte microRNAs (miRNAs), wurden als Akteure der RNA-Interferenz identifiziert. So wurden schon 1993 22-61bp lange RNA-Transkripte (small $R N A s$ ) des Gens lin-4 in C. elegans endeckt, die für kein Protein kodierten, aber homolog zu einem Abschnitt der mRNA für das Protein lin-14 waren. Hier wurde bereits eine RNA-RNAInteraktion vermutet, die an der Regulation des Gens für lin-14 beteiligt gewesen sein soll (Lee R et al. 1993).

Heute ist eine große Zahl miRNAs bekannt, die an Genregulationsmechanismen beteiligt sind (Martin und Caplen 2007). Vorläufermoleküle dieser miRNAs sind Primärtranskripte, sogenannte pri-microRNAs, die durch das zelleigene Enzym Drosha in pre-microRNAs prozessiert werden. Diese werden durch Exportin 5 aus dem Nukleus in das Zytoplasma transportiert. Hier wird durch das Dicer genannte Enzym die charakteristische Schleife der pre-microRNA entfernt, sodass ein reifes doppelsträngiges RNA-Molekül (miRNA) von 2123bp Länge entsteht (Bernstein et al. 2001). Diese reife miRNA wird durch eine Helikase in eine einzelsträngige RNA gespalten, welche in einen Ribonukleoproteinkomplex inkorporiert wird. Dieser Komplex wird als RNA-induced silencing complex (RISC) bezeichnet (Liu et al. 2004, Meister et al. 2004). Nach Anlagerung dieses Komplexes an die komplementäre mRNA wird diese durch die RNase Slicer vom 3`-Ende her degradiert oder in ihrer Konformation geändert, sodass die Translation gestoppt wird. Auch eine Kombination aus diesen beiden Mechanismen ist beschrieben (Meister et al. 2004). Diese Prozesse führen so zu einem Abbruch der Proteinbiosynthese.

Physiologische Aufgaben der RNA-Interferenz sind in antiviraler Abwehr, in transkriptionaler und vor allem in posttranskriptionaler Genregulation zu sehen. So sollen mehr als $30 \%$ aller Protein kodierenden Gene durch miRNAs reguliert werden (Martin und Caplen 2007).

Vor allem hat die RNA-Interferenz aber in molekularbiologischen Studien breite Anwendung gefunden. So kann durch Transfektion von exogen synthetisierten 21-23bp langen small interfering RNAs (siRNAs) oder sogenannten short hairpin RNAs (shRNAs) in Zielzellen eine spezifische Suppression eines Gens erreicht werden (Elbashir et al. 2001, Paddison et al. 2002). Die siRNAs ahmen die reifen miRNAs nach, während die shRNAs den pre-miRNAs entsprechen. Mit diesen dsRNAs kann eine transiente Gensuppression von 24-120h erreicht werden (Martin und Caplen 2007).

In die Zielzelle transfizierte spezielle Vektoren, z.B. Plasmide oder virale Vektoren, sind in der Lage, in vitro siRNAs oder shRNAs zu synthetisieren und so RNA-Interferenz zu induzieren (Brummelkamp et al. 2002, Paul et al. 2002). Der Vorteil hierbei ist, dass man mit 
diesen Vektoren sowohl transient als auch stabil über Wochen und Monate eine Gensuppression erreichen kann.

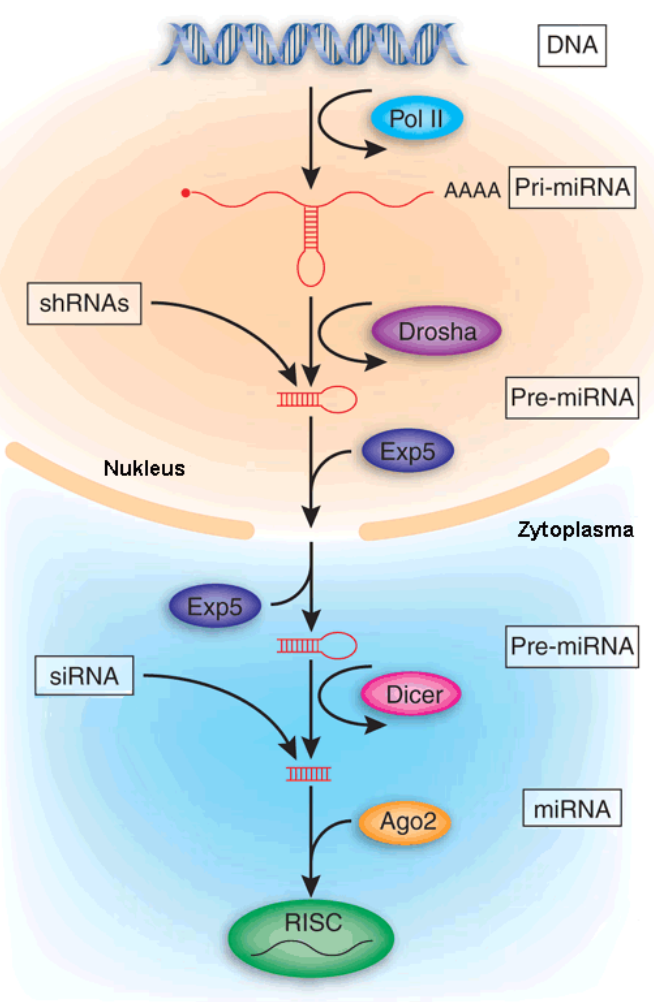

Abb. 4: Schematische Darstellung der RNA-Interferenz

Pol III = Polymerase III, Pri-miRNA = Primärtranskript der microRNA, shRNA = short hairpinRNA ( synthetisierte Pre-miRNA), Pre-miRNA = durch das Enzym Drosha prozessierte Pri-miRNA, Exp5 $=$ Exportin 5, siRNA $=$ small interferingRNA (气丷exogen synthetisierte miRNA), miRNA $=$ microRNA, Ago2 = Argonaute 2 (Endonuklease), RISC $=$ RNA-induced silencing complex (modifiziert nach Cullen 2005, S. 1164).

\subsection{Fragestellung}

Zielsetzung dieser Arbeit war eine siRNA-vermittelte Gensuppression von Runx2 in primären humanen Osteoblasten. Anhand der Folgen dieses Runx2-knock-downs auf die Genexpressionverhältnisse in den pHOB sollte auf Mechanismen der physiologischen Funktion dieses Transkriptionsfaktors während der Osteoblastendifferenzierung in vitro geschlossen werden.

Während für einen kurzfristigen knock-down sowohl exogen synthetisierte siRNAs als auch ein siRNA-Expressionsvektor benutzt werden konnten, sollte für einen längerfristigen knock-down ein siRNA-Expressionsvektor eingesetzt werden.

Zunächst sollte diese Methode in der Osteosarkomzellline HOS 58 etabliert und dann auf primäre mesenchymale Progenitorzellen (MSCs) übertragen werden. 


\section{Material und Methoden}

\subsection{Material}

\subsubsection{Zellkultur}

\section{Primäre humane Osteoblasten (pHOB)}

Diese Zellen wurden aus Knochenmaterial von verschiedenen Patienten gewonnen, die sich in den Abteilungen der Unfallchirurgie (Prof. Dr. K. M. Stürmer) und der Orthopädie (Prof. Dr. W. Schulz) des Universitätsklinikums Göttingen operativen Eingriffen unterzogen hatten. Sämtliche Knochenproben wurden aus dem Femurschaft, der Crista iliaca oder aus dem Tibiaplateau gewonnen. Hierfür lag von jedem Patienten eine schriftliche Einverständniserklärung für die Nutzung der entnommenen Proben zu Forschungszwecken vor. Der legitimierende Ethikantrag mit der Antragsnummer 9/5/01 und dem Studientitel „Etablierung eines humanen Osteoblasten-Zellkulturmodells zur Untersuchung der Differenzierung während der Zeit in Kultur" wurde genehmigt. Zur Vereinfachung und zum besseren Verständnis wurden die so kultivierten Zellen in dieser Arbeit pHOB genannt.

Tab. 1: Übersicht zum verwendeten Zellmaterial

\begin{tabular}{|c|c|c|c|c|c|}
\hline Versuch & Patient & Geschlecht & Alter & Entnahmeort & Passage \\
\hline Transiente Transfektion in pHOB (1) & I.Z. & W & 67 & Tibiaplateau & 1. \\
\hline Transiente Transfektion in pHOB (1) & M.L. & M & 11 & Crista iliaca & 1. \\
\hline Transfektionseffizienz & I.S. & W & 79 & Crista iliaca & 1. \\
\hline Lipofektionsoptimierung & I.Z. & W & 67 & Tibiaplateau & 2. \\
\hline Alternatives Transfektionssystem (1) & I.Z. & W & 67 & Tibiaplateau & 5. \\
\hline Alternatives Transfektionssystem (2) & I.Z. & W & 67 & Tibiaplateau & 3. \\
\hline $\begin{array}{c}\text { Transiente Transfektion mit } \\
\text { kurzzeitiger Puromycinselektion }\end{array}$ & G.F. & W & 81 & Tibiaplateau & 1. \\
\hline $\begin{array}{c}\text { Transiente Transfektion pHOB zur } \\
\text { Analyse mittels RNA-Microarray (1) }\end{array}$ & K.A. & M & 57 & Tibiaplateau & 1. \\
\hline $\begin{array}{c}\text { Transiente Transfektion pHOB zur } \\
\text { Analyse mittels RNA-Microarray (2) }\end{array}$ & L.D. & W & 72 & Tibiaplateau & 1. \\
\hline stabile Transfektion pHOB & R.E. & W & 79 & Tibiaplateau & 1. \\
\hline
\end{tabular}

\section{Humane Osteosarkomzelllinie (HOS 58)}

Diese Zelllinie fand ihren Ursprung in einem Osteosarkom eines 21-jährigen männlichen Patienten. Aus diesem malignen Knochentumor wurde Gewebe entnommen und Zellen 
dieses Gewebes wurden in ein Nacktmausmodell überführt, um eine Zelllinie mit guten proliferativen Eigenschaften zu gewinnen.

Die hierbei entstandene stabile Zelllinie HOS 58 ist charakterisiert durch eine Verdopplungszeit von 36h, einen cAMP-Anstieg nach Stimulation mit Parathormon und Synthese von Osteocalcin nach Stimulation mit Calcitriol (Kern et al. 1990, Schulz et al. 1993). Eine reguläre osteogene Mineralisation konnte bis heute nicht gezeigt werden, auch wenn in in-vitro-Experimenten eine gesteigerte Genexpression und Proteinbiosynthese des knochenspezifischen Matrixproteins Osteocalcin belegt werden konnte und somit eine osteogene Differenzierung angedeutet wird (Siggelkow et al. 1998a, Siggelkow et al. 2002). Im Unterschied zu primären humanen Osteoblasten konnte keine Regulierung des Kollagenstoffwechsels durch Ascorbinsäure (Vitamin C) gezeigt werden (Siggelkow et al. 1998b).

Tab. 2: Reagenzien für die Zellkultur

\begin{tabular}{|l|l|}
\hline Reagenz & Hersteller \\
\hline Dulbeccos MEM (DMEM) & PAA, Pasching \\
ISCOVE-Medium (IMDM) & PAA, Pasching \\
Opti MEM (serumfreies Medium) & Gibco BRL, Cölbe \\
PBS (- CaCl 2 - MgCl$_{2}$ ) & PAA, Pasching \\
FCS (fetales Kälberserum) & PAA, Pasching \\
DMSO & Merck, Darmstadt \\
L-Glutamin-Lösung 200mM & Gibco BRL, Cölbe \\
Penicillin/Streptomycin (je 100U/ml) & Gibco BRL, Cölbe \\
Trypsin-EDTA-Lösung & Gibco BRL, Cölbe \\
Trypanblau & Serva, Heidelberg \\
2-Mercaptoethanol & Sigma, Taufkirchen \\
RLT-Puffer (aus RNeasy mini Kit) & Qiagen, Hilden \\
TRIzol & Invitrogen, Karlsruhe \\
Chloroform & Roth, Karlsruhe \\
Isopropanol & Merck,Darmstadt \\
75\% Ethanol & J.T. Backer, Deventer, Holland \\
GlycoBlue & Ambion, Austin, USA \\
DNase & Qiagen, Hilden \\
\hline
\end{tabular}


Tab. 3: Geräte für die Zellkultur:

\begin{tabular}{|c|c|}
\hline Produkt & Hersteller \\
\hline Erlenmeyerkolben & Schott, Mainz \\
\hline Einmalpipetten $10 \mathrm{ml}$ & Greiner, Nürtingen \\
\hline Pipettenspitzen $10 \mu \mathrm{l}, 100 \mu \mathrm{l}, 1000 \mu \mathrm{l}$ & Biozym, Hessisch-Oldendorf \\
\hline Kryoröhrchen & Nalgene, Hereford, UK \\
\hline Flüssigstickstoff-Container & Cryoson, Schöllkrippen \\
\hline Behältnis für Kryoröhrchen & Nalgene, Hereford, UK \\
\hline Neubauer-Zählkammer & Brand, Wertheim \\
\hline Mikroplatte 6er Wells & Nunc, Roskilde, Dänemark \\
\hline $6 \mathrm{~cm}$ Platten & Greiner, Solingen \\
\hline Petrischale $9,4 \times 1,6 \mathrm{~cm}$ & Greiner, Nürtingen \\
\hline Petrischale klein & Nunc, Roskilde, Dänemark \\
\hline Kulturflaschen & Nunc, Roskilde, Dänemark \\
\hline Falconröhrchen & Becton-Dickinson, Mountain View, USA \\
\hline Reaktionsgefäß 0,5ml, 1,5ml & Eppendorf, Hamburg \\
\hline Pasteurpipetten & Brand, Wertheim \\
\hline Kodak Photofilm Ektachrom 64T & Kodak, New York, USA \\
\hline Sterifilter Minisart & Sartorius, Göttingen \\
\hline Absaugpumpe & Schütt, Göttingen \\
\hline Biofug 13R & Schütt, Göttingen \\
\hline Mikroskop CK 2 mit Kamera SC 35 & Olympus, Tokyo, Japan \\
\hline Bunsenbrenner & Schütt, Göttingen \\
\hline Pipettus & Hirschmann, Eberstadt \\
\hline Brutschrank Stericult 2000 Inkubator & Forma Scientific, Marietta, Ohio, USA \\
\hline Sterilbank & Schirp, Bork, Westfalen \\
\hline Wasserbad & Gebr. Rettberg, Göttingen \\
\hline Zentrifuge Zelllabor & Hettich, Lauenau \\
\hline Skalpell & Techno cut, Horsham, UK \\
\hline Zellschaber & Sarstedt, Newton, USA \\
\hline Fluoreszenzmikroskop & Carl Zeiss, Jena \\
\hline NanoDrop ND-1000 & NanoDrop, Wilmington, USA \\
\hline Bioanalyzer 2100 & Agilent, Böblingen \\
\hline
\end{tabular}

\subsubsection{Bakterienkultur}

Zur Herstellung chemisch kompetenter Bakterien wurden Escherichia coli der Linie top ten hausintern bezogen und genutzt. 
Tab. 4: Materialien für die Bakterienkultur

\begin{tabular}{|l|l|}
\hline Reagenz/ Gerät & Hersteller \\
\hline Tryptone & AppliChem, Darmstadt \\
Yeast extract (Hefe) & AppliChem, Darmstadt \\
$\mathrm{NaCl}$ & Merck, Darmstadt \\
$\mathrm{Ampicillin}$ & AppliChem, Darmstadt \\
$50 \%$ Glycerol & Sigma, Taufkirchen \\
\hline
\end{tabular}

\subsubsection{Nukleinsäuren}

\section{Verwendete siRNAs}

Tab. 5: Übersicht über verwendete siRNAs

\begin{tabular}{|l|l|}
\hline siRNA: & Hersteller \\
\hline siRNA, RUNX2 no.4 & Qiagen, Hilden \\
siRNA, scrambled & Qiagen, Hilden \\
\hline
\end{tabular}

\section{Verwendete Plasmide}

1) p-Silencer ${ }^{\mathrm{TM}}$ 4.1-CMV puro:

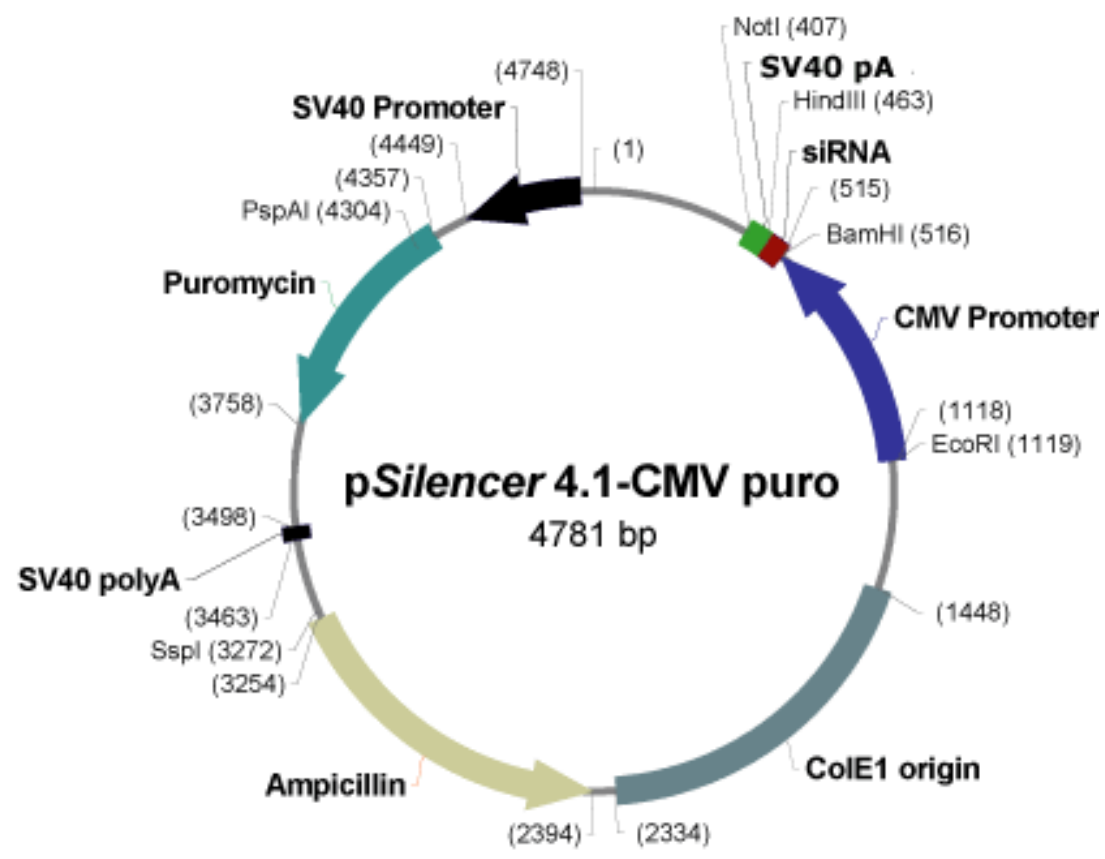

Abb. 5: Vektorkarte pSilencer 4.1-CMV puro (modifiziert nach http://www.ambion.com/techlib/prot/fm_5775.pdf, Stand 05.06.2011) 
Der p-Silencer ${ }^{\mathrm{TM}}$ 4.1-CMV puro, nachfolgend als pSi+ abgekürzt, ist ein 4781 Basenpaare (bp) großes Plasmid, welches für die in-vitro-Amplifikation von shRNA benutzt werden kann. pSi+ besitzt einen modifizierten Zytomegalievirus (CMV)-Promotor an der Stelle 516bp-1118bp, welcher mittels der zelleigenen RNA-Polymerase II die Transkription von shRNA reguliert. Wie bei Xia et al. 2002 beschrieben, führt dieses Promotorsystem zu hohen shRNA-Syntheseraten (Xia et al. 2002).

Um ein template, determinierend für eine spezifische shRNA, in pSi+ zu integrieren, wird das Plasmid mit den beiden Restriktionsendonukleasen BamH1 und HindllI geschnitten.

pSi+ enthält ein Puromycinresistenzgen (3758bp-4357bp), reguliert durch einen SV40 Promotor (4449bp-4748bp). Dieses Gen ermöglicht die Selektion von erfolgreich transfizierten Zellen. Das Aminonukleotid Puromycin ist ein von Streptomyces alboniger synthetisiertes Antibiotikum, welches antagonistisch die Peptidyl-Übertragung am $3^{`}$ Ende der Aminoacyl-tRNA inhibiert und somit zum Abbruch der Proteinbiosynthese führt (De la Luna und Ortin 1992).

Weiterhin ermöglicht ein Ampicillinresistenzgen (2394bp-3254bp) die Selektion von transformierten Bakterienkulturen.

Als Kontrollplasmid wurde ein p-Silencer benutzt, welches zwar die oben genannten molekularbiologischen Eigenschaften besitzt, aber ein template trägt, welches keine signifikanten Homologien zur menschlichen Gendatenbank aufweist. Nachfolgend wird dieses Plasmid als pSi- abgekürzt. 


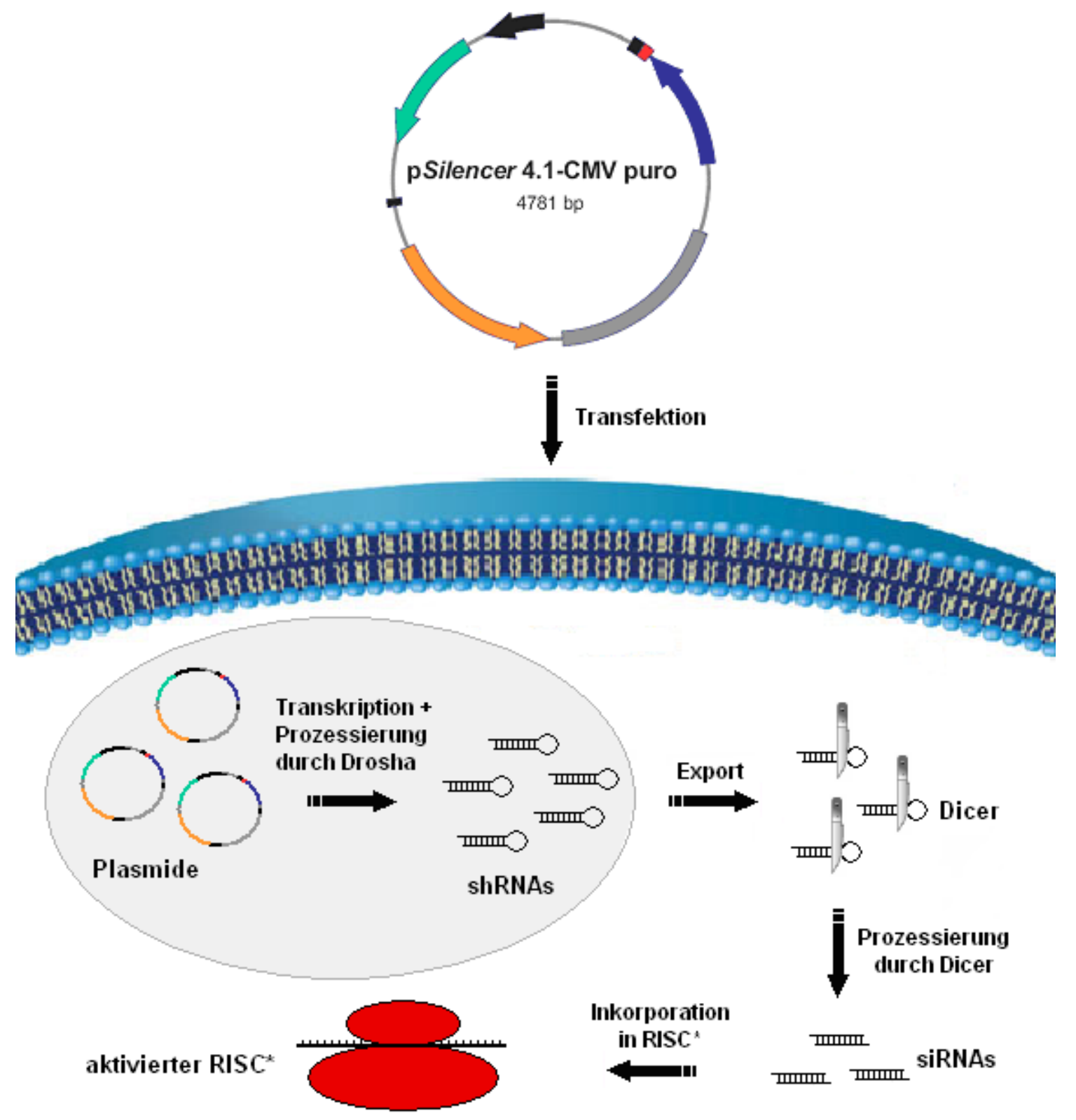

Abb. 6: Darstellung der Plasmidwirkung von pSi in transfizierten Zielzellen. In Zielzellen transfizierte pSi werden im Nukleus transkribiert und durch Drosha in shRNAs prozessiert. Diese werden aus dem Nukleus ins Zytoplasma exportiert, hier durch Dicer in siRNAs prozessiert und schließlich in den gensuppremierenden RISC* (RNA-induced silencing com/pex) inkorporiert (modifiziert nach http://www.ambion.com/techlib/prot/fm_5775.pdf, Stand 05.06.2011).

2) GFP (Grün-fluoreszierendes-Protein)-Plasmide zur Transfektionseffizienzkontrolle

- GFPtpz:

- pmaxGFP ${ }^{\mathrm{TM}}$. 
Tab. 6: Übersicht über verwendete Plasmide

\begin{tabular}{|c|c|c|}
\hline Plasmide & Charakteristika ${ }^{a} /$ Größe & Referenzl Herkunft \\
\hline p-Silencer ${ }^{\mathrm{TM}}$ 4.1-CMV puro & Ampir $^{r}$, Puro ${ }^{r}, 4781 \mathrm{bp}$ & Ambion/ Applied Biosystems \\
\hline GFPtpz & Ampir $^{r}, 4796$ bp & $\begin{array}{l}\text { Freundlicherweise } \\
\text { bereitgestellt von: Klin. } \\
\text { Pharmakologie, Universität } \\
\text { Goettingen, } \\
\text { Sequenz nicht publiziert }\end{array}$ \\
\hline pmaxGFP $^{\mathrm{TM}}$ & $\mathrm{Ampi}^{\mathrm{r}}, 3486 \mathrm{bp}$ & AMAXA \\
\hline
\end{tabular}

${ }^{a}$ Phänotypbezeichnungen: Ampi $^{r}=$ Ampicillinresistenz, Puro $^{r}=$ Puromycinresistenz

\section{Verwendete Oligonukleotide}

Für das Templatedesign, kodierend für die in-vitro-Transkription von siRNA, durch den Vektor p-Silencer ${ }^{\mathrm{TM}}$ 4.1-CMV puro, wurden folgende Oligonukleotide verwendet:

1) 5`-GATCCGCAGCACTCCATATCTCTATTCAAGAGATAGAGATATGGAGTGCTGCTGA-3`

2) 5`-AGCTTCAGCAGCACTCCATATCTCTATCTCTTGAATAGAGATATGGAGTGCTGCG-3`

Diese komplementären Oligonukleotide kodieren für ein siRNA-Konstrukt, welches für folgende Zielsequenz in der Runx2 mRNA komplementär ist:

\section{5'-CAG CAG CAC TCC ATA TCT CTA-3`}

Diese Zielsequenz ist spezifisch an 3 Stellen der Runx2 mRNA lokalisiert, was zu einer Wirkungsverstärkung der siRNA führt.

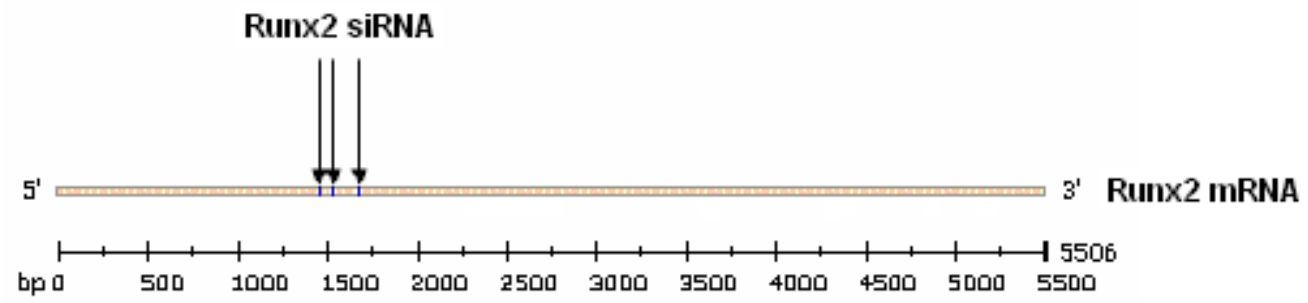

Abb. 7: Darstellung der Runx2 mRNA und den Zielsequenzen der Runx2 siRNA

Ausgewählt wurde diese siRNA (homolog zu der ebenfalls verwendeten exogen synthetisierten siRNA RUNX2 no.4 von Qiagen) aufgrund hoher zuvor gezeigter Gensuppressionsraten in den verwendeten Zellmodellen (HOS, pHOB) (Giesen 2007). 


\section{Agarose-Gelelektrophorese}

Tab. 7: Materialien für die Agarose-Gelelektrophorese

\begin{tabular}{|l|l|}
\hline Reagenz/ Gerät & Hersteller \\
\hline Tris Base & Roth Gmbh, Karlsruhe \\
Borsäure & Sigma, Taufkirchen \\
EDTA $(0,5 \mathrm{M})$ & Gibco BRL, Cölbe \\
Agarose & Biozym, Hessisch-OIdendorf \\
Ethidiumbromid & Sigma, Taufkirchen \\
DNA-Längenstandard & Invitrogen, Karlsruhe \\
Saccharose & Merck, Darmstadt \\
Harnstoff & Merck, Darmstadt \\
Bromphenolblau & Sigma, Taufkirchen \\
Spannungsgerät & Bio RAD, München \\
Elektrophoresekammer & Bio RAD, München \\
\hline
\end{tabular}

\section{Plasmidligation, -präparation und -linearisierung}

Tab. 8: Materialien für die Plasmidligation, -präparation und -linearisierung

\begin{tabular}{|l|l|}
\hline Reagenz & Hersteller \\
\hline 10x T4 DNA Ligase Puffer & Fermentas, St. Leon-Rot \\
T4 DNA Ligase $(5 \mathrm{U} / \mu \mathrm{l})$ & Fermentas, St. Leon-Rot \\
Tris/HCl (50mM) & Merck, Darmstadt \\
K-Acetat (3M) & Merck, Darmstadt \\
$\mathrm{NaOH}(200 \mathrm{mM})$ & Merck, Darmstadt \\
EDTA (10mM) & Merck, Darmstadt \\
$1 \%$ SDS & Fluka Chemie, Buchs \\
RNase & Qiagen, Hilden \\
Endofree Plasmid Maxi Kit & Qiagen, Hilden \\
$10 \times$ NE Puffer 3 & New England Biolabs, Ipswich, USA \\
Sca I (10,000U/ml) & New England Biolabs, Ipswich, USA \\
\hline
\end{tabular}

\section{Transfektion}

Tab. 9: Materialien für die Transfektion

\begin{tabular}{|l|l|}
\hline Reagenz/ Gerät & Hersteller \\
\hline Lipofektamin 2000 & Invitrogen, Karlsruhe \\
Plus Reagent & Invitrogen, Karlsruhe \\
Opti MEM & Gibco, Cölbe \\
MP Solution Kit $10 \mu l$ & Peqlab, Erlangen \\
Microporator & Peqlab, Erlangen \\
Human Chondrocyte Nucleofector Kit & AMAXA, Köln \\
Nucleofector & AMAXA, Köln \\
\hline
\end{tabular}




\section{RT-PCR}

Tab. 10: Materialien für die RT-PCR

\begin{tabular}{|l|l|}
\hline Reagenz/ Gerät & Hersteller \\
\hline $5 \times$ RT-Puffer & Invitrogen, Karlsruhe \\
dNTP $(0,1 \mu \mathrm{mol} / \mu \mathrm{l}) ;$ TTP,GTP,CTP,ATP & Roche, Mannheim \\
DTT $(0,1 \mathrm{~mol} / \mathrm{l})$ & Invitrogen, Karlsruhe \\
$\mathrm{P}(\mathrm{dT})_{15}-$ Primer $(11 \mu \mathrm{M})$ & Roche, Mannheim \\
$\mathrm{RNase}-$ Inhibitor $(40 \mathrm{U} / \mu \mathrm{l})$ & Roche, Mannheim \\
M-MLV $(200 \mathrm{U} / \mu \mathrm{l})$ & Invitrogen, Karlsruhe \\
Thermocycler Primus & MWG-Biotech, Ebersberg \\
Thermocycler Primus advanced 96 & PeqLab, Erlangen \\
PCR-Reaktionsgefäße & Biozym, Hessisch-Oldendorf \\
\hline
\end{tabular}

\section{Sequenzierung}

Tab. 11: Materialien für die Sequenzierung

\begin{tabular}{|l|l|}
\hline Reagenz/ Gerät & Hersteller \\
\hline DMSO & Roth, Karlsruhe \\
BigDye & Applied Biosystems, Foster City, USA \\
Sephadex G-50 & Sigma, Taufkirchen \\
ABI Prism 3100 Genetic Analyzer & Applied Biosystems, Foster City, USA \\
\hline
\end{tabular}

\section{Real-Time-PCR}

Tab. 12: Materialien für die Real-Time-PCR

\begin{tabular}{|l|l|}
\hline Reagenz & Hersteller \\
\hline SYBR Green & Invitrogen \\
\hline
\end{tabular}

Tab. 13: Verwendete Realtime-PCR-Primer

\begin{tabular}{|l|l|}
\hline Gene & Sequenz \\
\hline Runx2 & $\begin{array}{l}\text { vorwärts: TTCCAGACCAGCAGCACTC } \\
\text { rückwärts: CAGCGTCAACACCATCATT }\end{array}$ \\
\hline 3-Actin & $\begin{array}{l}\text { vorwärts: CTGGAACGGTGAAGGTGACG } \\
\text { rückwärts: AGTCCTCGGCCACATTGTGA }\end{array}$ \\
\hline L7 & $\begin{array}{l}\text { vorwärts: AGATGTACAGAACTGAAATTC } \\
\text { rückwärts: ATTTACCAAGAGATCGAGCAA }\end{array}$ \\
\hline Col10A1 & $\begin{array}{l}\text { vorwärts: TACCCCACCCTACAAAATGC } \\
\text { rückwärts:CATAGCAGGACTTCTTTGGTGA }\end{array}$ \\
\hline CTNNB1 & $\begin{array}{l}\text { vorwärts: GCCGGCTATTGTAGAAGCTG } \\
\text { rückwärts: GAGTCCCAAGGAGACCTTCC }\end{array}$ \\
\hline HSD11B1 & $\begin{array}{l}\text { vorwärts: AAATCCATGCAGGAAGATCC } \\
\text { rückwärts: CAGGTGTGACCCATGACTTG }\end{array}$ \\
\hline
\end{tabular}


SFRP1

vorwärts: GCCAGCAGATACACAGGACA

rückwärts: CATGGCTGAAAAAGCATGAA

\section{RNA Microarray one color}

Tab. 14: Materialien für den RNA Microarray one color

\begin{tabular}{|l|l|}
\hline \multicolumn{1}{|c|}{ Reagenz/ Gerät } & Hersteller \\
\hline RNA Spike-In Kit, one color & Agilent, Böblingen \\
2x HIRPM Hybridisations-Puffer & Agilent, Böblingen \\
2x Hybridisations-Puffer & Agilent, Böblingen \\
25x Fragmentations-Puffer & Agilent, Böblingen \\
10x Blocking-Agent & Agilent, Böblingen \\
RNeasy Mini Kit & Agilent, Böblingen \\
$20 x$ SSPE & Qiagen, Hilden \\
$20 \%$ N-Lauroylsarcosin & Sigma, Taufkirchen \\
Acetonitril & Sigma, Taufkirchen \\
Vortexer & VWR, Darmstadt \\
2100 BioAnalyzer & Eppendorf, Hamburg \\
Zentrifuge & Agilent, Böblingen \\
Heizblock & Eppendorf, Hamburg \\
Thermocycler & Eppendorf, Hamburg \\
Hybridisationskammer & Eppendorf, Hamburg \\
Backings & Agilent, Böblingen \\
Hybriditationsofen & Agilent, Böblingen \\
NanoDrop-ND1000 & Agilent, Böblingen \\
\hline & NanoDrop, Wilmington, USA \\
\hline
\end{tabular}

\subsection{Methoden}

\subsubsection{Zellkultur}

\subsubsection{Gewinnung von primären humanen Osteoblasten}

Die primären humanen Osteoblasten wurden aus Knochenproben, wie bei Siggelkow et al. 1999 beschrieben, gewonnen (Siggelkow et al. 1999). Diese Modifikation der Originalmethode von Beresford wurde routinemäßig durchgeführt (Auf'm Kolk et al. 1985, Beresford et al. 1984). Hierfür wurde die Knochenprobe, nach Entnahme im Operationssaal, in steriler physiologischer Kochsalzlösung aufbewahrt und unserer Abteilung zur Verfügung gestellt. Mittels steriler Pinzette und sterilem Skalpell wurde das Knochenstück von kortikalem Gewebe und Fettgewebe gesäubert. Das übrig gebliebene spongiöse 
Knochenmaterial wurde nun mit der Pinzette und dem Skalpell zerkleinert und mit PBS mehrmals von Blutbestandteilen gesäubert. Ca. 8 dieser $1 \mathrm{~mm}^{3}$ großen Knochenfragmente wurden nun in Gewebekulturschalen gegeben und jeweils mit nur einem Tropfen HOB-Medium bedeckt, um ein Wegschwimmen der Knochenstücke zu verhindern.

\subsubsection{Zellversorgung}

Die im Rahmen dieser Promotionsarbeit verwendeten Zellen wurden routinemäßig bei $37^{\circ} \mathrm{C}$, 95\% Luftfeuchtigkeit und $5 \% \mathrm{CO}_{2}$ im Brutschrank kultiviert und zweimal pro Woche mit frischem Medium versorgt (s.u.). Primäre Zellen wurden möglichst früh verwendet, eingefroren oder in ein größeres Zellgefäß ausgesät, wenn sie einen hohen Konfluenzgrad erreicht hatten. Tumorzellen wurden bei einem 100-prozentigen Konfluenzgrad passagiert (s.u.) und entweder in gewünschter Weise gesplittet $(1: 4 ; 1: 8)$ oder eingefroren (s.u.).

\subsubsection{Mediumwechsel}

Das verbrauchte Medium wurde mit einer Pasteurpipette bis auf ein Zehntel aus dem Zellkulturgefäß gesaugt und vorsichtig durch neues Medium ersetzt. Dabei wurde darauf geachtet, dass der Zellrasen nicht durch das Zufügen des neuen Mediums aufgewirbelt wurde.

$$
\begin{aligned}
& \text { HOS-Medium: } \\
& \text { ISCOVE-Medium } \\
& +10 \% \text { FCS } \\
& +0,5 \% \text { Pen/Strep-Lsg } \\
& +1 \% 200 \mathrm{mM} \text { L-Glutamin }
\end{aligned}
$$

pHOB-Medium:

DMEM

$+10 \%$ FCS

$+1 \%$ Pen/Strep-Lsg

$+1 \%$ 200mM L-Glutamin

\subsubsection{Trypsinierung von Zellen}

Beispielhaft wird hier das Trypsinieren aus Gewebekulturflaschen beschrieben:

Das Zellkulturmedium wurde vorsichtig mit einer Pasteurpipette abgesaugt und der Zellrasen wurde mit ca. 5ml PBS gewaschen. Zum Ablösen der Zellen wurden $2 \mathrm{ml}$ Trypsin auf den Zellrasen gleichmäßig verteilt und für 3-5min im Brutschrank inkubiert. Durch vorsichtiges Klopfen der Flasche wurde das Lösen der Zellen vom Flaschenboden begünstigt und darauffolgend mikroskopisch kontrolliert.

Durch Zugabe von $10 \mathrm{ml}$ Medium wurden die Zellen heruntergespült und in ein 15-mlFalconröhrchen überführt. Das im Medium enthaltene FCS stoppt hierbei die Aktivität des Trypsins. Durch Zentrifugation bei $2000 \mathrm{U} / \mathrm{min}$ wurden die Zellen pelletiert und in gewünschter Verdünnung in jeweiligem HOS 58- bzw. pHOB-Medium resuspendiert. 


\subsubsection{Lebendzellzahlbestimmung}

Die Zahl vitaler Zellen in einer Zellsuspension wurde durch Trypanblaufärbung und Auszählung in der Neubauer-Zählkammer bestimmt. Hierfür wurden $10 \mu \mathrm{l}$ der Zellsuspension

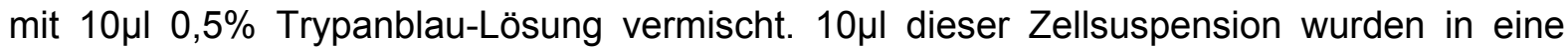
Neubauer-Zählkammer gegeben. Da vitale Zellen kein Trypanblau aufnehmen, wurden zur Lebenzellzahlbestimmung nur die ungefärbten Zellen gezählt.

\section{Trypanblau-Lösung:}

$9,9 \mathrm{~g} \mathrm{NaCl}$

$+0,5 \mathrm{~g}$ Trypanblau

ad $100 \mathrm{ml} \mathrm{H}_{2} \mathrm{O}_{\text {dest }}$

\subsubsection{Einfrieren von Zellen}

Die einzufrierenden Zellen wurden wie oben beschrieben abtrypsiniert. Statt der Resuspension in Kulturmedium wurde das Zellpellet in 1,8ml Einfriermedium resuspendiert und in Kryoröhrchen überführt. Diese Röhrchen wurden in ein mit Isopropanol gefülltes Einfriergefäß gestellt und für 2-3 Tage bei $-70^{\circ} \mathrm{C}$ gelagert und danach in einen Behälter mit flüssigem Stickstoff überführt.

$$
\begin{aligned}
& \text { Einfriermedium: } \\
& \text { DMEM } \\
& +10 \% \text { DMSO } \\
& +20 \% \text { FCS }
\end{aligned}
$$

\subsubsection{Auftauen von Zellen}

Dieses Verfahren wurde vornehmlich für die in der Laborsammlung eingefrorenen HOS 58-Zellen benutzt.

Die Zellen enthaltenden Kryoröhrchen wurden nach der Entnahme aus dem flüssigen Stickstoff bei $37^{\circ} \mathrm{C}$ im Wasserbad erwärmt bis nur noch ein kleiner Rest der Zellsuspension gefroren war. Die Zellsuspension wurde zu $8 \mathrm{ml}$ Medium in ein 15-ml-Röhrchen überführt und abzentrifugiert. Der Überstand wurde verworfen, das Zellpellet in Medium resuspendiert und in eine Zellkulturflasche überführt. Dadurch wurden die Reste von DMSO aus dem Einfriermedium entfernt, welche zytotoxisch auf die Zellen wirken. 


\subsubsection{Isolierung von Gesamt-RNA}

\section{RNeasy}

Die im Folgenden beschriebene Standardmethode wurde für alle benutzten Zellen angewandt.

Hierfür wurde der RNeasy-Mini-Kit und das RNase-Free DNase Set (Qiagen) benutzt. Der RNeasy-Mini-Kit liefert spezielle Säulen (RNeasy spin column), die eine Silika-Gel-Membran

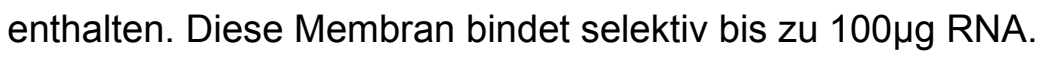

In mehreren Waschschritten wird diese RNA von Proteinen, genomischer DNA und sonstiger Verunreinigung gesäubert, um schließlich im letzten Schritt in RNase-freiem-Wasser eluiert zu werden.

Vor der Aufarbeitung wurden die Zellen mit PBS gewaschen. Der Zelllysepuffer gewährleistet einen degradationsfreien Zustand der Gesamt-RNA. Dies wird durch das im RLT-Puffer enthaltene Guanidin-Isothiocyanat erreicht, das eine Inaktivierung von RNasen bewirkt. Für eine Fläche von 9,6 $\mathrm{cm}^{2}$ („6-Well-Platte“) wurden $350 \mu$ l des Zelllysepuffers auf die Zellen gegeben. Nachfolgend wird immer von diesem Volumen ausgegangen.

Das Lysat konnte auch eingefroren und zu einem späteren Zeitpunkt aufgearbeitet werden. Zur Aufarbeitung wurden 350 $\mu$ l 70\%-iger Ethanol zu der Probe gegeben. Dieses Gemisch wurde gevortext, auf ein RNeasy spin column überführt und abzentrifugiert. Die Zell-RNA war nun in der Silika-Gel-Membran der RNeasy spin column gebunden. Nach einem

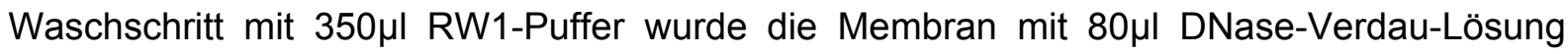
(RNase-Free DNase Set) benetzt und für 15min bei Raumtemperatur inkubiert. Nach einem

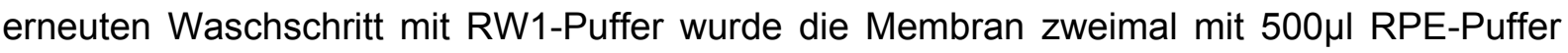
gesäubert. Nach Eluation mit 20-30 $\mu$ R Rase-freien-Wasser wurde die RNA-Konzentration mittels photometrischer Messung (s.u.) bestimmt. Zur Lagerung wurde die RNA bei $-80^{\circ} \mathrm{C}$ eingefroren.

Lysepuffer:

RLT-Puffer (Qiagen RNeasy Kit)

$+1 \%$ 2-Mercaptoethanol

\section{TRIzol-RNA-Aufbereitung}

Die RNA-Aufbereitung mittels TRIzol wurde i.R. dieser Doktorarbeit in Kooperation mit Frau Dr. rer Salinas-Riester im Transkriptomanalyselabor der Universität Göttingen durchgeführt. Bei dieser Methode wird das monophasige Gemisch aus Phenol und Guanidin-Isothiocyannat zur Aufbereitung von RNA aus Zellen oder Geweben benutzt.

Zur Zellhomogenisation wurde nach zweimaligem Waschen der Zellen mit PBS, 1ml TRIzol pro $1 \times 10^{6}$ Zellen auf die Zellen gegeben und danach in 1,5-ml-Reaktionsgefäße überführt. 
Zur Phasenseparation wurde nach fünfminütiger Inkubation $0,2 \mathrm{ml}$ Chloroform pro $\mathrm{ml}$ TRIzol hinzugegeben und nach weiterer Inkubation abzentrifugiert.

Die oberste farblose Phase der dreiphasigen Lösung enthält die gelöste RNA und wurde mit einer Pipette vorsichtig in ein weiteres 1,5-ml-Reaktionsgefäß überführt, wobei das dekantierte Volumen ca. $600 \mu$ l betrug.

Zur RNA-Präzipitation wurden 0,5ml Isopropanol zu dem Ansatz hinzugegeben, gevortext und nach Inkubation über Nacht bei $-20^{\circ} \mathrm{C}$ abzentrifugiert. Durch Hinzugabe von $1 \mu \mathrm{l}$ Glycoblue zum Präzipitationsansatz wurde der Präzipitationserfolg visuell sichtbar gemacht. Nach zweimaliger Waschung mit $1 \mathrm{ml} 75 \%$ igen Ethanols pro $1 \mathrm{ml}$ TRIzol wurde die RNA in $50 \mu l$ RNase-freiem Wasser eluiert und mittels NanoDrop hinsichtlich Menge sowie mittels Bionanalyzer hinsichtlich Qualität getestet.

\subsubsection{Bakterienkultur}

\subsubsection{Anzucht}

$\mathrm{Zu}$ kultivierende Bakterien wurden in LB-Medium angezogen und über Nacht mit leicht geöffnetem Deckel bei $37^{\circ} \mathrm{C}$ im Schüttler geschüttelt. Vorkulturen wurden in 15-mlFalconröhrchen, Hauptkulturen in 0,5-I-Flaschen kultiviert. Zur Anzucht auf Agarplatten wurden die Bakterien auf LB-Agarplatten ausgestrichen und ebenfalls über Nacht bei $37^{\circ} \mathrm{C}$ inkubiert. Diese Kulturen konnten bis zu 2 Wochen mit Paraffin verschlossen bei $4^{\circ} \mathrm{C}$

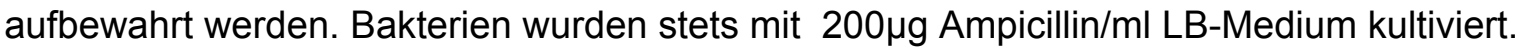

\begin{tabular}{ll} 
LB-Medium: & LB-Platten: \\
\hline $10 \mathrm{~g}$ Tryptone & $15 \mathrm{~g} \mathrm{Agar}$ \\
$+5 \mathrm{~g}$ Hefeextrakt & $+200 \mathrm{mg} \mathrm{Ampicillin}$ \\
$+10 \mathrm{~g} \mathrm{NaCl}$ & ad $1000 \mathrm{ml}$ LB-Medium \\
$+200 \mathrm{mg} \mathrm{Ampicillin}$ & $\mathrm{pH} 7,4$ \\
ad $1000 \mathrm{ml} \mathrm{H}_{2} \mathrm{O}_{\text {dest }}$ & \\
$\mathrm{pH} 7,4$ &
\end{tabular}

\subsubsection{Präparation chemisch kompetenter E.coli}

Um Escherichia coli für zirkuläre DNA aufnahmefähig zu machen, wurde erst eine Bakterienkultur bis zu einer $\mathrm{OD}_{550}$ von 0,48 in 100ml LB-Medium kultiviert. Das Wachstum wurde durch Kühlung auf Eis gestoppt. Nach Pelletierung wurden die Bakterien in $10 \mathrm{ml}$ Präparationspuffer 1 resuspendiert. Vor einer weiteren Pelletierung wurden die Bakterien für 
60min auf Eis inkubiert. Nach Resuspension in $1 \mathrm{ml}$ Präparationspuffer 2 wurden die Bakterien in $100 \mu$ Aliquots aufgeteilt.

Präparationspuffer 1:
Kaliumacetat $(\mathrm{pH} \mathrm{5,8)} \mathrm{30mM}$
Rubidiumchlorid 100mM
Manganchlorid 50mM
Calciumchlorid 10mM

\subsubsection{Bakterienglycerolstocks}

E.coli sind in einem Glycerolstock mindestens 2-3 Jahre haltbar. Hierzu wurde eine in LB-Medium hochgezogene Bakterienkultur mit vorgekühltem $50 \%$ Glycerol im Verhältnis 1:1 gemischt, in Kryoröhrchen überführt und bei $-80^{\circ} \mathrm{C}$ eingefroren.

\subsubsection{Arbeiten mit Nukleinsäuren}

\subsubsection{Photometrische Konzentrationsmessung}

Im Eppendorf Biophotometer wurde anhand der Absorption bei $260 \mathrm{~nm}$ über die OD indirekt die Konzentration der enthaltenen Nukleinsäuren bestimmt. Bei einer OD von 1 wurde von folgenden Konzentrationen ausgegangen:

$$
\begin{array}{ll}
\text { - RNA } & : 40 \mu \mathrm{g} / \mathrm{ml} \\
\text { - doppelsträngige DNA } & : 50 \mu \mathrm{g} / \mathrm{ml} \\
\text { - einzelsträngige DNA } & : 31 \mu \mathrm{g} / \mathrm{ml} .
\end{array}
$$

Hierfür wurde eine 1:50 Verdünnung der Probe im Vergleich zum Lösungsmittel, in der Regel $\mathrm{H}_{2} \mathrm{O}_{\text {dest }}$, gemessen. Anhand des $\mathrm{OD}_{260}: \mathrm{OD}_{280}$-Quotienten konnte auch der Reinheitsgrad der gemessenen Probe abgeschätzt werden. Proteinfreie doppelsträngige DNA-Lösungen sollten einen Wert von 1,8 und RNA-Proben von 1,8-2,0 aufweisen.

\subsubsection{Agarose-Gelelektrophorese}

Mit der Agarose-Gelelektrophorese können DNA-Moleküle ihrer Größe nach aufgetrennt werden. Die Wanderungsgeschwindigkeit linearer Moleküle ist dabei umgekehrt proportional zum Logarithmus ihres Molekulargewichts. Bei zirkulärer DNA können supercoiled-Strukturen auftreten, welche wegen der größeren Verdrillung schneller wandern 
und auf dem Gel als Banden bei fälschlich kleinem Molekulargewicht auftreten. Für analytische Gelelektrophoresen wurde stets ein 1,5-prozentiges-Gel, für präparative Zwecke stets ein 0,8-prozentiges-Gel benutzt. Bei einer mittleren Spannung von $80 \mathrm{~V}$ bis maximal $110 \mathrm{~V}$ wurden die nukleinsäurehaltigen Proben elektrophoretisch aufgetrennt. Die Banden werden durch Interkalierung von Ethidiumbromid in die DNA unter UV-Licht sichtbar gemacht. In Relation zu Größenmarkern kann die Größe der Nukleinsäuren abgeschätzt werden.

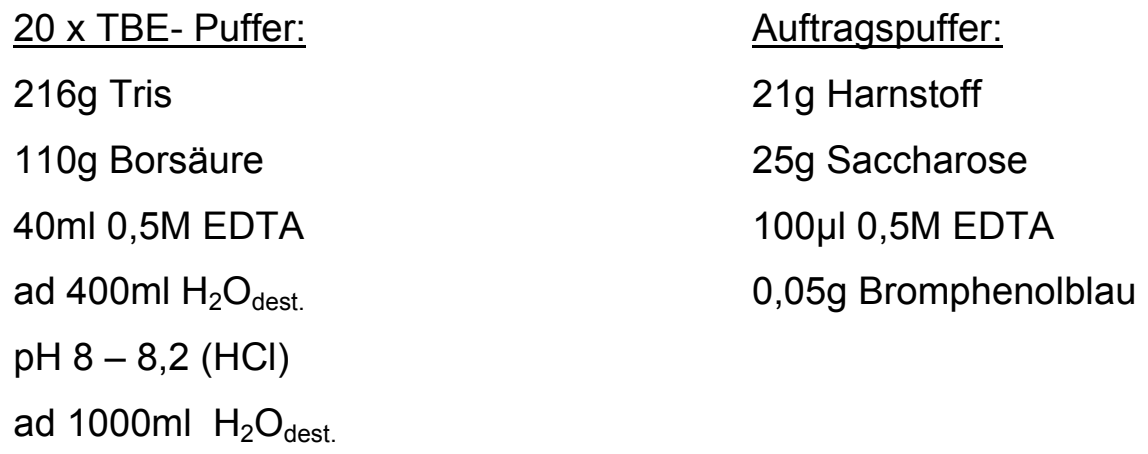

\subsubsection{Klonierung}

Die beiden Oligonukleotidstränge, welche für die Runx2 siRNA kodieren, wurden einmalig auf $90^{\circ} \mathrm{C}$ erhitzt und nachfolgend auf $37^{\circ} \mathrm{C}$ abgekühlt, sodass folgendes

Oligonukleotidkonstrukt entstanden ist:

5'-GATCCGCAGCACTCCATATCTCTATTCAAGAGATAGAGATATGGAGTGCTGCTGA-3` 3`-GCGTCGTGAGGTATAGAGATAAGTTCTCTATCTCTATACCTCACGACGACTTCGA-5`

Dieses Konstrukt konnte nun in den Vektor hineinkloniert (ligiert) werden.

\subsubsection{Ligation}

Für die Ligation wurden zwei Ligationsansätze angesetzt: ein Plus-Ansatz mit zu transformierenden Oligonukleotiden und ein Negativ-Ansatz als Kontrolle ohne Oligonukleotide. 
Tab. 15: Übersicht über den Ligationsansatz

\begin{tabular}{|c|c|c|}
\hline Reagenz & Plus-Ansatz & Negativ-Ansatz \\
\hline 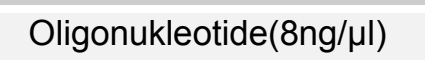 & $1 \mu \mathrm{l}$ & ---- \\
\hline $\mathrm{H}_{2} \mathrm{O}_{\text {dest. }}$ & ---- & $1 \mu \mathrm{l}$ \\
\hline $\mathrm{H}_{2} \mathrm{O}_{\text {dest. }}$ & $6 \mu \mathrm{l}$ & $6 \mu l$ \\
\hline 10x T4 DNA Ligase Puffer & $1 \mu \mathrm{l}$ & $1 \mu \mathrm{l}$ \\
\hline p-Silencer-Vektor & $1 \mu \mathrm{l}$ & $1 \mu \mathrm{l}$ \\
\hline T4 DNA Ligase $(5 \mathrm{U} / \mu \mathrm{l})$ & $1 \mu \mathrm{l}$ & $1 \mu l$ \\
\hline Gesamtansatz & $10 \mu \mathrm{l}$ & $10 \mu \mathrm{l}$ \\
\hline
\end{tabular}

Nach 1-3h Inkubation bei Raumtemperatur wurden die Ligationsansätze zur Transformation in chemisch kompetente $E$. coli genutzt.

\subsubsection{Transformation in chemisch kompetente $E$. coli}

$\mathrm{Zu}$ dem vollen Ligationsansatz wurden auf Eis $75 \mu \mathrm{l}$ chemisch kompetente $E$. coli hinzugegeben. Dieser Ansatz wurde vorsichtig geschwenkt und auf Eis 5.min inkubiert. Die Bakterien wurden tröpfchenweise auf eine $37^{\circ} \mathrm{C}$ vorgewärmte LB-Agar-Platte $(+200 \mu \mathrm{g}$ Ampicillin/ml) und mit einer vorher gebogenen Pasteurpipette vorsichtig und gleichmäßig verstrichen. Diese Platte wurde über Nacht bei $37^{\circ} \mathrm{C}$ inkubiert. E. coli, die den Vektor aufgenommen haben, konnten sich aufgrund der Ampicillinresistenz des Vektors klonal vermehren. Mit einer schmalen Pipettenspitze wurden einzelne Bakterienklone gepickt, in $5 \mathrm{ml}$ LB-Medium gegeben und wie vorher beschrieben kultiviert.

\subsubsection{Analytische Plasmidisolierung (Miniprep)}

Von der Übernachtkultur des transformierten Bakteriengemisches wurden $2 \mathrm{ml}$ Bakteriensuspension 10min abzentrifugiert.

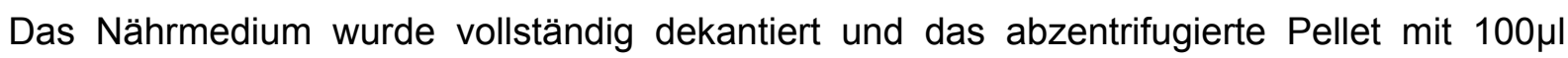

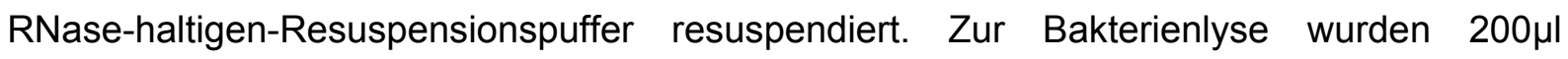
Lysepuffer zugegeben, vorsichtig geschwenkt und bei Raumtemperatur 3-5min inkubiert. Hiernach wurden $150 \mu \mathrm{l}$ Neutralisationspuffer hinzugegeben, $5 \mathrm{~min}$ inkubiert und $30 \mathrm{~min}$ bei 14.000U/min zentrifugiert. Nach der Zentrifugation war die Plasmid-DNA im Überstand gelöst, während der Zelldebris der Bakterien sich im Pellet niedergeschlagen hat. Nach Fällung mit 300 $\mathrm{\mu l}$ Isopropanol und Waschen mit $1 \mathrm{ml} 80 \%$-igen Ethanol wurde die DNA in $15 \mu \mathrm{H}_{2} \mathrm{O}_{\text {dest. }}$ resuspendiert. Diese Lösung konnte nun bis zu weiteren Analysen bei $-20^{\circ} \mathrm{C}$ eingefroren werden. 


\begin{tabular}{|c|c|c|}
\hline Resuspensionpuffer: & Lysepuffer: & Neutralisationspuffer: \\
\hline $50 \mathrm{mM}$ Tris $/ \mathrm{HCl} \mathrm{pH} 8.0$ & $200 \mathrm{mM}$ & $\mathrm{NaOH} 3 \mathrm{M}$ K-Acetat \\
\hline 10mM EDTA & $1 \%$ SDS & $\mathrm{pH} 5.5$ \\
\hline
\end{tabular}

\subsubsection{Präparative Plasmidisolierung (Maxiprep)}

Für die Plasmidgewinnung wurde der Endofree Plasmid Maxi Kit von Qiagen benutzt.

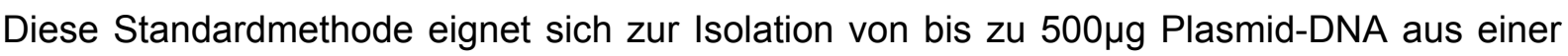
Bakterienkultur. Im Wesentlichen basiert die Methode auf der alkalischen Lyse der Bakterienkultur und einer anschließenden Bindung der freigesetzten Plasmid-DNA an eine Anionenaustauschermatrix, die sich in den Qiagen-tips-Säulen befindet. In Waschschritten wird die DNA von bakterieller RNA, bakteriellen Proteinen, Farbstoffen, niedermolekularen Verunreinigungen und auch von bakteriellen Endotoxinen befreit. Diese könnten bei anschließenden Transfektionen mit dem gewonnenen Plasmid stören. Im letzten Schritt der Methode wird die Plasmid-DNA in TE-Puffer eluiert und kann z.B. für Transfektionen eingesetzt werden.

Für die Maxiprep wurde eine transformierte Bakterienhauptkultur angezogen und abzentrifugiert.

Nach Dekantierung konnte das Pellet entweder gleich weiterverarbeitet oder bei $-20^{\circ} \mathrm{C}$ eingefroren werden. Nach Resuspension in 20ml Puffer P1, Zelllyse in 20ml Puffer P2 und Neutralisation mit 20ml Puffer P3 wurde die Lösung in eine QIAfilter-Maxi-Filtrationseinheit gefüllt, mit dem mitgelieferten Kolben durch den Filter in ein Auffanggefäß gedrückt und mit 2,5ml ER-Puffer auf Eis inkubiert. Während der Inkubation wurde eine Qiagen-tip-500-Säule mit 10ml QBT Puffer äquilibriert. Das gefilterte Gemisch wurde nun auf diese Säule gegeben. Durch die Bindung der Plamid-DNA an die Anionenaustauschermatrix des Qiagen-tips wurde in diesem Schritt die Plasmid-DNA von dem Lösungsmittel getrennt. Nach zweimaligem Waschen mit $30 \mathrm{ml}$ QC-Puffer wurde die DNA mit 15ml QN-Puffer eluiert, mit 10,5ml Isopropanol präzipitiert und anschließend mit $5 \mathrm{ml} 70 \%$ Ethanol gewaschen. Endgültig eluiert wurde die DNA in 50-150 $\mu$ l TE-Puffer.

Die DNA-Konzentration wurde wie vorher beschrieben photometrisch bestimmt, die Lagerung erfolgte bei $-20^{\circ} \mathrm{C}$.

\subsubsection{Plasmidlinearisierung}

Da bei stabilen Transfektionen höhere Transfektionsraten durch linearisierte als durch zirkuläre Plasmide erreicht werden, wurde der zirkuläre pSilencer mit der 
Restriktionsendonuklease Sca I linearisiert. Dieses Enzym schneidet den Vektor an der Position 2947bp. Damit liegt die Schnittstelle innerhalb des für die Ampicillinresistenz kodierenden Gens. Die Ampicillinresistenz des Plasmids wird jedoch nur für die Amplifikation in Bakterien genutzt und ist damit bei einer Transfektion in eukaryoten Zellen nicht mehr erforderlich.

Tab. 16: Übersicht über den Linearisierungsansatz:

\begin{tabular}{|c|c|}
\hline Reagenz & Volumen \\
\hline p-Silencer & $20 \mu \mathrm{l}$ \\
\hline 10x NE Puffer 3 & $5 \mu \mathrm{l}$ \\
\hline Sca I & $2 \mu \mathrm{l}$ \\
$\mathrm{H}_{2} \mathrm{O}_{\text {dest. }}$ & $23 \mu \mathrm{l}$ \\
\hline Gesamtansatz & $\mathbf{5 0 \mu l}$ \\
\hline
\end{tabular}

Dieser Ansatz wurde über Nacht bei $37^{\circ} \mathrm{C}$ inkubiert. Durch eine analytische Agarose-Gelelektrophorese wurde die Reaktion überprüft. Nach Abschluss der Reaktion wurde zur Aufreinigung der geschnittenen DNA der QIAQuick Gel Extraction Kit von Qiagen benutzt. Hierfür wurde die linearisierte DNA in einer Agarose-Gelelektrophorese mit einem präparativen 0,8-prozentigen-Agarosegel von noch zirkulärer DNA getrennt. Die Bande der linearisierten DNA wurde mit einem Skalpell ausgeschnitten und gewogen.

Bis zu 400mg Agarosegel konnten mit einer QIAquick spin column aufgereinigt werden. Es wurden 3 Volumen QG-Puffer hinzugegeben, wobei $1 \mu$ l Puffer $1 \mathrm{mg}$ Gel entsprach. Dieser Ansatz wurde bei $50^{\circ} \mathrm{C}$ geschmolzen. Nach Zugabe von 1 Volumen Isopropanol wurde der Ansatz auf eine QIAquick spin column überführt und abzentrifugiert.

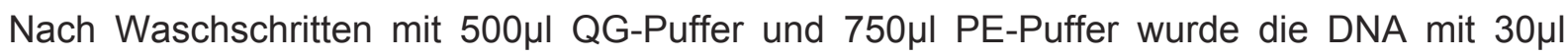
EB-Puffer eluiert. Die DNA-Konzentration des Eluats wurde photometrisch bestimmt und die Linearisierung des Plasmids wurde abermals durch eine analytische Agarose-Gelelektrophorese überprüft.

\subsubsection{Transfektion}

Um Nukleinsäuren in den Zellkern einer Zielzelle einzuschleusen, bedarf es eines effizienten Transfektionssystems. Hierfür wurden drei verschiedene Transfektionssysteme getestet und schließlich genutzt. Namentlich handelt es sich dabei 1) um die Lipofektion mittels Lipofectamine 2000 von Invitrogen, 2) um die Mikroporation mittels Microporator von Peqlab und 3) um die Nukleofektion mit dem human chondrocyte nucleofector kit von AMAXA. 


\section{Lipofektion}

Seit Felgner et al. 1987 die Möglichkeit des Nukleinsäuretransports in Zellen via kationischen Lipiden, sogenannten cationic liposomes (CLs), zeigen konnten, wurde dieses Verfahren vielfach in Zellkulturen, Tiermodellen und in vivo genutzt (Dass 2004).

Man geht davon aus, dass kationische Phospholipide in hydrophiler Umgebung Lipidvesikel mit einer doppelschichtigen Phospholipidmembran bilden, an die sich die negativ geladenen Nukleinsäuren anlagern und als sogenannte Lipoplexe oder cationic lipid-nucleic acid complexes (CLNACs) Zellmembranen, vergleichbar mit Endosomen, penetrieren können. Intrazellulär fusionieren diese Endosomen entweder mit der Kernmembran und entlassen so die Nukleinsäuren direkt ins Karyoplasma oder sie werden in lysosomalen Prozessen abgebaut und entlassen so die Nukleinsäuren ins Zytoplasma.

Moderne Transfektionsreagenzien, wie z.B. das in dieser Arbeit verwendete Lipofectamine 2000, bestehen meistens aus einem Gemisch von kationischen und neutralen Lipiden. Der Anteil der neutralen Lipide, im Falle des Lipofectamines das gebräuchliche Dioleoylphosphatidylethanolamine (DOPE), hilft im Fusionsprozess der Lipide zum Vesikel und stabilisiert jenes, was von besonderer Bedeutung ist, da sich die kationischen Lipide aufgrund ihrer positiven Ladung voneinander abstoßen (Hafez et al. 2001, Zuidam und Barenholz 1998). Liposomen ohne einen Anteil neutraler Lipide haben niedrigere Transfektionsraten als Liposomen mit neutralen Lipiden, wie Mui et al. 2000 zeigen konnten. Vorteile der Lipofektion sind gute Handhabung und geringe Zytotoxizität (z.B. im Vergleich zur Elektroporation), wobei geringe Transfektionsraten in primären Zellen und in einigen Zellinien sich als nachteilig erwiesen haben. Für die Transfektionsrate sind unter anderem das Verhältnis verschiedener Lipide, das Lipid/Nukleinsäureverhältnis und die Größe der Nukleinsäuren entscheidend (Dass 2004).

Praktische Durchführung der Lipofektion:

Vor der Transfektion wurden ca. $(0,5-1)^{\star} 10^{5}$ Zellen in 6-Well-Platten ausgesät und bis zu einem Konfluenzgrad von 90-95\% kultiviert. Für die Transfektion wurden 2 Ansätze (Ansatz A und Ansatz B) pro Well wie folgt angesetzt.

Tab. 17: Übersicht über den Lipofektionsansatz

\begin{tabular}{|c|c|c|}
\hline Reagenz & Ansatz A & Ansatz B \\
\hline Plasmid-DNA & $1 \mu \mathrm{g}-4 \mu \mathrm{g}$ & ---- \\
\hline Plus-Reagenz & $4 \mu \mathrm{l}$ & ---- \\
\hline Lipofectamine 2000 & ---- & $10 \mu \mathrm{l}-12 \mu \mathrm{l}$ \\
\hline OptiMem & $125 \mu \mathrm{l}$ & $125 \mu \mathrm{l}$ \\
\hline Inkubation (RT) & $15 \mathrm{~min}$ & $5 \mathrm{~min}$ \\
\hline
\end{tabular}


Beide Ansätze wurden vereinigt und bei Raumtemperatur 15min inkubiert. Währenddessen wurden die Zellen mit PBS gewaschen und mit 1,5ml OptiMem bedeckt. Das Transfektionsreagenz wurde nun tröpfchenweise auf die Zellen gegeben und durch vorsichtiges Schwenken auf dem Zelllrasen verteilt. Das Transfektionsmedium wurde, je nach Versuch, für 3-24h auf den Zellen belassen, wobei standardmäßig nach $3 \mathrm{~h} 1,5 \mathrm{ml}$ Vollmedium mit doppeltem FCS (20\%), ohne Antibiotikum hinzupipettiert wurde.

\section{Mikroporation, Nukleofektion und Elektroporation}

Sowohl die Mikroporation als auch die Nukleofektion basieren auf dem Prinzip der Elektroporation. Diese Methode wurde erstmals 1982 als Möglichkeit des Gentransfers in Mauszellen von Neumann et al. publiziert (Neumann et al. 1982). Während sich in den Anfängen die Anwendung der Elektroporation größtenteils auf die Transformation von Bakterien beschränkte, ist sie heute eine etablierte Methode um RNA, DNA aber auch eine große Bandbreite anderer Moleküle wie zum Beispiel lonen oder sogar Antikörper in Zellen einzuschleusen. Dies gelang sowohl in vitro, in vivo als auch in Patienten (Gehl 2003).

Durch Applikation eines Spannungspulses an Zellen wird die Zellmembran kurzzeitig destabilisiert, sodass sie für exogene Moleküle permeabel wird. Die Effizienz dieses Vorgangs ist unter anderem abhängig von der Spannungsstärke, der Dauer und der Anzahl der Spannungspulse sowie dem Elektroporationspuffer.

Praktische Durchführung der Mikroporation:

Bei der Mikroporation mit dem Microporator von Peqlab wird eine spezielle Pipettenspitze mit einer Goldelektrode als Reaktionsraum der Elektroporation genutzt. In dieser Arbeit wurden 10- $\mu$ l-Pipettenspitzen benutzt.

Die Zellen wurden von dem Kulturgefäß abtrypsiniert und mit PBS gewaschen. Nach Abzentrifugation wurden die Zellen in Resuspensionspuffer in einer Konzentration von $5^{\star} 10^{6}$ Zellen $/ \mathrm{ml}$ resuspendiert. Aus dieser Zellsuspension wurden ca. $120 \mu \mathrm{l}$ in 1,5-mlReaktionsgefäße vorgelegt und mit $4 \mu \mathrm{g}$ Plasmid-DNA vermischt. Dieses Gemisch wurde mit der Elektroporationspipettenspitze aufgenommen. Nach Transfektion unter den unten angegebenen Bedingungen wurden die transfizierten Zellen in vorgewärmtes Medium gegeben.

Tab. 18: Mikroporationsprotokoll:

\begin{tabular}{|c|c|c|}
\hline Spannung & Pulslänge & Pulszahl \\
\hline $99 \mathrm{~V}$ & $40 \mathrm{~ms}$ & 1 \\
\hline
\end{tabular}


Praktische Durchführung der Nukleofektion:

Die Transfektionen mittels Nukleofektion wurden in Kooperation mit der Arbeitsgruppe von Herrn Prof. Miosge, Georg-August-Universität Göttingen, durchgeführt. Es wurde hierfür das human chondrocyte nucleofector kit von AMAXA benutzt.

Die zu transfizierenden Zellen wurden mittels Zellschaber von dem Kulturgefäß abgelöst und in ein 15-ml-Falconröhrchen überführt. Diese Zellsuspension wurde abzentrifugiert, in $1 \mathrm{ml}$ PBS resuspendiert und die Zellzahl wurde ermittelt.

Pro Transfektionsansatz wurden $5^{\star} 10^{5}$ Zellen in $15-\mathrm{ml}$-Falconröhrchen gegeben und abermals abzentrifugiert. Um eine hohe Toxizität zu vermeiden, wurden die nachfolgenden Schritte für jeden Transfektionsansatz nacheinander ausgeführt: Das Zellpellet wurde in $100 \mu \mathrm{l}$ Chondrocyte Nucleofector Solution (inkl. Supplement) resuspendiert und je nach

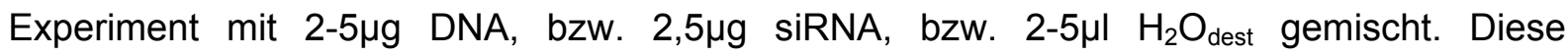
Suspension wurde in die mitgelieferte Einmalküvette überführt und mit dem Programm U-24 im Nucleofector transfiziert. Zu dieser Suspension wurde nun nach der Transfektion $500 \mu l$ auf $37^{\circ} \mathrm{C}$ vorgewärmtes Vollmedium mit $20 \%$ FCS in die Küvette gegeben. Der volle Ansatz wurde nun mit der mitgelieferten Einmalpipette aus der Küvette entnommen und tröpfchenweise gleichmäßig in $1,5 \mathrm{ml}$, auf $37^{\circ} \mathrm{C}$ vorgewärmtes, Medium mit $20 \% \mathrm{FCS}$ gegeben. Nach 24-stündiger Kultivierung wurde ein Mediumwechsel mit Medium und 10\% FCS gemacht.

\subsubsection{Polymerase-Ketten-Reaktion}

Die Polymerase-Ketten-Reaktion (PCR) als Methode zur spezifischen Amplifikation bestimmter DNA-Abschnitte wurde 1983 von dem späteren Chemienobelpreisträger Kary Mullis entwickelt und 1985 von Saiki et al. publiziert. Die PCR ist eine Standardmethode, die sich die Aktivität einer DNA-Polymerase zu Nutze macht. Als Beispiel einer thermostabilen DNA-Polymerase ist die taq-Polymerase zu nennen, die ursprünglich aus dem thermophilen Eubacterium Thermus aquaticus gewonnen wurde und standardmäßig in der PCR-Technik eingesetzt wird. Neben der Polymerase werden zwei Primer benötigt, die auf den beiden Einzelsträngen der DNA den jeweiligen Startpunkt festlegen und so die Sequenz zwischen sich als PCR-Produkt definieren. Grundsätzlich kann man 3 verschiedene PCR-Phasen unterscheiden, die zyklisch wiederholt werden:
1) Denaturierung
2) Anlagerung
3) Verlängerung. 
1) Bei der Denaturierung wird der PCR-Ansatz auf $94-96^{\circ} \mathrm{C}$ erhitzt. Hierbei werden durch Verlust der Wasserstoffbrückenbindungen die DNA-Doppelstränge in Einzelstränge aufgebrochen. Im ersten Zyklus wird diese Denaturierungszeit häufig länger gewählt, um sowohl alle DNA-Doppelstränge, als auch aneinander gelagerte Primer in Einzelstränge zu überführen. Dieser Vorgang wird als Initialisierung bezeichnet.

2) In der Anlagerungs-Phase wird der Ansatz auf ca. $50^{\circ} \mathrm{C}$ heruntergekühlt, um eine Anlagerung der spezifischen Primer an den homologen DNA-Abschnitt zu ermöglichen.

3) In der Verlängerungsphase wird der Ansatz auf $68-72^{\circ} \mathrm{C}$ erhitzt. Bei diesen Temperaturen katalysiert die DNA-Polymerase ab dem Primer in $3^{`}-5^{`}-$ Richtung die Synthese eines komplementären Stranges.

Da beim ersten Zyklus kein Endpunkt der DNA-Synthese festgelegt ist, synthetisiert die DNA-Polymerase DNA-Stränge, die in 5'-Richtung länger als die Zielsequenz sind. Schon im zweiten Zyklus jedoch entstehen Ketten von definierter Länge, da sich der zweite Primer an die neu synthetisierten Stränge anlagert und die DNA-Polymerase die neuen Stränge nur bis zum „ehemaligen Startpunkt“ verlängern kann.

Diese Phasen werden zyklisch wiederholt, wobei die Anzahl der Zyklen sowie die benötigten Temperaturen, je nach Primer und Zielsequenz variieren. Die Anzahl der Stränge, die länger als die ursprüngliche Sequenz sind, steigt in den ersten Zyklen nur linear, da bei jedem Zyklus nur die „Original-DNA“ als Matrize dient. Die Anzahl der Stränge mit definierter Länge steigt jedoch anfangs exponentiell, da bei jedem Zyklus neue Matrizen synthetisiert werden.

1) Denaturierung:

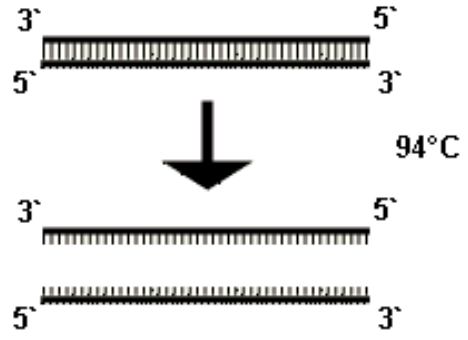

Ab 2. Zyklus:

2) Anlagerung:
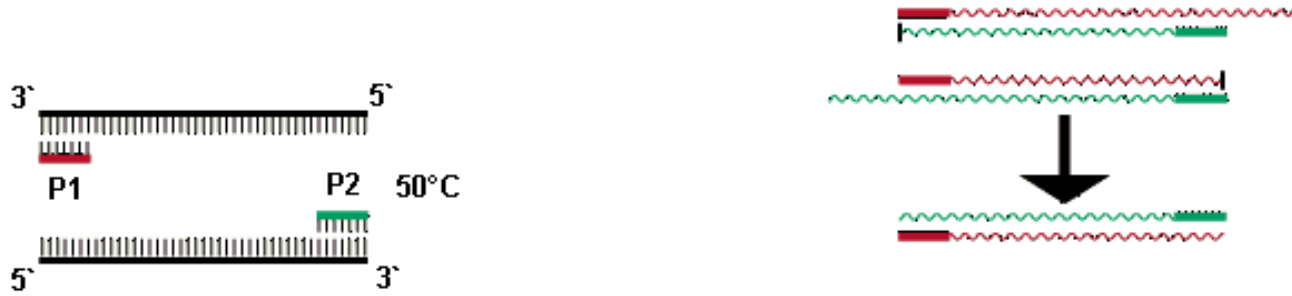

3) Verlängerung:

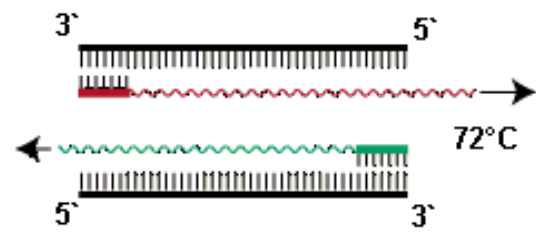

Abb. 8: Schematische Darstellung einer PCR (modifiziert nach „http://www.flmnh.ufl.edu/cowries/amplify.html“, Stand 23.08.2010) 


\section{Reverse Transkiption (RT-PCR)}

Um die durch die in 2.2.1.8 beschriebenen Methoden gewonnene Gesamt-RNA und insbesondere die darin enthaltende mRNA Genanalysen mittels PCR zugänglich zu machen, ist eine Umschreibung in komplementäre cDNA-Einzelstränge erforderlich.

Hierfür wurde die Reverse-Transkriptase des Moloney-Mäuseleukämievirus (M-MLV RT) genutzt (Frohman et al. 1988). In Anwesenheit von unspezifischen Primern und Nukleotiden synthetisiert dieses Enzym bei optimalen Reaktionsbedingungen zur Ausgangs-RNA komplementäre cDNA. Hierfür lagern sich die unspezifischen Primer an die Poly-A-Sequenz der RNA an, worauf die Reverse-Transkriptase eine DNA-Kettenverlängerung initiiert. Die M-MLV RT weist keine RNase und DNA-Endonuklease-Aktivität auf, so dass es weder zu einer Reduktion der Ausgangs-RNA noch der amplifizierten cDNA kommt.

Tab. 19: Übersicht über den RT-PCR-Ansatz

\begin{tabular}{|c|c|}
\hline Reagenz & Volumen \\
\hline $5 \times$ RT-Puffer & $8,0 \mu \mathrm{l}$ \\
\hline $\mathrm{IH}_{2} \mathrm{O}_{\text {dest }}$ & $0,5 \mu \mathrm{l}$ \\
\hline $\mathrm{dNTP}-$ Mix $(10 \mathrm{mM})$ & $8,0 \mu \mathrm{l}$ \\
\hline $\mathrm{DTT}(100 \mathrm{mM})$ & $4,0 \mu \mathrm{l}$ \\
\hline $\mathrm{p}(\mathrm{dT})_{15}-$ Primer $(11 \mu \mathrm{M})$ & $8,0 \mu \mathrm{l}$ \\
\hline $\mathrm{RNase-Inhibitor}(40 \mathrm{U} / \mu \mathrm{l})$ & $0,5 \mu \mathrm{l}$ \\
\hline M-MLV $(200 \mathrm{U} / \mu \mathrm{l})$ & $2,0 \mu \mathrm{l}$ \\
\hline RNA-Lsg $(200-500 \mathrm{ng})$ & $9,0 \mu \mathrm{l}$ \\
\hline Gesamtansatz & $\mathbf{4 0 \mu l}$ \\
\hline
\end{tabular}

Tab. 20: RT-PCR-Amplifikationsprogramm

\begin{tabular}{|c|c|c|}
\hline Zeit & Temperatur & Zyklen \\
\hline $60 \mathrm{~min}$ & $38^{\circ} \mathrm{C}$ & \\
\hline $10 \mathrm{~min}$ & $72^{\circ} \mathrm{C}$ & 1 \\
\hline$\infty$ & 4 & \\
\hline
\end{tabular}

Die amplifizierte cDNA wurde bei $-20^{\circ} \mathrm{C}$ gelagert.

\section{Sequenzierung}

Im Rahmen dieser Promotionsarbeit wurde zur DNA-Sequenzierung die von F. Sanger entwickelte Didesoxymethode benutzt (Sanger et al. 1977).

Das DNA-Segment von Interesse wird mittels Sequenzierungs-PCR linear jeweils vom 5 -Ende her amplifiziert. Im Gegensatz zur bidirektionalen Amplifikation wird in dieser Reaktion ein DNA-Strang nur in einer Richtung amplifiziert. Der benutzte 
Reaktionsmastermix BigDye enthält dNTPs, fluoreszenzmarkierte ddNTPs und eine DNA-Polymerase. Bei der linearen DNA-Amplifikation kommt es zum Abbruch der Kettenverlängerung, wenn statt eines dNTPs ein fluoreszenzmarkiertes ddNTP mit fehlender Hydroxygruppe am 3‘-C-Atom eingebaut wird. So entstehen bei genügender Zyklenzahl DNA-Stränge jeder Länge mit fluoreszenzmarkierten endständigen Basen, die durch elektrophoretische Auftrennung und Photodetektion bestimmt werden können. Hierdurch erhält man die zum untersuchten DNA-Segment komplementäre Sequenz.

Um Verfälschungen durch überschüssige fluoreszenzmarkierte ddNTPs zu vermeiden, folgte nach der Sequenzierungs-PCR eine Aufreinigung mittels Zentrifugation über mit SephadexG-50-gefüllte Säulen. Die Sequenzanalyse erfolgte an einem ABI Prism 3100 Genetic Analyzer.

Tab. 21: Übersicht über den Sequenzierungs-PCR-Ansatz

\begin{tabular}{|c|c|}
\hline Reagenz: & Volumen/ Ansatz: \\
\hline $\mathrm{H}_{2} \mathrm{O}_{\text {dest. }}$ & $6.1 \mu \mathrm{l}$ \\
\hline $\mathrm{DMSO}$ & $0.5 \mu \mathrm{l}$ \\
\hline Primer & $1 \mu \mathrm{l}$ \\
\hline BigDye & $1.4 \mu \mathrm{l}$ \\
\hline Probe & $1 \mu \mathrm{l}$ \\
\hline Gesamtansatz & $\mathbf{1 0 \mu l}$ \\
\hline
\end{tabular}

Tab. 22: Sequenzierungs-PCR-Amplifizierungsprogramm

\begin{tabular}{|c|c|c|}
\hline Zeit & Temperatur & Zyklen \\
\hline 2 min & $94^{\circ} \mathrm{C}$ & \\
\hline 15 sek & $96^{\circ} \mathrm{C}$ & \multirow{2}{*}{1} \\
\hline 15 sek & $56.5^{\circ} \mathrm{C}$ & \\
\hline $4 \min$ & $60^{\circ} \mathrm{C}$ & 24 \\
\hline & $\mathrm{GOTO} 2$ & 1 \\
\hline 7 min & $72^{\circ} \mathrm{C}$ & \multirow{2}{*}{1} \\
\hline$\infty$ & $4^{\circ} \mathrm{C}$ & \\
\hline
\end{tabular}

\section{Real-Time-PCR}

Um Genexpressionen nach der cDNA-Synthese quantitativ zu messen, wurde die Standardmethode der Cyber-green-Real-Time-PCR gewählt. Bei dieser Methode wird eine PCR mit dem Primer von Interesse in Anwesenheit einer mit DNA interkalierenden, fluoreszierenden Substanz durchgeführt. Während des PCR-Laufes wird ständig die Fluoreszenz gemessen. Da die Fluoreszenz proportional zu der Menge des PCR-Produktes 
ist, kann indirekt auf dessen Menge geschlossen werden. Um eine vergleichbare Quantifizierung zu ermöglichen, wurde hierfür der Ct-Wert gemessen. Der Ct-Wert beschreibt den Zyklus, bei dem die Fluoreszenz erstmalig signifikant über die Hintergrundfluoreszenz steigt.

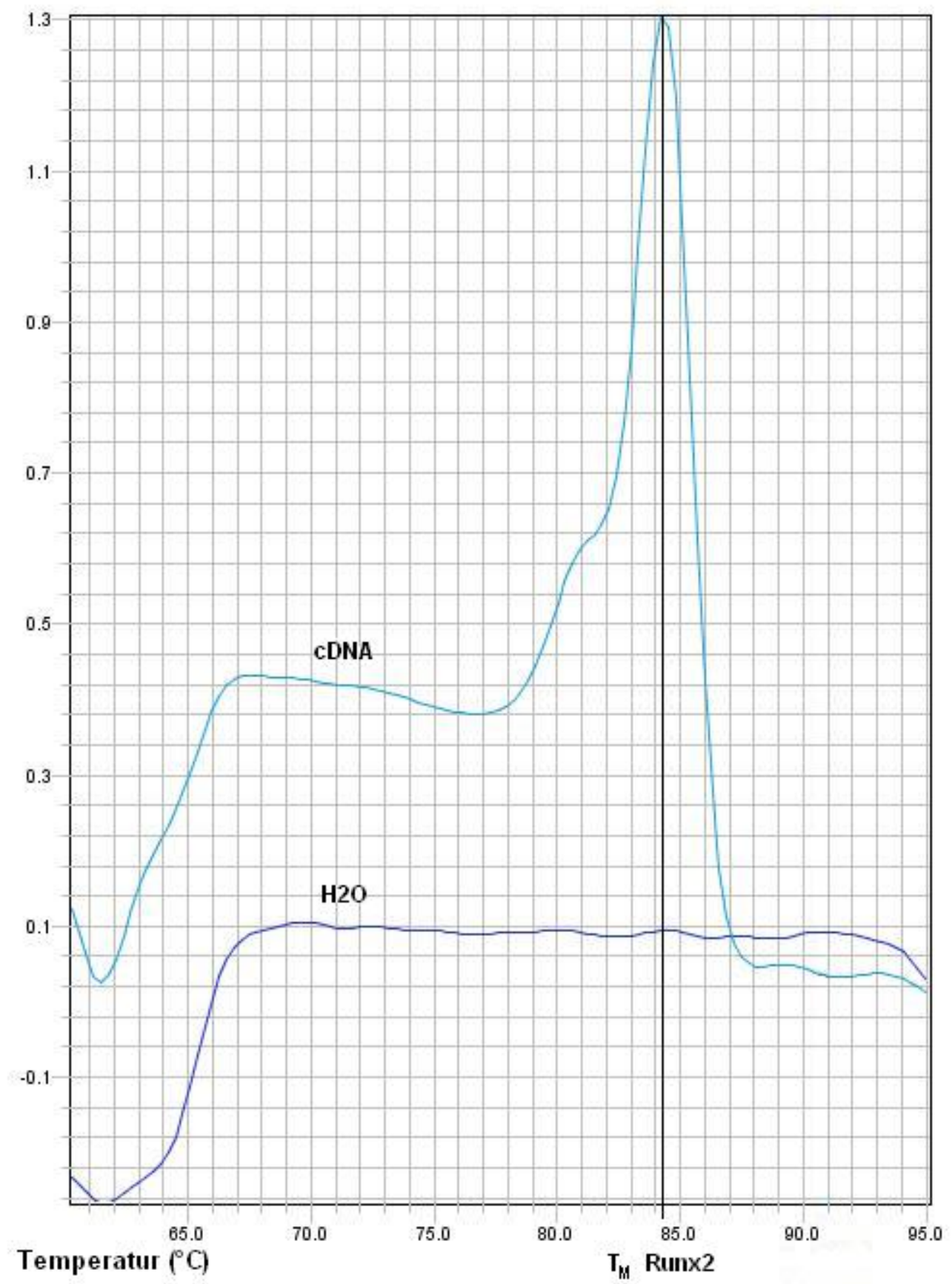

Abb. 9: Beispiel einer Schmelzkurve: dargestellt sind zwei Schmelzkurven (cDNA, $\mathrm{H}_{2} \mathrm{O}$ ) nach Realtime-PCR mit Runx2 Primer. In der cDNA-Probe wurde Runx2 DNA spezifisch vervielfältigt, was durch den Peak bei $T_{M}$ Runx2 ersichtlich ist.

Zur Messung der PCR-Spezifität wurde nach dem jeweiligen Lauf eine Schmelzkurvenanalyse durchgeführt, bei der die Abnahme der Fluoreszenz während des Aufschmelzens der DNA bei langsamer Temperaturerhöhung registriert wird. Hierbei macht 
man sich die höhere Schmelztemperatur des doppelsträngigen spezifischen PCR-Produktes gegenüber der niedrigeren Schmelztemperatur unspezifischer Primer-Dimere zunutze. Demnach hat jedes PCR-Produkt eine charakteristische Schmelztemperatur TM, die von der Länge und dem GC-Gehalt des Produktes abhängig ist.

Um eine Vergleichbarkeit verschiedener PCR-Läufe zu gewährleisten, wurden alle PCRLäufe eines Experiments in demselben Real-Time-PCR-Gerät durchgeführt.

Tab. 23: Übersicht über den Realtime-PCR-Ansatz

\begin{tabular}{|c|c|}
\hline Reagenz & Volumen \\
\hline Cyber green & $4,5 \mu \mathrm{l}$ \\
\hline $\mathrm{H}_{2} 0$ dest. & $2,5 \mu \mathrm{l}$ \\
\hline Primer sense & $1 \mu \mathrm{l}$ \\
\hline Primer antisense & $1 \mu \mathrm{l}$ \\
\hline cDNA-Lsg & $1 \mu \mathrm{l}$ \\
\hline Gesamtansatz & $\mathbf{1 0 \mu l}$ \\
\hline
\end{tabular}

Mit Doppelwertbestimmung, sowie zwei Leerwerten wurde die PCR in einem One Step plus von $\mathrm{ABI}$ mit folgender Instrumenteneinstellung durchgeführt:

Tab. 24: verwendetes Realtime-PCR-Programm

\begin{tabular}{|c|c|c|}
\hline Zeit & Temperatur & Zyklen \\
\hline 20 sek & $95^{\circ} \mathrm{C}$ & \multirow{2}{*}{40} \\
\hline 3 sek & $95^{\circ} \mathrm{C}$ & \\
\hline 30 sek & $60^{\circ} \mathrm{C}$ & \\
\hline \multicolumn{2}{|c|}{ Schmelzkurvenanalyse } \\
\hline
\end{tabular}

\section{Housekeeping-Gene}

Um weiterhin eine Vergleichbarkeit verschiedener Proben zu gewährleisten, wurde im gleichen Lauf zusätzlich zum Zielgen je ein housekeeping-Gen gemessen.

Housekeeping-Gene sind Gene, deren Expressionen unabhängig von den experimentellen Bedingungen sind. Anhand der Expression des housekeeping-Gens in der Real-Time-PCR kann indirekt auf die Ausgangsmenge der eingesetzten DNA geschlossen werden. Durch Subtraktion des Ct-Wertes des housekeeping-Gens von dem Ct-Wert des Zielgens wird so der eventuelle Fehler unterschiedlich eingesetzter Ausgangsmengen minimiert. So können bei ähnlich hohen Ct-Werten des housekeeping-Gens verschiedener Proben unterschiedliche Expressionen von Zielgenen mit einem hohen Grad der Evidenz bestimmt werden.

So wurde für jedes Experiment ein housekeeping-Gen bestimmt, welches die geringste Variation im Ct-Wert der gemessenen Proben aufwies. 


\section{Transformierung}

Zur Quantifizierung der Genexpression wurden die gemessenen Ct-Werte transformiert. Hierfür wurde folgende Formel angewendet (Livak und Schmittgen 2001):

$$
Y=2^{-\Delta c t}
$$

Der erhaltene Wert gab uns die $\mathrm{x}$-fache Änderung der Expression des Zielgens im Verhältnis zum housekeeping-Gen an.

Bsp: Ct-Wert des Zielgens (Runx2): 27,5

Ct-Wert des housekeeping-Gens ( $\beta$-Actin): 19,5

$$
\begin{aligned}
& Y=2^{-(27,5-19,5)} \\
& Y=2^{-(8)} \\
& Y=0,00390625 \text { (quantitative Genexpression) }
\end{aligned}
$$

\subsubsection{Microarray}

Der RNA-Microarray ist eine Methode zur Genexpressionsanalyse von bis zu $3,5^{*} 10^{4}$ verschiedenen Genen, wobei die Hybridisierung farblich markierter (gelabelter), fluoreszierender RNA- oder DNA-Fragmente einer Probe an lokal fest gebundene, genspezifische Oligonukleotide verwendet wird. Anhand der Fluoreszenzmessung nach der Hybridisierung wird auf die Menge gebundener Nukleinsäurenfragmente und damit auf die Genexpression in der Probe geschlossen.

Im Rahmen dieser Arbeit kam ein RNA-Microarray mit one color design zur Anwendung, der in Kooperation mit Dr. rer. nat. Salinas-Riester im Transkriptomanalyselabor der Universität Göttingen angefertigt wurde.

Hierfür wurden die zu untersuchenden RNA-Proben, mit einer Ausgangsmenge von 200ng, mittels RT-PCR zuerst in cDNA umgeschrieben. Zur Primer- und Probendenaturierung wurde folgender Reaktionsansatz gewählt und für $10 \mathrm{~min}$ im Thermocycler auf $65^{\circ} \mathrm{C}$ erhitzt:

Tab. 25: Übersicht über den Denaturierungsansatz

\begin{tabular}{|c|c|}
\hline Reagenz & Volumen \\
\hline RNA (200ng) & $8,3 \mu \mathrm{l}$ \\
\hline Spike Mix & $2 \mu \mathrm{l}$ \\
\hline T7-Promoter & $1,2 \mu \mathrm{l}$ \\
\hline Gesamtansatz: & $\mathbf{1 1 , 5 \mu l}$ \\
\hline
\end{tabular}


Pro Probe wurde nun folgender RT-PCR-Mastermix hinzugegeben und im Thermocycler erst für $2 \mathrm{~h}$ auf $40^{\circ} \mathrm{C}$ und anschließend für $15 \mathrm{~min}$ auf $65^{\circ} \mathrm{C}$ erhitzt:

Tab. 26: Übersicht über den RT-PCR-Ansatz

\begin{tabular}{|c|c|}
\hline Reagenz & Volumen \\
\hline $5 x$ First Stand Buffer & $4 \mu \mathrm{l}$ \\
\hline DTT $(0.1 \mathrm{M})$ & $2 \mu \mathrm{l}$ \\
\hline dNTP $(10 \mathrm{mM})$ & $1 \mu \mathrm{l}$ \\
\hline MMLVRT & $1 \mu \mathrm{l}$ \\
\hline RNaseOUT & $0.5 \mu \mathrm{l}$ \\
\hline Gesamtansatz & $\mathbf{8 , 5 \mu l}$ \\
\hline
\end{tabular}

Die entstandene cDNA wurde nun in einer nächsten Reaktion wieder in cRNA transkribiert. Die benutzte RNA-Polymerase inkorporiert hierbei, mit fluoreszierenden Cyanin 3 (Су3) modifizierte, Nukleotide in die Transkripte.

Folgender Reaktionsansatz wurde hierfür gewählt und für $2 \mathrm{~h}$ bei $40^{\circ} \mathrm{C}$ im Thermocycler inkubiert:

Tab. 27: Übersicht über den Labeling-Ansatz

\begin{tabular}{|c|c|}
\hline Reagenz & Volumen \\
\hline $\mathrm{H}_{2} \mathrm{O}_{\text {dest. }}$ & $15.3 \mu \mathrm{l}$ \\
\hline $4 x$ Transcription Buffer & $20 \mu \mathrm{l}$ \\
DTT $(0.1 \mathrm{M})$ & $6 \mu \mathrm{l}$ \\
NTP & $8 \mu \mathrm{l}$ \\
\hline PEG $(50 \%)$ & $6.4 \mu \mathrm{l}$ \\
RNaseOUT & $0.5 \mu \mathrm{l}$ \\
\hline Anorganische Pyrophosphatase & $0.6 \mu \mathrm{l}$ \\
\hline T7 RNA Polymerase & $0.8 \mu \mathrm{l}$ \\
\hline Cyanin 3CTP & $2.4 \mu \mathrm{l}$ \\
\hline Gesamtansatz & $60 \mu \mathrm{l}$ \\
\hline
\end{tabular}

Nach Aufreinigung der cRNA mit dem RNeasy Kit von Qiagen (s. 2.2.1.8) wurde die gelabelte cRNA hinsichtlich Quantität und Cy3-Inkorporationsrate mittels NanoDrop gemessen. Diese Methode macht sich hierfür die Absorptionsmaxima der RNA von 260nm und des Cy3 von 550nm zu Nutze, wobei sich die Cy3-Inkorporationsrate wie folgt berechnen lässt:

Cy3-Inkorporationsrate $[\mathrm{pmol} / \mu \mathrm{g}]=$ Cy3 $[\mathrm{pmol}] / \mathrm{cRNA}[\mu \mathrm{g}] \times 1000$ 
Im nächsten Schritt wurden die cRNA-Stränge mit folgendem Reaktionsansatz für 30min bei $40^{\circ} \mathrm{C}$ fragmentiert:

Tab. 28: Übersicht über den Fragmentationsansatz

\begin{tabular}{|c|c|}
\hline Reagenz & Volumen bzw. Masse \\
\hline Cy3 gelabelte cRNA & $600 \mathrm{ng}$ \\
\hline 10x Blocking Agent & $5 \mu \mathrm{l}$ \\
\hline 25x Fragmentationspuffer & $1 \mu \mathrm{l}$ \\
RNase-freies Wasser & ad $25 \mu \mathrm{l}$ \\
\hline Gesamtansatz & $\mathbf{2 5 \mu l}$ \\
\hline
\end{tabular}

Gestoppt wurde diese Reaktion mit 25 $\mu \mathrm{l}$ 2x GEx Hybridisationspuffer HIRPM. Nun folgte eine 17 stündige Hybridisierung mit den Array gebundenen Oligonukleotiden in einem ozonfreien Raum bei $65^{\circ} \mathrm{C}$ im Hybridisierungsofen. Hiernach wurden die Arrays zweimalig (Waschpuffer 1+2) gewaschen, um überschüssige cRNA zu entfernen. Gescannt wurden die Arrays in einem Agilent 2100 BioAnalyzer.

\begin{tabular}{ll} 
Waschpuffer 1: & Waschpuffer 2: \\
\hline $350 \mathrm{ml} \mathrm{H}_{2} \mathrm{O}_{\text {dest. }}$ & $249 \mathrm{ml} \mathrm{H}_{2} \mathrm{O}_{\text {dest. }}$ \\
$150 \mathrm{ml} \mathrm{20x} \mathrm{SSPE}$ & $750 \mu \mathrm{l} \mathrm{20x} \mathrm{SSPE}$ \\
$125 \mu \mathrm{l} \mathrm{20 \%} \mathrm{N-Lauroylsarcosine}$ & $62,5 \mu \mathrm{l} \mathrm{N}$-Lauroylsarcosine
\end{tabular}

\section{Microarray Statistik:}

Alle statistischen Analysen wurden mit Hilfe der Statistiksoftware "http://cran.r-project.org/“" erstellt. Um normalisierte Daten, als Grundlage weiterer Analysen, zu generieren, wurde ein sogenanntes normalization procedure in Form der „vsn“ angewendet (Huber et al. 2002).

Die Expressionsunterschiede einzelner Gene wurden aus einem linearen Modell errechnet, welches auf jedes Gen einzeln angewendet wurde (Smyth 2005). Wenn das Ergebniss dieser Kalkulation beachtenswert erschien, wurden t-tests berechnet und abhängige $p$-Werte geschätzt.

Jedes Gen wurde mit zwei Parametern charakterisiert. Dem p-Wert und dem sogenannten fold change, wobei als fold change das Verhältnis der Genexpression im Bezug auf das Grundniveau, der Vergleichsexpression, bezeichnet und zur Basis 2 logarithmiert dargestellt wird. Werte mit $p<0.05$ wurden als signifikant angesehen. 


\subsubsection{Statistik}

Für die Statistik der Realtime-PCR, sowie für die Erstellung von Graphen wurde die Statistiksoftware GraphPad Prism 4 (Goliath, La Jolla, USA) benutzt.

Die statistische Auswertung der Realtime-PCR beinhaltete unpaarige t-Testverfahren. 


\section{Ergebnisse}

\subsection{Plasmidvorarbeiten}

\subsubsection{Templatedesign, Klonierung, Sequenzierung}

Bei der Auswahl einer geeigneten Runx2 siRNA fiel die Entscheidung auf die Runx2 siRNA No. 4 von Qiagen, da sich diese Zielsequenz auf der Runx2 mRNA im selben Zellmodell hinsichtlich knock-down-Effizienz als effektiv herausgestellt hat (Giesen 2007).

Dieser siRNA entsprechende Oligonukleotide wurden ligiert und in den siRNAExpressionsvektor p-Silencer 4.1 puro zwischen die Restriktionsendonukleaseschnittstellen BamH1 und HindIII kloniert.

Mittels Sequenzierung wurde der regelhafte Einbau nachgewiesen.

\subsubsection{Glycerolstock, Maxiprep, Plasmidlinearisierung}

Von drei erfolgreich klonierten Plasmidklonen wurden Glycerolstocks angelegt und asserviert. Mehrfach wurde eine Maxiprep zur Plasmidgewinnung durchgeführt. Vereinfachend wird in den Beschreibungen der folgenden Experimente von $\mathrm{pSi}+$ als dem Runx2-siRNA-Expressionsvektor und von pSi- als dem scrambled siRNA exprimierenden Kontrollvektor gesprochen.

Plasmidlineariserungen wurden mit der Restriktionsendonuklease Sca I durchgeführt. Hierbei gewonnenes, linearisiertes Plasmidmaterial wurde in späteren Transfektionsexperimenten verwendet. 


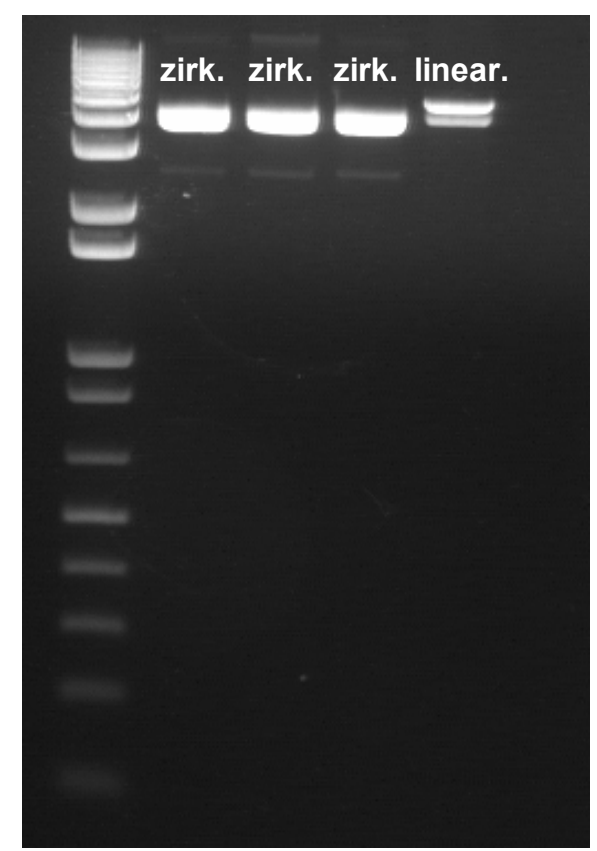

Abb. 10: zeigt beispielhaft die Agarose-Gelelektrophorese einer pSi+ Linearisierung. Spuren 1-3: zirkuläre Plasmid-DNA, Spur 4: zirkuläre Plasmid-DNA plus zusätzlich linearisierte Plasmid-DNA. 1000bp DNA-Leiter als Größenmarker

\subsection{Optimale Puromycinkonzentration}

Dieser Vorversuch wurde zur Bestimmung der optimalen Puromycinkonzentration für die Selektion von erfolgreich mit pSi transfizierten Zellen durchgeführt. Als optimale Konzentration wurde, wie auch vom Hersteller empfohlen, die niedrigste Puromycindosis definiert, die innerhalb von 5 Tagen letal für alle nichttransfizierten Zellen wirkt.

Getestet wurde dies in HOB- und HOS 58-Zellen.

Hierfür wurden $2 * 10^{4}$ Zellen/Well einer 6-Well-Platte mit Puromycin zusätzlich zum jeweiligen Medium kultiviert.

Folgende Puromycinkonzentrationen wurden verwendet:

$0 \mathrm{ng} / \mathrm{ml}, 50 \mathrm{ng} / \mathrm{ml}, 100 \mathrm{ng} / \mathrm{ml}, 250 \mathrm{ng} / \mathrm{ml}, 500 \mathrm{ng} / \mathrm{ml}, 1000 \mathrm{ng} / \mathrm{ml}, 2000 \mathrm{ng} / \mathrm{ml}, 4000 \mathrm{ng} / \mathrm{ml}$. Mit $n=2$ wurden die Versuche einmal wiederholt.

Als Ergebnis (Fotos nicht gezeigt) ergab sich sowohl für HOS 58- als auch für pHOB-Zellen eine optimale Puromycinkonzentration von 500ng/ml Medium, da diese Konzentration als die am niedrigsten titrierte Lösung innerhalb von 5 Tagen letal für alle kultivierten Zellen wirkte. 


\subsection{Transiente Transfektion in humaner Osteosarkomzelllinie 58}

\subsection{1}

Transiente Transfektion HOS 58 (1)

Intention dieses Versuchs war eine Runx2-Suppression durch, von pSi+ exprimierter, siRNA

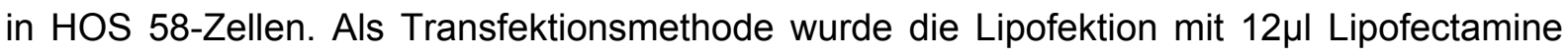
2000/Well gewählt. 24h nach der Transfektion wurde das antibiotikafreie Transfektionsmedium vollständig durch antibiotikahaltiges Medium ersetzt. Die RNAIsolierung erfolgte $48 \mathrm{~h}$ posttransfektionell. Die Ergebnisse dieses Versuches sind in folgenden Abbildungen dargestellt:

A)

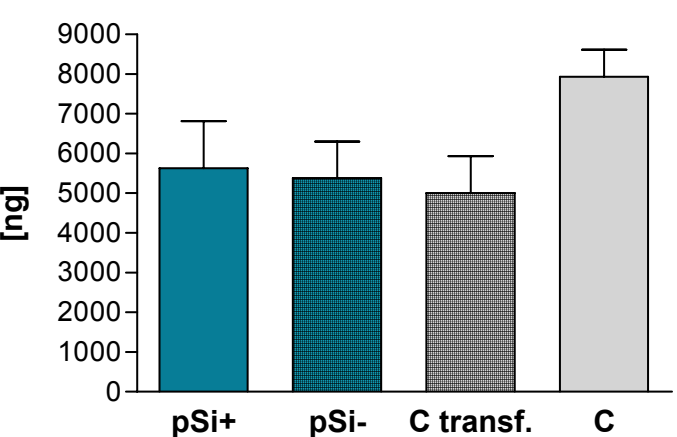

B)

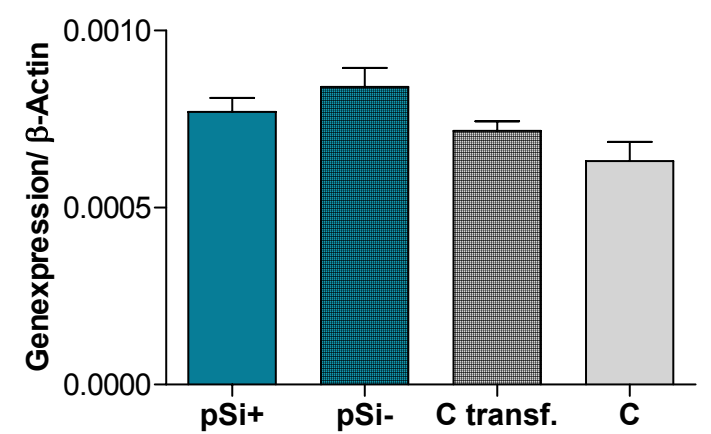

C)

$\beta$-Actin

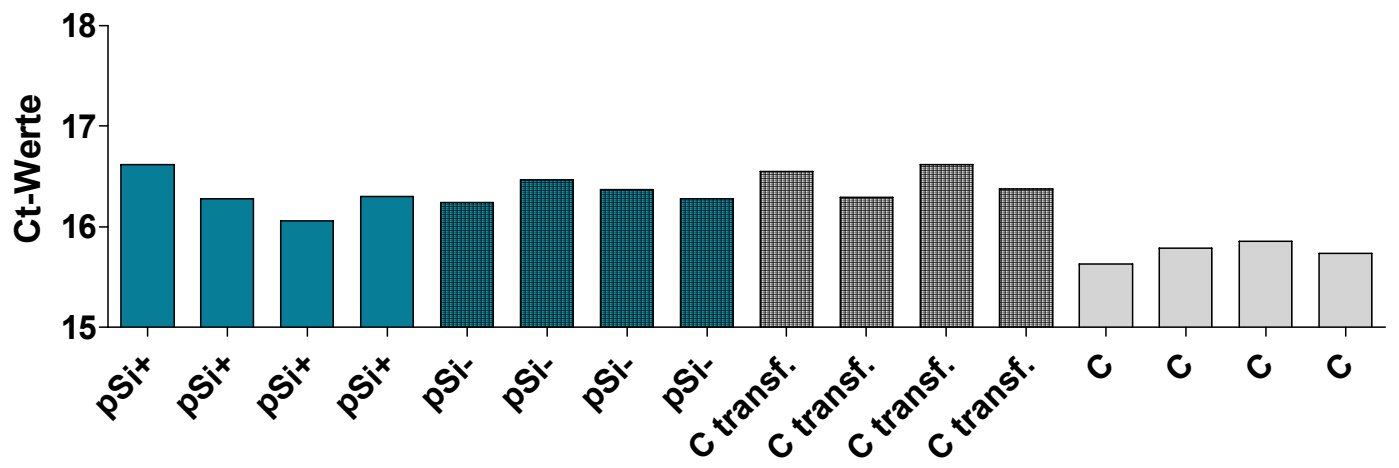

Abb. 11: Darstellung A) der isolierten RNA-Gesamtmenge; B) der Genexpression von Runx2 in der RealtimePCR und C) der Ct-Werte des housekeeping-Gens $\beta$-Actin in der Realtime-PCR, nach Transfektion mittels Lipofektion von $1 \mu \mathrm{g} \mathrm{pSi+}(\mathrm{pSi}+), 1 \mu \mathrm{g} \mathrm{pSi-}(\mathrm{pSi}-)$ und $1 \mu \mathrm{H}_{2} \mathrm{O}$ (C transf.) sowie nach Kultivierung ohne Transfektion (C) in HOS 58-Zellen. Die Darstellungen A) und B) zeigen die Mittelwerte (mit $n=4$ ) und den entsprechenden Standardfehlern (SEM), die Darstellung C) zeigt Einzelwerte. 
Die Darstellung der isolierten RNA-Gesamtmenge lässt einen nur geringen zytotoxischen Effekt der Lipofektion vermuten. Die Realtime-PCR-Analyse zeigte in allen Ansätzen eine Runx2-Expression auf gleichem Niveau.

In der Expressionsanalyse des housekeeping-Gens $\beta$-Actin zeigte sich in den transfizierten Proben eine gleich starke Expression, während die untransfizierten Proben niedrigere Ct-Werte und damit höhere Expressionen aufwiesen.

Zusammenfassend ließ sich in diesem Versuch keine Runx2-Gensuppression durch pSi+ in HOS 58-Zellen erreichen. Es wurde allerdings ein unspezifischer Effekt der Lipofektion auf die Expression des housekeeping-Gens $\beta$-Actin bei nur geringer Toxizität der Transfektionsmethode beobachtet.

\subsubsection{Transiente Transfektion HOS 58 (2)}

Zur Bestätigung der in Versuch 3.3.1 ermittelten Ergebnisse wurde abermals eine Transfektion unter identischen Bedingungen, wie oben beschrieben, durchgeführt:
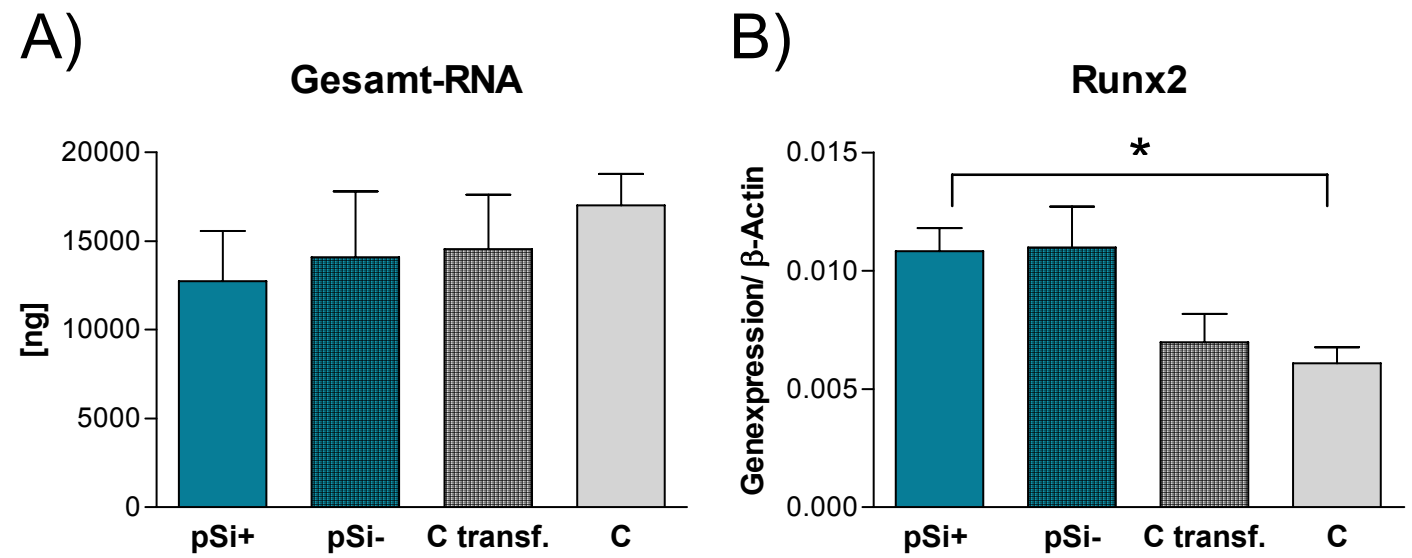

Abb. 12: Darstellung A) der isolierten RNA-Gesamtmenge; B) der Genexpression von Runx2 in der RealtimePCR, nach Transfektion mittels Lipofektion von $1 \mu \mathrm{g} \mathrm{pSi+}(\mathrm{pSi}+)$, $1 \mu \mathrm{g} \mathrm{pSi-}(\mathrm{pSi}-)$ und $1 \mu \mathrm{l} \mathrm{H}_{2} \mathrm{O}(\mathrm{C}$ transf.) sowie nach Kultivierung ohne Transfektion $(C)$ in HOS 58-Zellen. Die Darstellungen zeigen die Mittelwerte $(m i t n=4)$ und den entsprechenden Standardfehlern (SEM), signifikante Ergebnisse sind mit einem Stern (*) gekennzeichnet.

Bei vernachlässigbarer Zytotoxizität durch die Lipofektion (s. Abb. 12) ließ sich auch in diesem Transfektionsversuch keine Runx2-Gensuppression durch pSi+ nachweisen. Im Vergleich zu mit pSi- transfizierten Zellen konnte kein Unterschied in der Runx2Genexpression detektiert werden. Im Vergleich zu untransfizierten Zellen zeigte pSi+ sogar eine signifikante Induktion $(p=0,0071)$ um $78 \%$ bei gleichstarker Expression des housekeeping-Gens $\beta$-Actin in allen Ansätzen (Daten nicht abgebildet). Da auch eine Induktion durch pSi- zu beobachten war, wurde dies als unspezifischer Effekt bei der 
Transfektion von pSi gewertet. Aufgrund dieser Ergebnisse wurden zunächst die knock-down-Versuche in der Zelllinie HOS 58 eingestellt.

\subsubsection{Transiente Transfektion HOS 58 (3)}

Da mit der Nukleofektion im weiteren Verlauf für pHOB-Zellen ein effizientes Transfektionssystem gefunden wurde (s. Versuch 3.4.6) und mit der kurzzeitigen Puromycinselektion ein Versuchsansatz zur Demaskierung einer möglichen Runx2-Gensuppression durch pSi+ geschaffen wurde (s. Versuch 3.4.7), stellte sich die Frage, ob nicht auch in HOS 58-Zellen mit den für pHOB-Zellen etablierten Methoden eine pSi(+)-Wirkung detektiert werden könne.

1) $5 * 10^{5}$ HOS 58 -Zellen wurden mittels Nukleofektion transfiziert. Die Gesamt-RNA wurde $72 \mathrm{~h}$ posttransfektionell isoliert.

Zur Transfektionsratenkontrolle diente eine Transfektion mit GFP-Plasmid.

A)

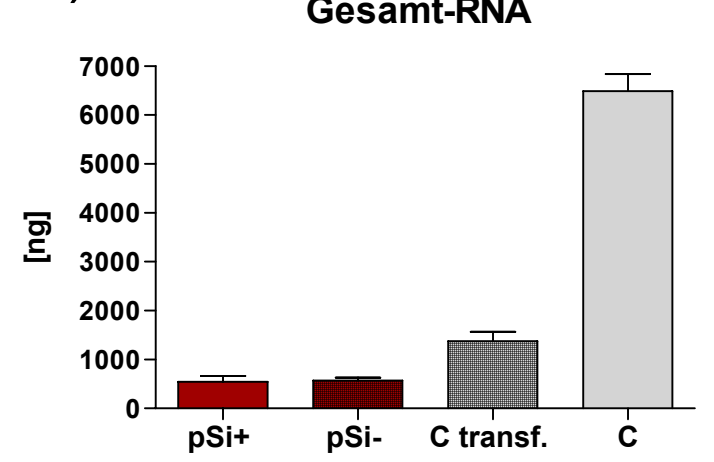

B)

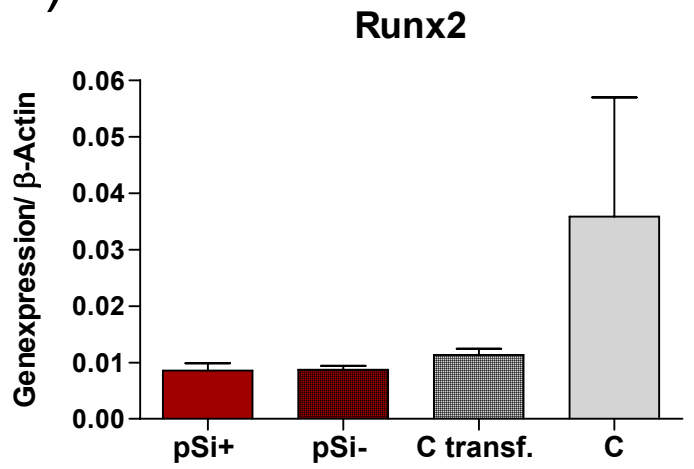

Abb. 13: Darstellung A) der isolierten RNA-Gesamtmenge; B) der Genexpression von Runx2 in der RealtimePCR, nach Transfektion mittels Nukleofektion von $5 \mu \mathrm{g} \mathrm{pSi+} \mathrm{(pSi+),} 5 \mu \mathrm{g}$ pSi- (pSi-) und $5 \mu \mathrm{H}_{2} \mathrm{O}(\mathrm{C}$ transf.) sowie nach Kultivierung ohne Transfektion (C) in HOS 58-Zellen. Die Darstellungen A) und B) zeigen die Mittelwerte (mit $n=3$ ) und den entsprechenden Standardfehlern (SEM).

Die Nukleofektion zeigt sich in HOS 58-Zellen, bei einer visuell geschätzten GFP-Transfektionsrate von $70 \%$ (s. Abb. 14), als stark zytotoxisch. So konnten aus $\mathrm{H}_{2} \mathrm{O}$ transfizierten Zellen lediglich 1400ng statt 6500ng RNA isoliert werden. pSi transfizierte Zellen erbrachten sogar nur 600ng isolierte RNA, was einer Reduktion der Gesamt-RNA von ca. $91 \%$ entspricht.

pSi+ transfizierte Zellen zeigten keine differenzierte Plasmidwirkung auf die Runx2-Genexpression im Vergleich zu pSi- transfizierten Zellen.

2) $5 * 10^{5}$ HOS 58 -Zellen wurden mittels Nukleofektion transfiziert und $24 \mathrm{~h}$ nach der Transfektion mit 250ng Puromycin pro ml Medium für weitere 48h kultiviert. 
Zur Transfektionratenkontrolle diente eine Transfektion mit GFP-Plasmid.
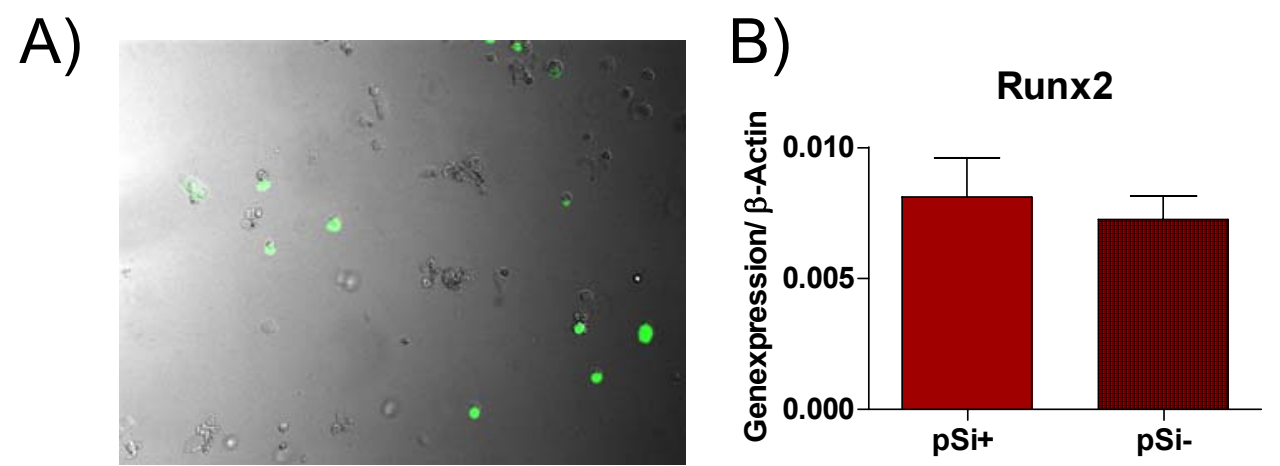

Abb. 14: A) fluoreszenzmikroskopisches Bild: Transfektion HOS58 mit GFP-Plasmid mittels Nukleofektion B) Darstellung der Genexpression von Runx2 in HOS 58-Zellen in der Realtime-PCR nach Transfektion mittels Nukleofektion von $5 \mu \mathrm{g} \mathrm{pSi+} \mathrm{(pSi+),} 5 \mu \mathrm{g}$ pSi- (pSi-) und nach $24 \mathrm{~h}$ anschließender Puromycinselektion mittels Antibiose mit 250ng Puromycin/ml Medium. Die Darstellung zeigt die Mittelwerte (mit $n=3$ ) und den entsprechenden Standardfehler (SEM)

Bei einer visuell geschätzten Transfektionsrate von 70\% (s.Abb. 14) konnte auch mit der kurzzeitigen Puromycinselektion in diesem Versuch keine differenzierte Plasmidwirkung von pSi+ auf die Genexpression von Runx2 demaskiert werden. Insgesamt konnte somit weder mit der Lipofektion noch mit der Nukleofektion ein Effekt des siRNA-Expressionvektors pSi+ auf die Runx2 Genexpression in HOS 58-Zellen gefunden werden.

\subsection{Transiente Transfektion in primären humanen Osteoblasten}

\subsubsection{Transiente Transfektion in pHOB (1)}

Ziel des Versuches war der Nachweis einer Gensuppression von Runx2 durch pSi+ in pHOB-Zellen. Hierfür wurden $5^{\star} 10^{4}$ Zellen/Well einer Primärkultur Osteoblasten unter den gleichen Bedingungen wie in Versuch 3.3.1 mit Lipofectamine 2000 transfiziert. 
A)

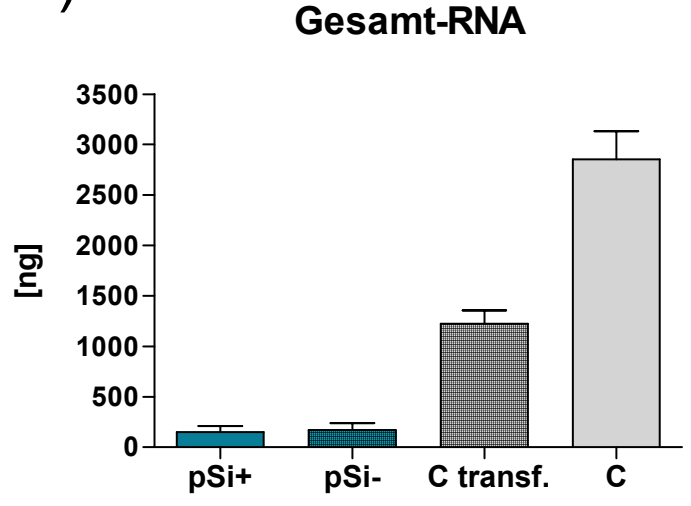

B)

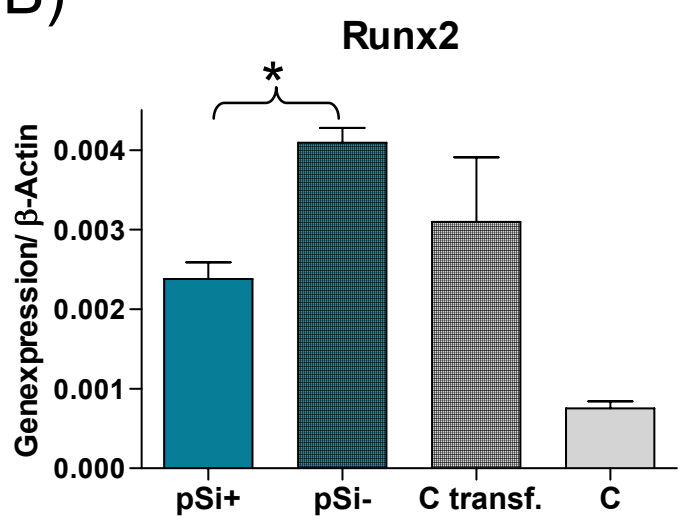

C)

$\beta$-Actin

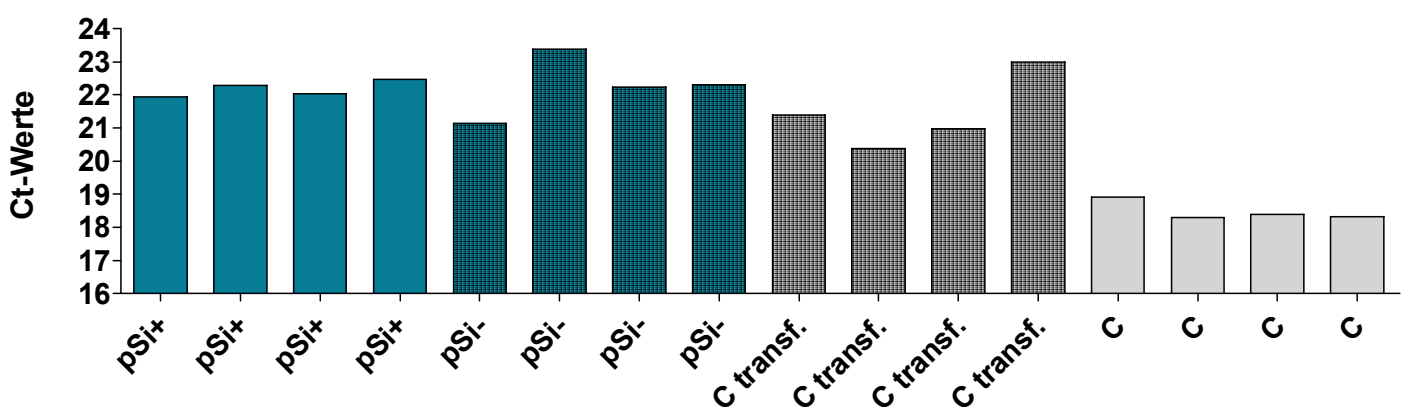

Abb. 15: Darstellung A) der isolierten RNA-Gesamtmenge; B) der Genexpression von Runx2 in der RealtimePCR und C) der Ct-Werte des housekeeping-Gens $\beta$-Actin in der Realtime-PCR, nach Transfektion mittels Lipofektion von $1 \mu \mathrm{g} \mathrm{pSi+}(\mathrm{pSi}+)$, $1 \mu \mathrm{g}$ pSi- (pSi-) und $1 \mu \mathrm{l} \mathrm{H}_{2} \mathrm{O}$ (C transf.) sowie nach Kultivierung ohne Transfektion (C) in pHOB-Zellen. Die Darstellungen A) und B) zeigen die Mittelwerte (mit $n=4)$ und den entsprechenden Standardfehlern (SEM), zu den direkten Kontrollzellen (pSi-) signifikante Ergebnisse sind mit einem Stern $\left({ }^{*}\right)$ gekennzeichnet, die Darstellung C) zeigt Einzelwerte.

Hohe Zytotoxizität in den mit pSi transfizierten Zellen führte, wie in Abb. 15 zu erkennen, zu sehr geringer isolierter RNA-Gesamtmenge. Um eine RT-PCR zu ermöglichen mussten alle pSi-Proben eingeengt werden. Eine Genexpressionsanalyse mittels Realtime-PCR (s.Abb. 15) zeigte eine signifikante $(p=0.0008)$ Suppression der Runx2-Genexpression in pSi(+)-transfizierten-Zellen im Vergleich zu pSi(-)-transfizierten-Zellen um 42\%.

Im Vergleich zu den mit Wasser transfizierten Zellen war eine nicht signifikante Suppression um 23\% der Runx2-Genexpression zu beobachten.

Die Analyse der Genexpression des housekeeping-Gens $\beta$-Actin (s. Abb. 15) zeigte im Vergleich von transfizierten zu untransfizierten Zellen einen Unterschied von mehr als 3,5 CtWerten. Deshalb scheint der Vergleich mit untransfizierten Zellen nicht sinnvoll. 


\subsubsection{Transiente Transfektion pHOB (2)}

Zur Ergebnisbestätigung des Versuchs 3.4.1 wurde dieses Experiment wiederholt. Abweichend zur Versuchsdurchführung in Versuch 3.4.1 wurden während der RNA-Isolation das Zelllysat von 2 Wells pro Probe pSi+ und pSi- gepoolt.
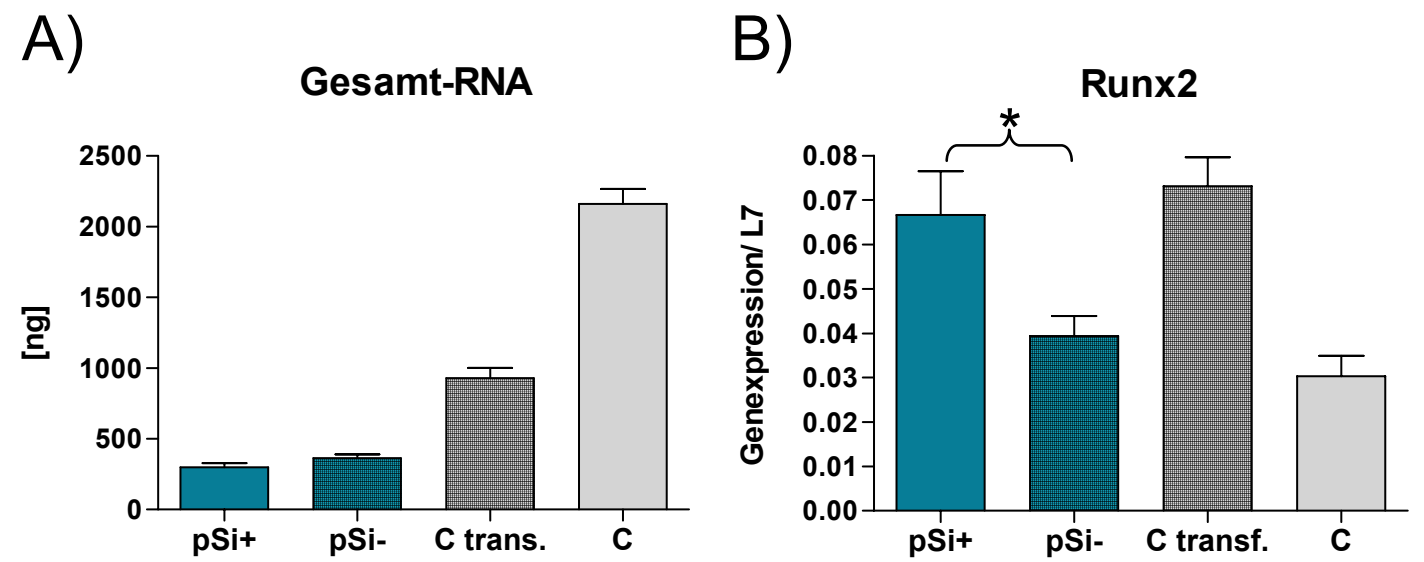

C)

L7

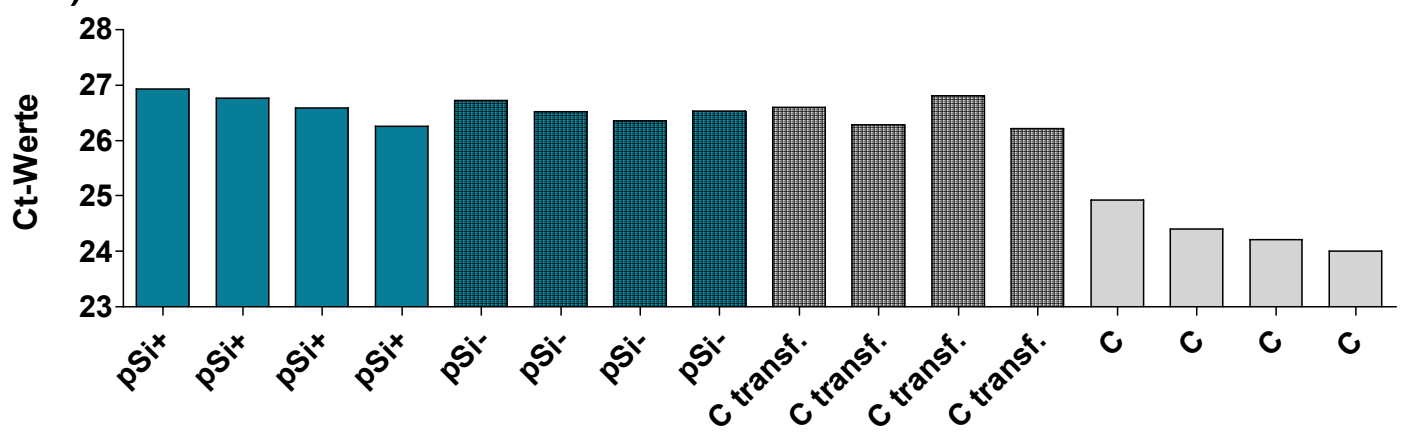

Abb. 16: Darstellung A) der isolierten RNA-Gesamtmenge; B) der Genexpression von Runx2 in der RealtimePCR und C) der Ct-Werte des housekeeping-Gens L7 in der Realtime-PCR, nach Transfektion mittels Lipofektion von $1 \mu \mathrm{g} \mathrm{pSi+}(\mathrm{pSi}+), 1 \mu \mathrm{g}$ pSi- (pSi-) und $1 \mu \mathrm{H}_{2} \mathrm{O}$ (C transf.) sowie nach Kultivierung ohne Transfektion (C) in pHOB-Zellen. Die Darstellungen A) und B) zeigen die Mittelwerte (mit $n=4)$ und den entsprechenden Standardfehlern (SEM), zu den direkten Kontrollzellen ( $p S i-)$ signifikante Ergebnisse sind mit einem Stern $\left({ }^{*}\right)$ gekennzeichnet, die Darstellung C) zeigt Einzelwerte.

Bei starker Zytotoxizität der Transfektion (s. Abb. 16) zeigte sich statt der erwarteten Runx2Suppression eine signifikante Induktion $(p=0,0465)$ der Runx2-Expression im Vergleich von mit pSi+ zu mit pSi- transfizierten Zellen um 70\%. Im Vergleich zu mit Wasser transfizierten Zellen zeigte sich kein signifikanter Unterschied. Der Vergleich mit untransfizierten Zellen erscheint aufgrund der unterschiedlich starken Expression des housekeeping-Gens L7 (s. Abb. 16) nicht sinnvoll. 


\subsubsection{Transfektionseffizienz}

Infolge der gegensätzlich erscheinenden Ergebnisse der Versuche 3.4.1 und 3.4.2 war es Ziel dieses transienten Transfektionsversuches die generelle Transfizierbarkeit von Plasmiden in pHOB zu überprüfen. Hierfür wurde ein Ansatz mit GFP-Plasmid transfiziert.

Zusätzlich wurde auf Genexpressionsebene der Vergleich zwischen mit pSi+ transfizierten und mit exogen synthetisierter (konventioneller) siRNA transfizierten Zellen gezogen.

Um weiterhin den Einfluss der molekularen Plasmidstruktur auf die Suppressionspotenz von pSi+ zu analysieren, wurde sowohl mit linearisierten als auch mit zirkulärem Plasmid transfiziert.

Als Transfektionsmethode wurde weiterhin die Lipofektion mit Lipofectamine 2000 gewählt, abermals wurden die Zellen von zwei Wells pro Probe pSi gepoolt.
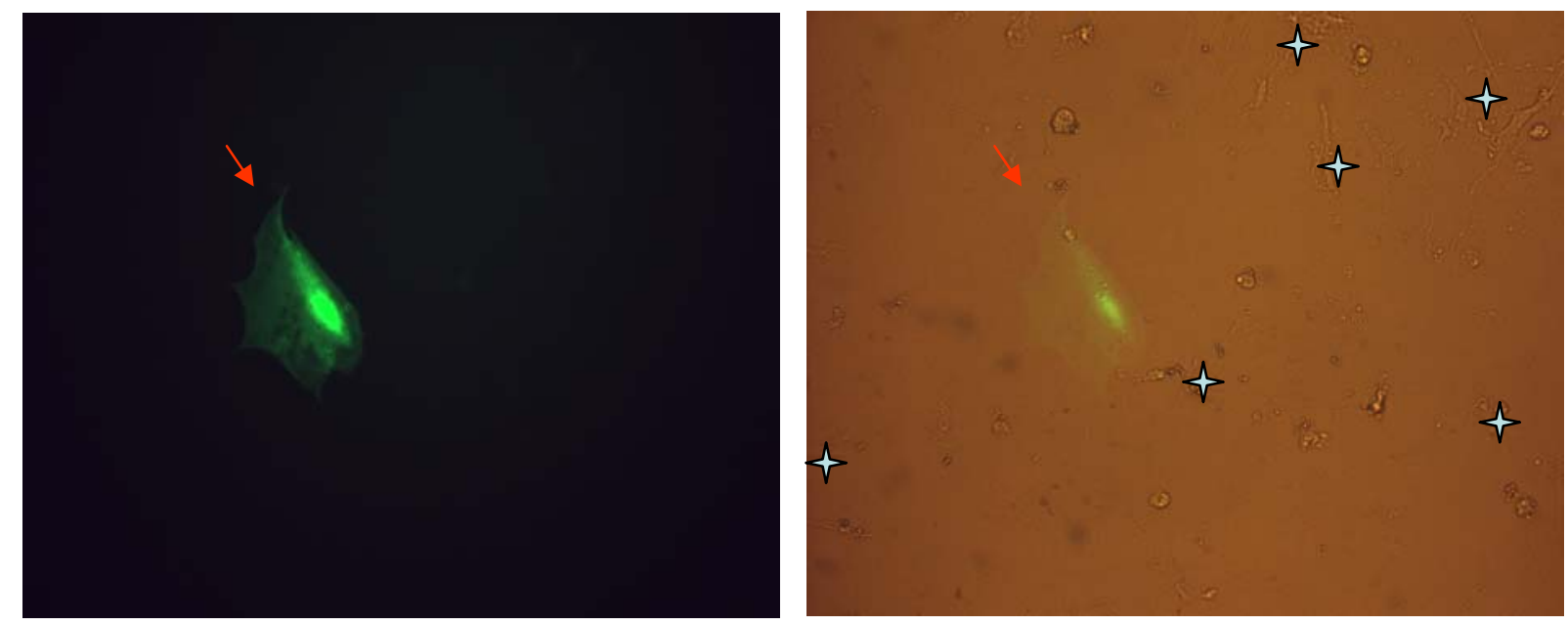

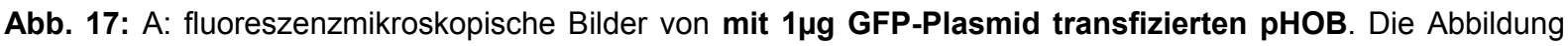
zeigte eine erfolgreich transfizierte, GFP-synthetisierende, Zelle (Pfeil) sowie schemenhaft untransfizierte Zellen (Sterne).

Aufgrund der fluoreszenzmikroskopischen Auswertung (s. Abb. 17) konnte die Transfizierbarkeit von pHOB-Zellen mit GFP-Plasmid-DNA durch die Lipofektion bestätigt werden. Auffallend war allerdings der geringe Anteil grünfluoreszendierender Zellen an der Gesamtzellzahl, sodass von einer geringen GFP-Transfektionsrate (visuell geschätzt $<5 \%$ ) ausgegangen werden musste. Da das transfizierte GFP-Plasmid eine ähnliche molekulare Größe (4796bp) wie pSi (4781bp) aufweist, wurde davon ausgegangen, dass auch pSi eine entsprechende Transfektionsrate besitzt. 


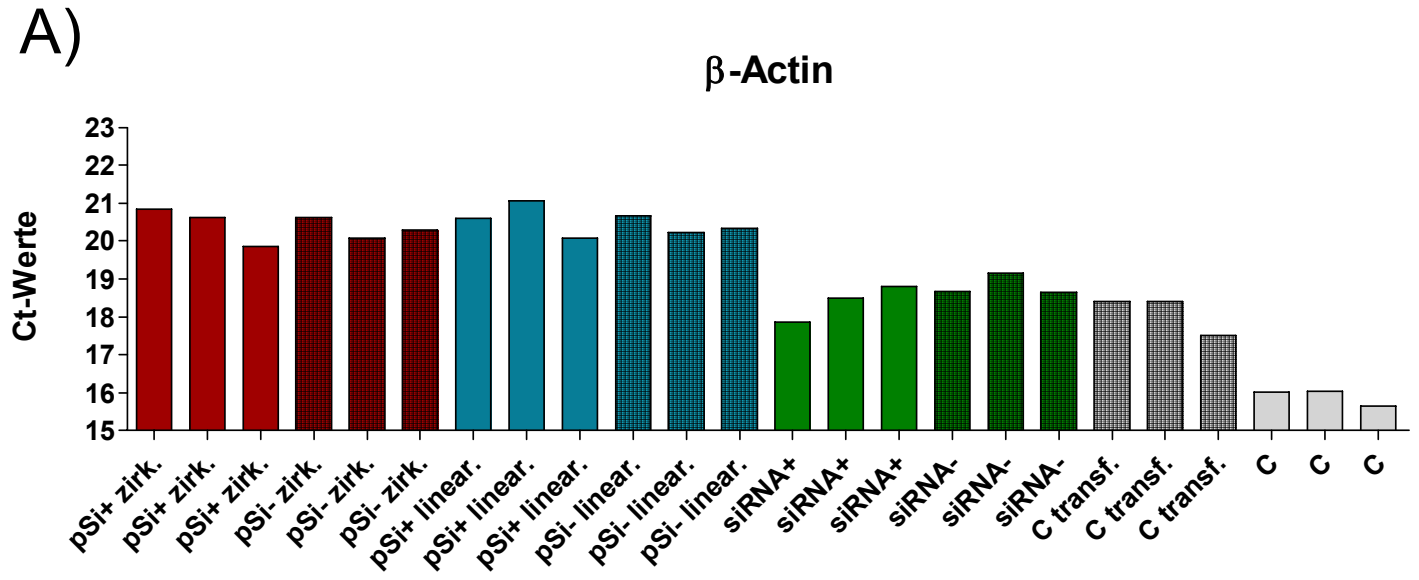

C)

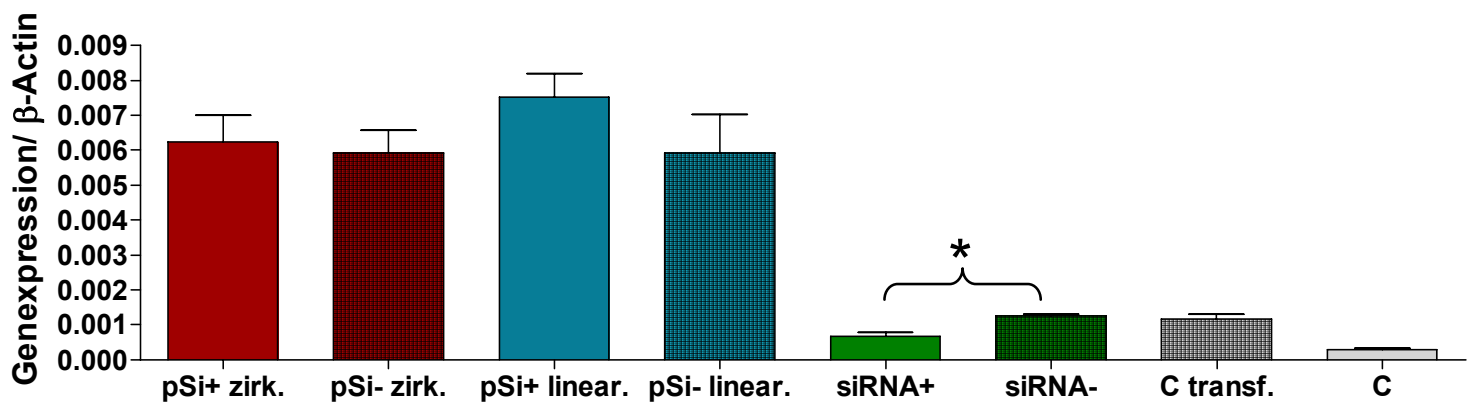

Abb. 18: Darstellung A) der Ct-Werte des housekeeping-Gens $\beta$-Actin und B) der Genexpression von Runx2 in der Realtime-PCR, nach Transfektion mittels Lipofektion mit $1 \mu \mathrm{g}$ zirkulärem pSi+ (pSi+ zirk.), $1 \mu \mathrm{g}$ zirkulärem pSi- (pSi- zirk.), $1 \mu \mathrm{g}$ linearisiertem pSi+ (pSi+ linear.), $1 \mu \mathrm{g}$ linearisiertem pSi- (pSi- linear.), $1 \mu \mathrm{g}$ Runx2 siRNA (siRNA+), $1 \mu \mathrm{g}$ scrambled siRNA (siRNA-) und $1 \mu \mathrm{H} \mathrm{H}_{2} \mathrm{O}$ (C transf.) sowie nach Kultivierung ohne Transfektion in pHOB-Zellen. Die Darstellungen A) zeigt Einzelwerte, die Darstellung B) zeigt die Mittelwerte (mit $n=3)$ und den entsprechenden Standardfehlern (SEM), zu den direkten Kontrollzellen (siRNA-)signifikante Ergebnisse sind mit einem Stern $\left({ }^{*}\right)$ gekennzeichnet.

Abermals konnte eine starke Zytotoxizität beobachtet werden (Daten nicht gezeigt). So wiesen mit Wasser transfizierte Zellen eine Reduktion der Gesamt-RNA um ca. 40\%, mit siRNA transfizierte Zellen um ca. $65 \%$ und mit Plasmiden transfizierte Zellen um ca. $85 \%$ im Vergleich zu untransfizierten Zellen auf.

In der Analyse des housekeeping-Gens $\beta$-Actin zeigte sich eine dreigeteilte Gruppierung (s. Abb. 18). Während mit Plasmid transfizierte Zellen höhere Ct-Werte als mit Wasser und siRNA transfizierte Zellen aufwiesen, zeigten diese wiederum höhere Ct-Werte als untransfizierte Zellen, was auf einen unspezifischen Effekt der Lipofektion mit Wasser und siRNA und davon abzugrenzen mit Plasmiden auf die $\beta$-Actin-Genexpression hinweist.

Während die mit pSi+ im Vergleich zu mit pSi- transfizierten Zellen eine Runx2Genexpression auf gleichem Niveau aufwiesen, konnte mittels der konventionellen Runx2 siRNA im Vergleich zur scrambled siRNA eine signifikante $(p=0,0094)$ Suppression von Runx2 um 47\% erreicht werden. Relativierend muss angemerkt werden, dass zur besseren 
Vergleichbarkeit zu den mit Plasmid transfizierten Zellen suboptimale Versuchsbedingungen für die Transfektion der chemisch exogen synthetisierten siRNA in Kauf genommen wurde. So wurde z.B., wie es laut Hersteller für Plasmid-DNA-Transfektionen empfohlen wird, bei einem Konfluenzgrad der Zellen von 90\% transfiziert, statt, wie es für die Transfektion mit siRNA empfohlen wird, bei einem Konfluenzgrad von 50-60\%. In der Vergangenheit konnte im selben Zellkulturmodell mit einer wiederholten zusätzlichen Transfektion von Runx2 siRNA mit Lipofectamine 2000 nach 5 Tagen und Aufarbeitung nach weiteren 96h eine Gensuppressionsrate von über 90\% erreicht werden (Giesen 2007).

Weder durch zirkuläres noch durch linearisiertes pSi+ konnte im Vergleich zu korrespondierenden pSi(-)-Ansätzen eine Runx2-Suppression beobachtet werden. Im Vergleich der linearisierten Plasmide deutet sich sogar eine nicht signifikante Induktion durch $\mathrm{pSi}+$ an.

\subsubsection{Lipofektionsoptimierung}

Intention dieses transienten Transfektionsversuches war es höhere PlasmidTransfektionsraten zu erreichen.

$\mathrm{Zu}$ diesem Zweck wurden pHOB-Zellen mit einer erhöhten Plasmid-DNA-Konzentration von $4 \mu \mathrm{g}$ statt $1 \mu \mathrm{g}$ pro Well transfiziert.

Des Weiteren wurde der Einfluss der Inkubationsdauer mit dem Plasmid enthaltenden Transfektionsmedium auf die Transfektionsrate und Runx2-Expression überprüft. Hierfür wurden drei Zeiträume gewählt: $6 \mathrm{~h}, 12 \mathrm{~h}$ und 24h. Die Transfektionsrate wurde mit GFP-Plasmid kontrolliert. Ein 2:1 „pooling“ der Zelllysate bei der RNA-Isolierung sollte die zur Analyse ausreichende RNA-Gesamtmenge sicherstellen. 


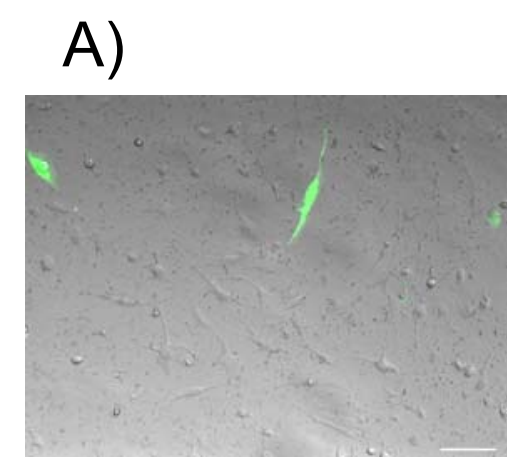

C)
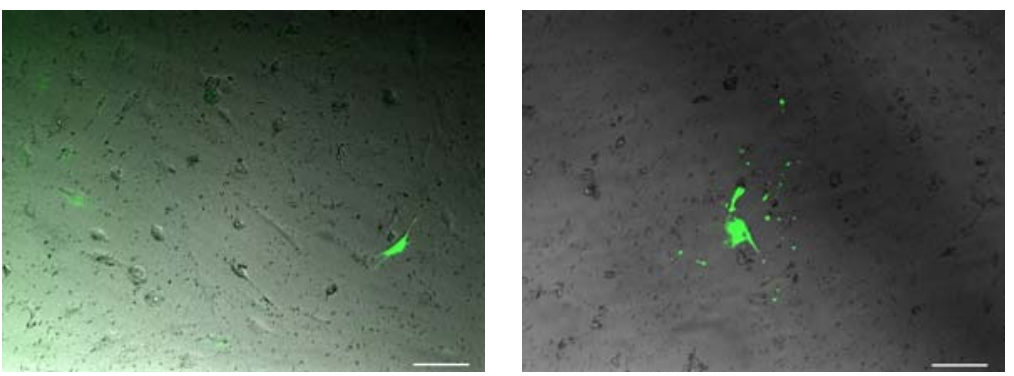

RNA-Gesamtmenge

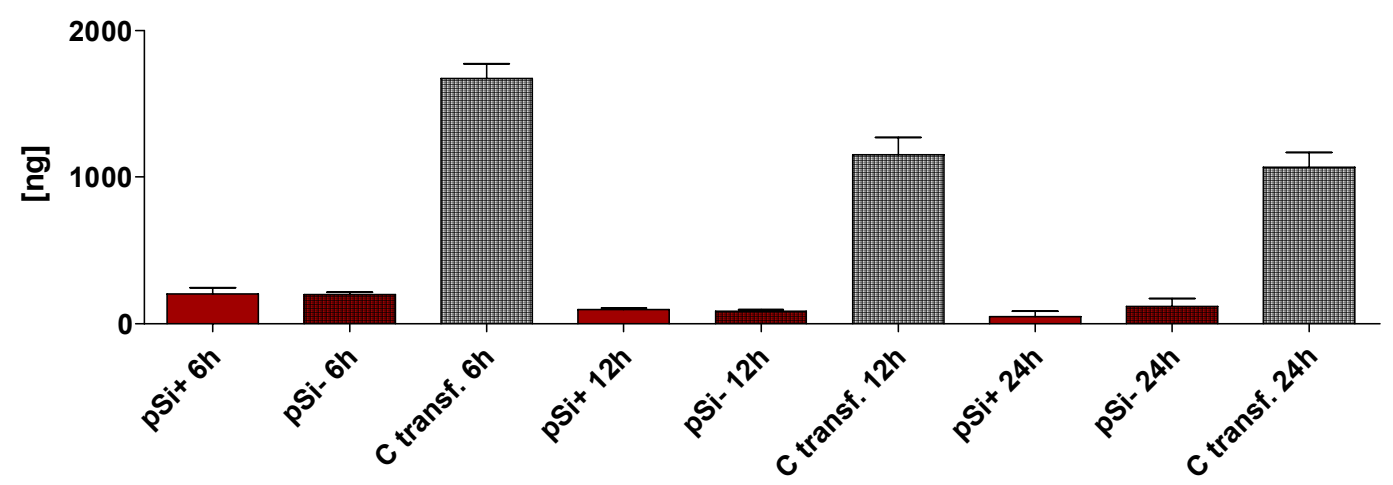

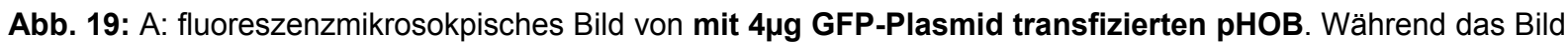
des 6h-Ansatzes (links) einzelne erfolgreich mit GFP-Plasmid transfizierte Zellen mit mehreren umgebenden Zellen zeigt, stellt sich im 12h-Ansatz (Mitte) zwar ein höherer Anteil erfolgreich transfizierter Zellen dar, aber auch eine geringere Anzahl umgebender Zellen. Der 24h-Ansatz (rechts) zeigt eine erfolgreich transfizierte Zelle ohne umgebende untransfizierte Zellen, GFP in der Umgebung der transfizierten Zelle lässt einen Austritt von Zytoplasma aus der Zelle vermuten. B: Darstellung der isolierten RNA-Gesamtmenge von mit $4 \mu \mathrm{g} p \mathrm{Si}(+), 4 \mu \mathrm{g}$ pSi(-) und $4 \mu \mathrm{l} \mathrm{H}_{2} \mathrm{O}$ (C transf.) für $6 \mathrm{~h}, 12 \mathrm{~h}$ bzw. 24h transfizierten pHOB.

Es zeigte sich eine höhere GFP-Transfektionsrate, je länger die Zellen mit dem Transfektionsmedium inkubiert wurden. Die Zellen, die über $6 \mathrm{~h}$ mit dem Transfektionsmedium inkubiert wurden, wiesen eine visuell geschätzte GFP-Transfektionsrate von ca. $10 \%$, die $12 \mathrm{~h}$ inkubierten Zellen von ca. $20 \%$ und die $24 \mathrm{~h}$ inkubierten Zellen von ca. 30\% auf.

Zwar konnte durch diesen Versuchsansatz die Transfektionsrate gesteigert werden, die Zytotoxizität des Ansatzes nahm aber nicht tolerable Ausmaße an (s. Abb. 19). Mit Plasmiden transfizierte und mit Transfektionsmedium 24h inkubierte Zellen wiesen eine Reduktion der Gesamt-RNA um ca. 93\% bereits im Vergleich zu mit Wasser transfizierten Zellen auf. So konnte aus der isolierten Gesamt-RNA aller pSi-Ansätze, die länger als $6 \mathrm{~h}$ mit dem Transfektionsmedium inkubiert wurden, trotz RNA-Einengung keine genügend hohe 
RNA-Konzentration für eine RT-PCR gewonnen werden, obwohl bei der RNA-Isolierung alle pSi-Ansätze 2:1 gepoolt wurden.

\subsubsection{Alternatives Transfektionssystem (1)}

Da sich bei der Transfektion mittels Lipofektion entweder eine zu niedrige Transfektionsrate bei tolerabler Zytotoxizität (s. Versuch 3.4.3) oder eine annehmbare Transfektionsrate bei nicht tolerabler Zytotoxizität (s. Versuch 3.4.4) unter getesteten Bedingungen zeigte, musste ein effizienteres Transfektionssystem gefunden werden.

Hierfür wurde die Mikroporation mittels Mikroporator getestet. Da es sich hierbei um einen Vorversuch handelte, wurden HOB-Zellen einer höheren Passage (Passage 5) genutzt.
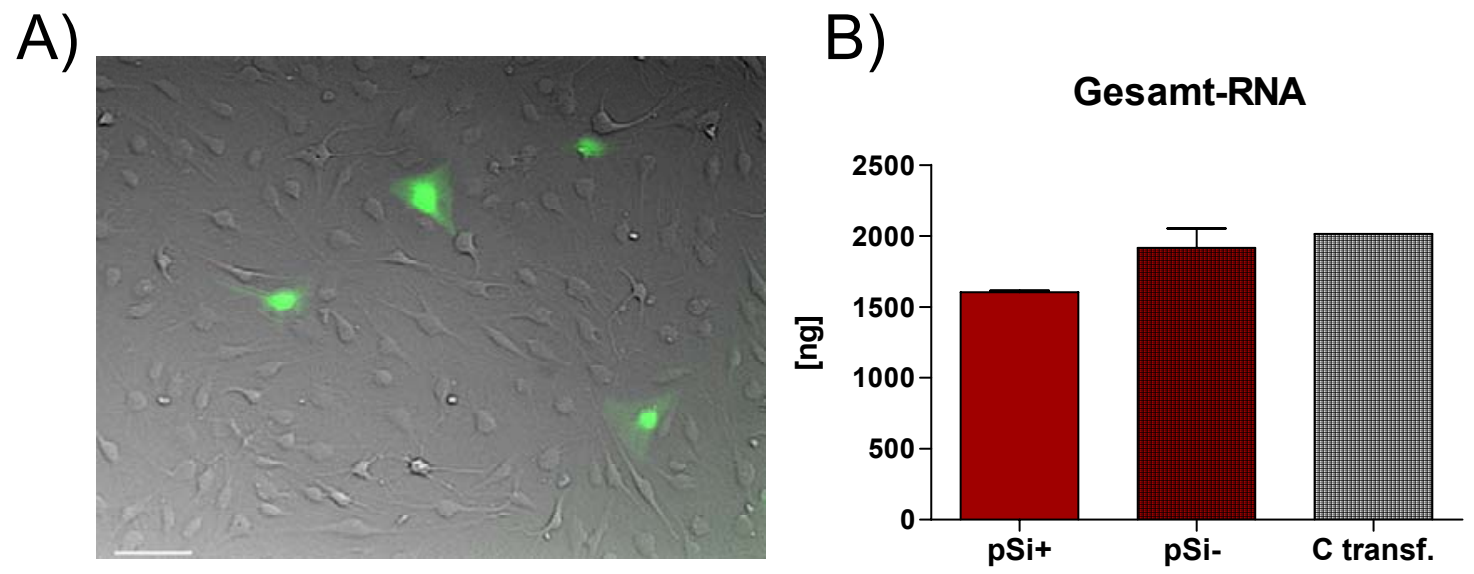

Abb. 20: A: fluoreszenzmikrosokpisches Bild von mit $4 \mu \mathrm{g}$ GFP-Plasmid mittels Mikroporation transfizierten HOB. B: Darstellung der isolierten RNA-Gesamtmenge von mit $4 \mu \mathrm{g} \mathrm{pSi}(+)(\mathrm{n}=2), 4 \mu \mathrm{g} \mathrm{pSi}(-)(\mathrm{n}=2)$ und $4 \mu \mathrm{l} \mathrm{H}_{2} \mathrm{O}$ (C transf.) $(n=1)$ transfizierten HOB.

Bei einer geschätzten GFP-Transfektionsrate von ca. $10 \%$ zeigte sich eine geringe Zytotoxizität des Transfektionsystems beim Vergleich von mit Plasmiden zu mit Wasser transfizierten Zellen (s. Abb. 20). Bei einer orientierenden Analyse des Genexpressionverhaltens von Runx2 (Daten nicht gezeigt) zeigte sich weder eine signifikante Suppression noch eine Induktion durch das Plasmid pSi+ im Vergleich zum Kontrollplasmid pSi- bei gleich starker Expression des housekeeping-Gens $\beta$-Actin (Daten nicht gezeigt).

\subsubsection{Alternatives Transfektionssystem (2)}

Als zweites alternatives Transfektionssystem wurde die Nukleofektion mittels Nukleofektor von AMAXA getestet. Es wurden wiederum HOB-Zellen einer höheren Passage (Passage 3) genutzt. 


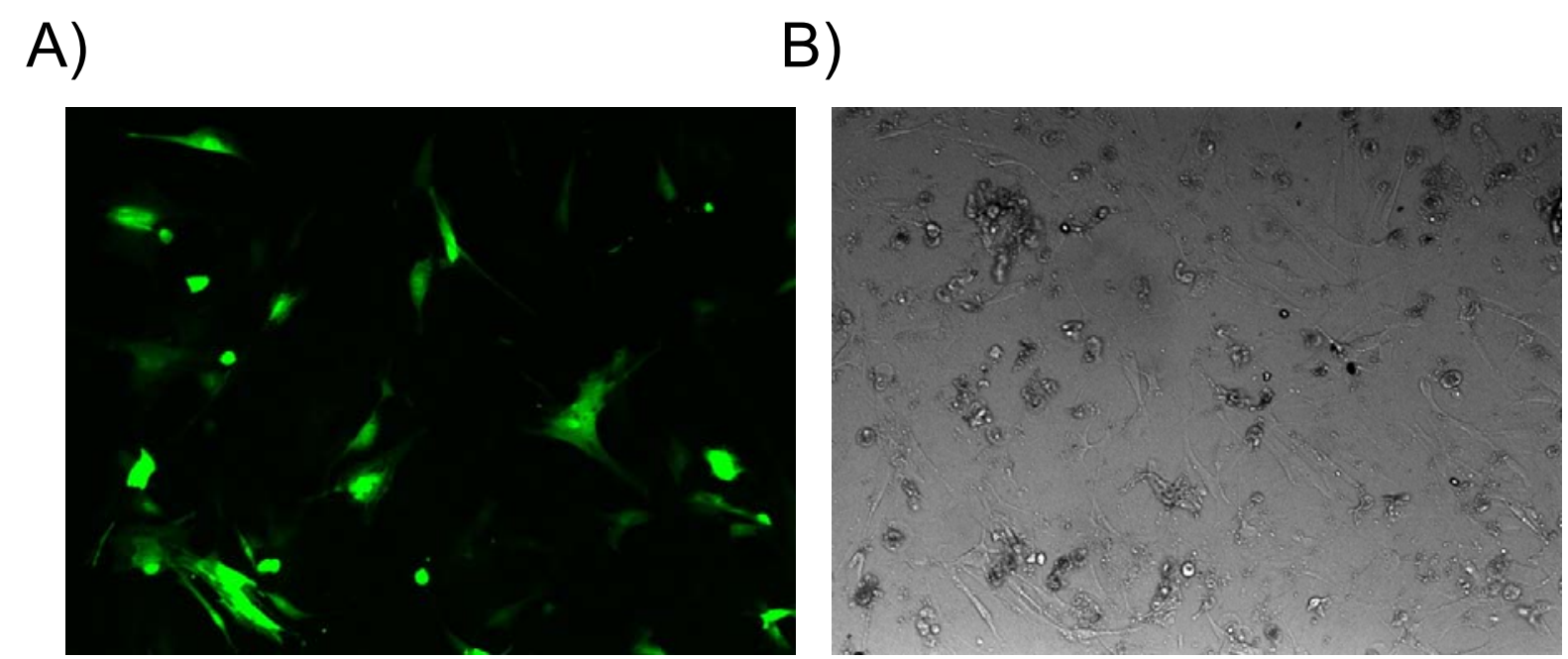

Abb. 21: A) fluoreszenzmikroskopisches und B) lichtmikroskopisches Bild von mittels Nukleofektion mit $4 \mu \mathrm{g}$ GFP-Plasmid transfizierten HOB.

Es zeigte sich, dass dieses Transfektionssystem in der Lage war, HOB-Zellen mit einer GFP-Transfektionsrate von ca. 90\% zu transfizieren (s. Abb. 21).

Auffallend war zudem die hohe Fluoreszenzintensität sowohl im Nukleus als auch im Zytoplasma der GFP-exprimierenden-Zelle.

Eine orientierende Runx2-Genxpressionsanalyse (Daten nicht gezeigt) zeigte keinen signifikanten Unterschied zwischen mit pSi+ und mit pSi- transfizierten Zellen.

Über die Zytotxoizität dieses Transfektionssystems konnte aufgrund der Versuchsanordnung in diesem Versuch keine quantitative Aussage gemacht werden.

\subsubsection{Transiente Transfektion mit kurzzeitiger Puromycinselektion}

Ziel des Versuches war eine mögliche Runx2-Suppression durch pSi+ zu demaskieren und damit anlalysierbar zu machen. Hierfür wurden erfolgreich transfizierte Zellen mittels Puromycinantibiose selektiert. Erfolgreich mit pSi transfizierte Zellen mit regelrechter Plasmidaktivität sind resistent gegenüber dem Antibiotikum Puromycin in adäquater Dosierung und überleben folglich, während untransfizierte Zellen oder Zellen mit fehlerhafter Plasmidaktivität den Zelltod erleiden.

Als geeignete Puromycinkonzentration fiel die Entscheidung auf die Hälfte der in Versuch 3.2 ermittelteten optimalen Puromycinkonzentration, um die Zytotoxizität der von der Transfektion belasteten Zellen tolerabel zu halten.

Mittels Nukleofektion wurden $5^{\star} 10^{5}$ Zellen einer pHOB-Kultur transfiziert und nach 24 Stunden mit 250ng/ml Puromycin behandelt. Als Kontrolle für die regelrechte Puromycinwirkung dienten mit $\mathrm{H}_{2} \mathrm{O}$ transfizierte Zellen. 3 bzw. 7 Tage nach Transfektion 
wurde die Gesamt-RNA isoliert. Zur Kontrolle der Transfektionsrate wurde zusätzlich mit GFP-Plasmid transfiziert.

A)

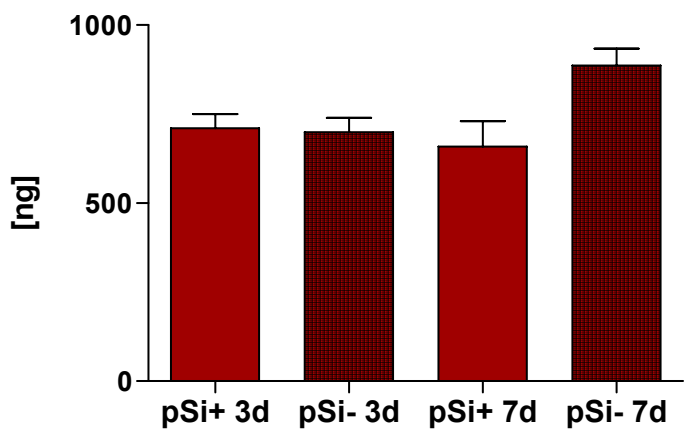

B)

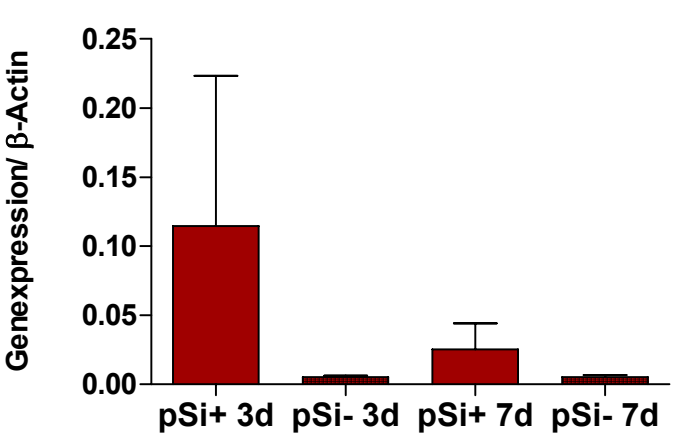

Abb. 22: Darstellung A) der isolierten RNA-Gesamtmenge und B) der Genexpression von Runx2 in der Realtime-PCR, nach Transfektion mittels Nukleofektion von $5 \mu \mathrm{g} \mathrm{pSi}(+), 5 \mu \mathrm{g} \mathrm{pSi}(-)$ und anschließender Antibiose mit 250ng/ml Puromycin für 3 Tage (3d) bzw. 7 Tage(7d) in pHOB-Zellen. Die Darstellungen A) und B) zeigen die Mittelwerte (mit $n=3$ ) und den entsprechenden Standardfehlern (SEM).

Bei einer GFP-Transfektionsrate von visuell geschätzt >90\% (Bild nicht gezeigt), musste von einer stark erhöhten Zytotoxizität des Versuchsansatzes ausgegangen werden, da der Mittelwert der RNA-Gesamtmenge nach 3 Tagen bei ca. 700ng lag und damit ca. 3900ng weniger RNA als bei dem vergleichbaren Versuchsansatz in Versuch 3.4 .6 (Daten nicht gezeigt) aufgearbeitet werden konnte.

Obwohl keine Signifkanzen erreicht werden konnten, wies sowohl der pSi+ 3d- als auch der pSi+ 7d-Ansatz eine Tendenz zur Induktion der Runx2-Genexpression im Vergleich zum entsprechenden Kontrollplasmid auf. So war im Ansatz pSi+ 3d im Vergleich zum Ansatz pSi- 3d eine 20,8-fache Induktion zu erkennen. Die Runx2-Expression im pSi+ 7d-Ansatz war im Vergleich zum pSi- 7d-Ansatz um 3,7-fach induziert.

Das housekeeping-Gen $\beta$-Actin war in allen Ansätzen etwa gleich stark exprimiert (Daten nicht gezeigt).

\subsubsection{Transiente Transfektion pHOB zur Analyse mittels RNA-Microarray}

Die vorhergehenden Versuche ließen vermuten, dass pSi+ in einigen pHOB-Kulturen statt der gewünschten Runx2 supprimierenden Wirkung eine Induktion der Runx2-Genexpression in Form eines Rescue Effektes bewirken könne.

Um diese Zellprozesse genauer zu analysieren und die Auswirkung eines Runx2-knockdowns auf pHOB-Zellen im Detail zu verstehen, wurde ein Transfektionsversuch zur Auswertung mit der Methode des RNA-Microarrays entworfen. Mittels Nukleofektion wurden mit $\mathrm{n}=3$ pHOB-Zellen mit pSi+, pSi-, konventioneller Runx2 siRNA, scrambled siRNA und mit 
$\mathrm{H}_{2} \mathrm{O}$ mittels Nukleofektion (AMAXA) transfiziert. Als zusätzliche Kontrolle dienten untransfizierte Zellen. Mit pSi transfizierte Zellen wurden mit 250ng/ml Puromycin kultiviert und nach 6 Tagen aufgearbeitet, während alle anderen Zellen ohne Puromycinantibiose nach 4 Tagen aufgearbeitet wurden. Diese Versuchsanordnung ergab sich aus den bisherigen Ergebnissen mittels Puromycinantibiose und aus laborinternen Studien mit der Transfektion konventioneller Runx2 siRNA, in der mit diesem Kultivierungszeitraum effiziente knock-down-Ergebnisse erzielt werden konnten (Giesen 2007). Vor der Microarraystudie wurde eine Realtime-PCR angefertigt:

A)

\section{Gesamt-RNA}

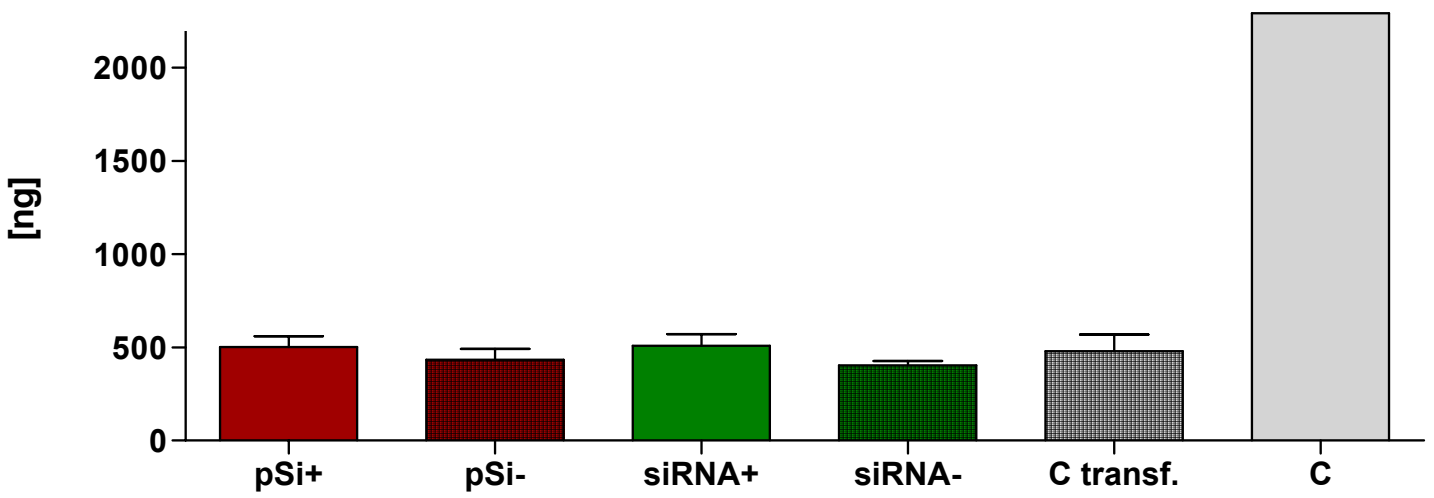

B)

Runx2

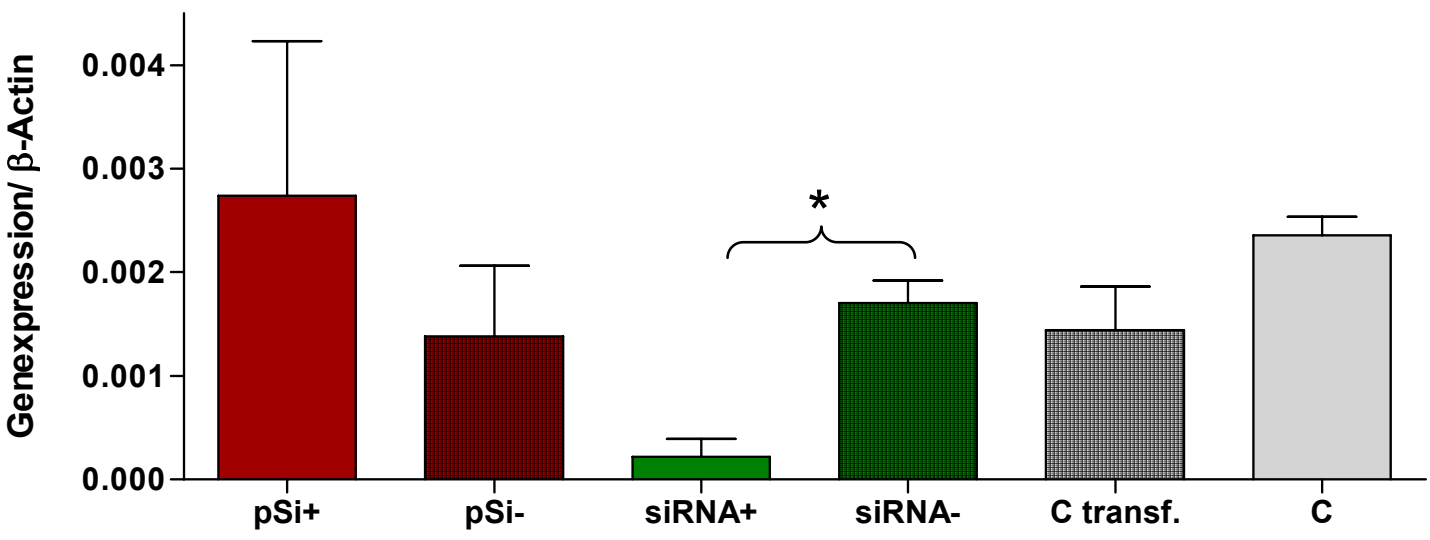

Abb. 23: Darstellung A) isolierten RNA-Gesamtmenge und B) der Genexpression von Runx2 in der Realtime-

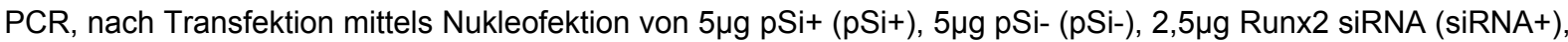
2,5 $\mu \mathrm{g}$ scrambled siRNA (siRNA-), und $5 \mu \mathrm{l} \mathrm{H}_{2} \mathrm{O}$ (C transf.) sowie nach Kultivierung ohne Transfektion (C) in pHOB-Zellen. Die Darstellung zeigt die Mittelwerte (mit $n=3$ ) und den entsprechenden Standardfehlern (SEM), zu den direkten Kontrollzellen (siRNA-) signifikante Ergebnisse sind mit einem Stern ( ${ }^{*}$ ) gekennzeichnet. 
Bei einer Reduktion der RNA-Gesamtmenge aller transfizierten Ansätzen auf ca. $20 \%$ im Vergleich zu allen untransfizierten Kontrollzellen, zeigte die Realtime-PCR eine Tendenz zur Induktion der Runx2-Genexpression um das 2-fache durch pSi+ im Vergleich zu pSi-. Diese Tendenz erreichte allerdings kein Signifikanzniveau.

Weiterhin konnte eine erfolgreiche, signifikante $(p=0,0058)$ Runx2-Gensuppression durch Runx2 siRNA im Vergleich zu scrambled siRNA um 87\% gezeigt werden.

Aufgrund dieser Ergebnisse wurde entschieden in einer Microarraystudie die molekularbiologische Auswirkung von pSi+ und konventioneller Runx2 siRNA+ auf pHOB-Zellen zu untersuchen.

Um genügende RNA-Mengen bereitzustellen, mussten erneut $p H O B-Z e l l e n$ mit $n=6$ mit $p S i$ mittels Nukleofektion (AMAXA) transfiziert und posttransfektionell unter oben genannten Bedingungen kultiviert werden.

Isoliert wurde die Gesamt-RNA in diesem Fall mittels Trizolaufarbeitung, um die RNAIsolationsmenge zu erhöhen.

Ergänzend muss erwähnt werden, dass das Knochen-Ausgangsmaterial dieser pHOB-Zellen nicht von demselben Patienten wie die mit konventioneller Runx2 siRNA transfizierten Zellen stammte.

\subsubsection{Vergleich der verschiedenen Transfektionssysteme}

Wie in Tab. 29 ersichtlich zeigte die Nukleofektion (AMAXA) mit ca. 90\% mit Abstand die höchste GFP-Plasmid-Transfektionsrate der getesteten Transfektionssysteme. Damit konnten mit der Nukleofektion 9-mal mehr Zellen mit diesem Plasmid transfiziert werden als mit der Methode der Mikroporation und sogar 18-mal mehr Zellen als mit der Methode der Lipofektion.

\begin{tabular}{|c|c|c|c|}
\hline & Mikroporation $^{\text {1) }}$ & Lipofektion $^{2)}$ & Nukleofektion $^{3)}$ \\
\hline $\begin{array}{c}\text { Transfektionsrate } \\
\text { GFP- Plasmid }\end{array}$ & ca. $10 \%$ & ca. $5 \%$ & ca. $90 \%$ \\
\hline
\end{tabular}

Tab. 29: Vergleich der getesteten Transfektionssysteme anhand der Transfektionsrate von GFP-Plasmid. Verglichen wurden Mikroporation ${ }^{1}$ von Peqlab, Lipofektion ${ }^{2}$ mit Lipofectamine 2000 und Nukleofektion $^{3}$ mit AMAXA, basierend auf ${ }^{1)} 3.4 .5,{ }^{2)} 3.4 .3,{ }^{3)} 3.4 .6,3.4 .7$.

Bein näherer Betrachtung fiel auf, dass bei der Transfektion exogen synthetisierter siRNA sowohl mit der Lipofektion als auch mit der Nukleofektion hohe Runx2 Gensuppressionsraten erzielt werden konnten (Lipofektion - >90\%, Nukleofektion 87\%). Die Lipofektion zeigte sich hier aber als weniger zytotoxisch. Die aufgearbeitete RNAGesamtmenge fiel mit 35\% im Vergleich zu untransfizierten Zellen 15\% höher aus als bei der 
Aufarbeitung von mit der Nukleofektion transfizierten Zellen. Die Nukleofektion zeigte sich aber als gleich zytotoxisch auf sowohl mit Wasser, siRNA als auch mit Plasmiden transfizierte Zellen. Damit war die Nukleofektion (RNA-Gesamtmenge: 20\%) für die Transfektion von Plasmiden in pHOB deutlich zellschonender als die Lipofektion (RNAGesamtmenge: 6-15\%).

Zusammengefasst erwies sich die Nukleofektion aufgrund der hohen GFP-Transfektionsrate (>90\%) und der im Vergleich geringeren Zytotoxizität als geeignetere Methode für die Transfektion von Plasmiden, während sich die Lipofektion, aufgrund höherer Runx2 Gensuppressionsrate und niedrigerer Zytotoxizität, als Transfektionsmethode für die Transfektion von exogen synthetisierter siRNA empfahl.

\begin{tabular}{|c|c|c|c|c|}
\hline & \multicolumn{2}{|c|}{ Lipofektion } & \multicolumn{2}{|c|}{ Nukleofektion } \\
\hline & $\operatorname{siRNA}{ }^{1,2)}$ & $p S i^{2,3,4)}$ & siRNA $^{5)}$ & $p S i^{5)}$ \\
\hline $\begin{array}{l}\text { Runx2 Genexpression } \\
\text { (signifikant mit } \mathrm{p}<0.05 \text { ) }\end{array}$ & $\begin{array}{c}\mathbf{4 7 \%}->90 \% \\
\text { Suppression } \\
\text { durch }^{1,2)} \\
\text { siRNA+ }\end{array}$ & $\begin{array}{c}\text { 43\% Suppression } \\
\text { - } 70 \% \text { Induktion }^{4)} \\
\text { durch pSi+ }\end{array}$ & $\begin{array}{c}\mathbf{8 7 \%} \\
\text { Suppression+ }+^{5)} \\
\text { durch siRNA }\end{array}$ & $\begin{array}{c}\text { keine } \\
\text { - 20,8-fache } \\
\text { Induktion }^{5} \\
\text { durch pSi+ }\end{array}$ \\
\hline $\begin{array}{c}\text { RNA-Gesamtmenge } \\
\qquad(100 \%= \\
\text { untransfizierte } \mathrm{pHOB})\end{array}$ & $\begin{array}{c}35 \%^{2)}-\text { keine } \\
\text { Daten }{ }^{1)}\end{array}$ & $6 \%^{2,4)}-15 \%^{3)}$ & ca. $20 \%^{5)}$ & ca. $20 \%^{5)}$ \\
\hline
\end{tabular}

Tab. 30: Vergleich der beiden Transfektionssysteme Lipofektion mit Lipofectamine 2000 und Nukleofektion mit AMAXA in pHOB der 1. Passage. Dargestellt sind die Runx2 Genexpressionsraten und die RNA-Gesamtmenge im Vergleich zu untransfizierten Kontrollzellen basierend auf ${ }^{1)}$ (Giesen 2007), ${ }^{2)} 3.4 .3,{ }^{3)}$ $3.4 .1,{ }^{4)} 3.4 .2,{ }^{5)} 3.4 .8$

\subsubsection{RNA-Microarray one-color}

Es wurde eine Microarraystudie im Vergleich der gepoolten Proben pSi+ und pSi- sowie davon unabhängig von den Proben si+ und si- (aus Versuch 3.4.8.1) angefertigt.

\section{p-Silencer(+)-Wirkung auf pHOB:}

Der Microarray zeigt neben der signifikanten Regulation von mehr als 500 Transkripten auf den ersten Blick eine Induktion der Runx2 mRNA in pHOB nach Transfektion mit pSi+ um einen fold change von +5.0 (d.h. eine 32-fache Induktion). Grundsätzlich wird im RNAMicroarray jedes Transkript durch die Bindung an mehrere verschiedene Oligonukleotide nachgewiesen, um eine gesicherte Aussage über die Genexpression machen zu können. Zu der Detektion der Runx2 mRNA wurden im Microarray drei verschiedene Oligonukleotide 
(Oligonukleotid 1-3) verwendet, die jeweils einen anderen spezifischen Abschnitt der Runx2 mRNA erkennen. Zur Lokalisation der verschiedenen Zielsequenzen dieser Oligonukleotide siehe Abb. 24.

\section{Oligonukleotid 1}

(ID: A_32_P148058)

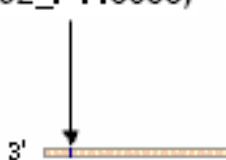

Oligonukleotid 2

(ID: A_24_P69267)
Oligonukleotid 3

(ID: A_32_P161762)

5' Runx2 mRNA

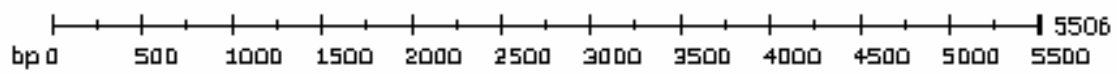

Abb.24: Schematische Darstellung der Zielsequenzlokalisation in der Runx2 mRNA der im Array verwendeten Oligonukleotide 1-3.

Die gemessene 32-fache Induktion von Runx2 wurde jedoch lediglich von Oligonukleotid 2 mit der Agilent ID A_24_P69267 signifikant detektiert. Die beiden anderen Oligonukleotide (1 und 3) zeigten keinen signifikanten Unterschied in der Runx2- Expression (s.Tab. 31)

\begin{tabular}{|c|c|c|c|c|c|}
\hline $\begin{array}{c}\text { Gencode } \\
\text { (NCBI) }\end{array}$ & Genname & $\begin{array}{l}\text { Oligonukleotid } \\
\text { (Agilent ID) }\end{array}$ & $\begin{array}{c}\text { fold change } \\
\left(\log 2^{x}\right)\end{array}$ & $\begin{array}{l}\text { „X- fache" } \\
\text { Expression }\end{array}$ & p-Wert \\
\hline \multirow{3}{*}{ Runx2* } & \multirow{3}{*}{$\begin{array}{l}\text { Runt-related } \\
\text { transcription } \\
\text { factor } 2\end{array}$} & 1 (A_32_P148058) & +0.30 & 1,2-fach $(\uparrow)$ & 0.17 \\
\hline & & 2 (A_24_P69267) & +5.00 & 32-fach $\uparrow \uparrow$ & 0.01 \\
\hline & & 3 (A_32_P161762) & -0.30 & 1,2-fach $(\downarrow)$ & 0.32 \\
\hline
\end{tabular}

Tab. 31: Die Tabelle zeigt die mRNA Expression von Runx2 in mit pSi+ im Vergleich zu mit pSi- transfizierten pHOB. Dargestellt sind Gencode (nach NCBI), Genname (nach NCBI), detektierende Oligonukleotide (Agilent ID), mRNA Expression in fold change (Verhältnis der Genexpression im Bezug auf die Vergleichsexpression zur Basis 2 logarithmiert) und "-fachen" - Wert sowie p-Wert. Mit $p<0.05$ signifikante Ergebnisse sind mit * gekennzeichnet.

Das detektierende Oligonukleotid 2 (A_24_P69267) erkennt einen Abschnitt im ersten Drittel des Runx2-Transkriptes (s. Abb. 25). Interessanterweise sind die in Abb. 25A rot hervorgehobenen 17 Nukleotide der detektierenden Oligonukleotidsequenz ebenfalls in der sense-Sequenz der von pSi+ synthetisierten siRNA identisch wiederzufinden (s. Abb. 25B). In dem antisense-Strang der siRNA ist sie dementsprechend komplementär vorhanden (grün in Abb. 21B). 


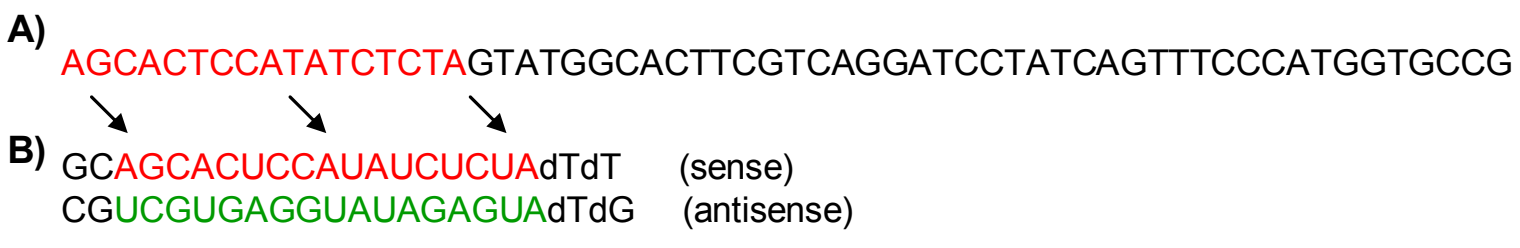

Abb. 25: A) Sequenz des detektierenden Oligonuleotids 2: A_24_P69267 und B) Sequenz der von pSi+ synthetisierten Runx2 siRNA

Dies lässt eine direkte Messung der von pSi+ in pHOB synthetisierten Runx2 siRNA vermuten, da nur das Oligonukleotid, welches aufgrund der Sequenz spezifisch die Runx2 siRNA binden könnte, diese starke Runx2 Induktion aufzeigt.

\begin{tabular}{|l|l|c|c|c|}
\hline \multicolumn{2}{|c}{$\begin{array}{c}\text { Gencode } \\
\text { (NCBI) }\end{array}$} & \multicolumn{2}{c}{$\begin{array}{c}\text { Genname } \\
\text { fold change } \\
\left(\text { log2 }{ }^{\mathbf{x}} \text { ) }\right.\end{array}$} & \multicolumn{2}{c|}{$\begin{array}{c}\text { „X-fache } \\
\text { Expression }\end{array}$} & p-Wert \\
\hline Runx2* & $\begin{array}{l}\text { Runt-related } \\
\text { transcription factor } 2\end{array}$ & +5.00 & 32,00 -fach $\uparrow \uparrow$ & 0.01 \\
\hline IBSP* $^{*}$ & Bone Sialoprotein & +1.50 & 2,80 -fach $\uparrow$ & 0.01 \\
\hline SPP1* & Osteopontin & -0.54 & 1,45 -fach $\downarrow$ & 0.03 \\
\hline BGLAP & Osteocalcin & +0.18 & 1,13 -fach $\uparrow$ & 0.41 \\
\hline AP & Alkalische Phosphatase & +0.21 & 1,15 -fach $\uparrow$ & 0.34 \\
\hline COL1A1 & Typ I Kollagen & -0.03 & 1,02 -fach $\downarrow$ & 0.90 \\
\hline RANKL & $\begin{array}{l}\text { tumor necrosis factor } \\
\text { (ligand) superfamily, } \\
\text { member 11 }\end{array}$ & +0.70 & 1,62 -fach $\uparrow$ & 0.33 \\
\hline COL10A1 & Typ X Kollagen & -0.47 & 1,39 -fach $\downarrow$ & 0.06 \\
\hline
\end{tabular}

Tab. 32: Die Tabelle zeigt die mRNA Expression verschiedener zum Knochen- und Knorpelstoffwechsel zugehöriger Gene in mit pSi+ im Vergleich zu mit pSi- transfizierten pHOB. Dargestellt sind Gencode (nach $\mathrm{NCBI}$ ), Genname (nach NCBI), mRNA Expression in fold change (Verhältnis der Genexpression im Bezug auf die Vergleichsexpression zur Basis 2 logarithmiert) und „-fachen“ - Wert sowie p-Wert. Mit p<0.05 signifikante Ergebnisse sind mit * gekennzeichnet.

Neben der 32-fachen Expression des Runx2-Transkriptes konnte in dem Microarray eine Regulierung der knochenspezifischen Proteine Bone Sialoprotein und Osteopontin durch pSi+ gezeigt werden. Hier findet sich eine signifkante 2,8-fache Induktion sowie eine signifikante 1,45-fache Suppression. Weitere osteogene Marker, namentlich Osteocalcin, knochenspezifische alkalische Phosphatase, Typ-I-Kollagen und tumor necrosis factor (ligand) superfamily, member 11 (RANKL) wiesen keine signifikante Regulation durch das Plasmid pSi+ auf. Das für hypertrophe Chondrozyten charakterisierende Typ-X-Kollagen war tendentiell 1,39-fach supprimiert, diese Suppression erreichte mit einem $p$-Wert von 0.06 allerdings nicht Signifikanzniveau. 


\section{Runx2 siRNA-Wirkung auf pHOB:}

\begin{tabular}{|c|c|c|c|c|c|}
\hline $\begin{array}{l}\text { Gencode } \\
\text { (NCBI) }\end{array}$ & Gen & $\begin{array}{l}\text { Oligonukleotid } \\
\text { (Agilent ID) }\end{array}$ & $\begin{array}{l}\text { fold change } \\
\left(\log 2^{x}\right)\end{array}$ & $\begin{array}{l}\text { „X-fache" } \\
\text { Expression }\end{array}$ & p-Wert \\
\hline \multirow{3}{*}{ Runx2* } & \multirow{3}{*}{$\begin{array}{l}\text { Runt-related } \\
\text { transcription } \\
\text { factor } 2\end{array}$} & 1 (A_32_P148058) & 0.00 & 0-fach $(\leftrightarrow)$ & 0.990 \\
\hline & & 2 (A_24_P69267) & $-0,70$ & 1,62-fach $\downarrow$ & 0.720 \\
\hline & & 3 (A_32_P161762) & -2.30 & 4,92-fach $\downarrow \downarrow$ & 0.006 \\
\hline
\end{tabular}

Tab. 33: Die Tabelle zeigt die mRNA-Expression von Runx2 in mit siRNA+ im Vergleich zu mit siRNAtransfizierten pHOB. Dargestellt sind Gencode (nach NCBI), Genname (nach NCBI), detektierende Oligonukleotide (Agilent ID), mRNA Expression in fold change (Verhältnis der Genexpression im Bezug auf die Vergleichsexpression zur Basis 2 logarithmiert) und „-fachen“ - Wert sowie p-Wert. Mit $p<0.05$ signifikante Ergebnisse sind mit * gekennzeichnet.

Der Microarray zeigt eine $2^{2,3}$-fache Suppression der Runx2 mRNA in mit Runx2 siRNA transfizierten Zellen, was in etwa einer Runx2-Suppression von $80 \%$ entspricht.

Diese Suppression wurde von dem Microarrayoligonukleotid mit der Agilent ID A_32_P161762 detektiert. Die Zielsequenz dieses Oligonukleotids ist in Nähe des 5 '-Endes des Runx2-Transkripts lokalisiert (s. Abb. 24), sodass dieses Oligonukleotid als besonders aussagekräftig gilt, was sich aus der Tatasache begründet, dass unspezifische Degradation von zu messender RNA naturgemäß vom 3'-Ende beginnt.

Dieser Runx2-knock-down hatte einen signifikanten Expessionsunterschied von 214 weiteren Transkripten um mindestens 50\% zur Folge. 


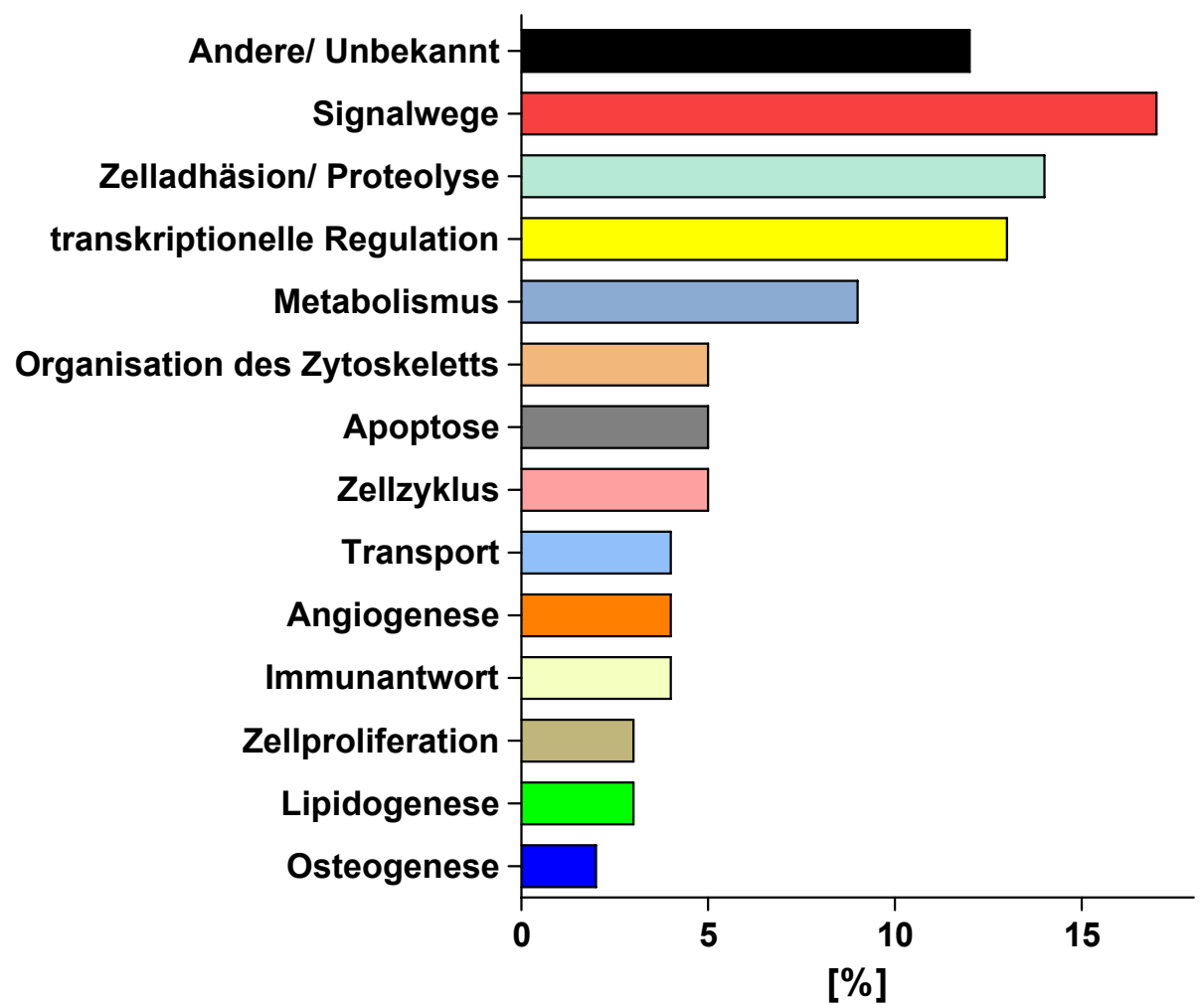

Abb. 26: Die Darstellung zeigt die Ontologie des Runx2-knock-downs durch Runx2 siRNA im Vergleich zu scrambled siRNA in pHOB. Dargestellt ist, wieviel Prozent der 215 vom knock-down modulierten Gene an welchen Zellprozessen beteiligt sind.

Von den 215 vom Runx2-knock-down signifikant beeinflussten Genen konnten, aufgrund des heutigen Kenntnisstandes, 88\% differenzierten Zellprozessen zugeordnet werden (s. Abb. 26). 17\% dieser Gene sind z.B. bekannt dafür in Zellsignalprozessen eine Rolle zu spielen. Weitere $13 \%$ sind in transkriptionelle Regulationsvorgänge involviert. Erwartungsgemäß sind $2 \%$ der modulierten Gene an osteogenetischen Vorgängen beteiligt. Interessanterweise zeigt der Microarray, dass $3 \%$ der beeinflussten Gene im Fettstoffwechsel und $4 \%$ in der Angiogenese eine Rolle spielen. Dies ist exemplarisch im Folgenden im Detail dargestellt. 


\section{Runx2-knock-down: Auswirkungen auf Knochen- und Knorpelstoffwechsel}

\begin{tabular}{|c|c|c|c|c|}
\hline $\begin{array}{l}\text { Gencode } \\
\text { (NCBI) }\end{array}$ & Genname & $\begin{array}{l}\text { fold change } \\
\left(\log 2^{x}\right)\end{array}$ & $\begin{array}{l}\text { „X-fache" } \\
\text { Expression }\end{array}$ & p-Wert \\
\hline Runx2* & $\begin{array}{l}\text { Runt-related } \\
\text { transcription factor } 2\end{array}$ & -2.30 & 4,92 - fach $\downarrow \downarrow$ & 0.006 \\
\hline SP7 & Osterix & -0.07 & $1,04-$ fach $\leftrightarrow$ & 0.97 \\
\hline CTNNB1* & beta 1 Catenin & -1.40 & 2,64 - fach $\downarrow$ & 0.01 \\
\hline BGLAP* & Osteocalcin & -1.00 & 2,00 - fach $\downarrow$ & 0.02 \\
\hline SPP1* & Osteopontin & -0.93 & 1,91 - fach $\downarrow$ & 0.02 \\
\hline IBSP & Bone Sialoprotein & -0.78 & $1,72-$ fach $\downarrow$ & 0.07 \\
\hline AP & $\begin{array}{l}\text { Alkalische } \\
\text { Phosphatase }\end{array}$ & +0.07 & $1,05-$ fach $\leftrightarrow$ & 0.87 \\
\hline COL1A1 & Typ-I-Kollagen & -0.69 & 1,61 - fach $\downarrow$ & 0.06 \\
\hline RANKL & $\begin{array}{l}\text { tumor necrosis factor } \\
\text { (ligand) superfamily, } \\
\text { member } 11\end{array}$ & -1.30 & 2,46 - fach $\downarrow$ & 0.18 \\
\hline COL10A1* & Typ-X-Kollagen & -2.30 & 4,92 - fach $\downarrow \downarrow$ & 0.002 \\
\hline ITGA6* & Integrin alpha 6 & -2.00 & 4.00 - fach $\downarrow \downarrow$ & 0.002 \\
\hline
\end{tabular}

Tab. 34: Die Tabelle zeigt die mRNA-Expression verschiedener zum Knochen- und Knorpelstoffwechsel zugehöriger Gene in mit Runx2 siRNA im Vergleich zu mit scrambled siRNA transfizierten pHOB. Dargestellt sind Gencode (nach NCBI), Genname (nach NCBI), mRNA Expression in fold change (Verhältnis der Genexpression im Bezug auf die Vergleichsexpression zur Basis 2 logarithmiert) und „-fachen“ - Wert sowie p-Wert. Mit $p<0.05$ signifikante Ergebnisse sind mit * gekennzeichnet.

Der Runx2-knock-down bewirkte eine signifikante Suppression der in den Knochenstoffwechsel involvierten Gene Osteocalcin, Osteopontin und Integrin alpha 6. $\beta 1$ Catenin, als wichtiger Transkriptionsfaktor in der Osteoblastendifferenzierung beschrieben, zeigte ebenfalls eine signifikante 2,64-fache Abnahme, was einer Suppression von ca. $62 \%$ entspricht. Das für hypertrophe Chondrozyten charakteristische Gen Typ-XKollagen wies eine Suppression von über $80 \%\left(2^{2.3}\right.$-fache) auf.

Die osteoblastentypischen, Gene Bone Sialoprotein und Typ-I-Kollagen sowie der essentielle Faktor für die Osteoklastendifferenzierung tumor necrosis factor (ligand) superfamily, member 11 (RANKL) wiesen zwar eine Tendenz zur Abnahme auf, dies verfehlte allerdings Signifikanzniveau.

Die knochenspezifische AP sowie der osteoblastäre Transkriptionsfaktor Osterix waren in ihrem Expressionsmuster vom Runx2-knock-down unbeeinflusst. 


\section{Runx2-knock-down: Auswirkungen auf Wnt-Signalweg}

\begin{tabular}{|c|c|c|c|c|}
\hline $\begin{array}{l}\text { Gencode } \\
\text { (NCBI) }\end{array}$ & Genname & $\begin{array}{l}\text { fold change } \\
\left(\log 2^{x}\right)\end{array}$ & $\begin{array}{l}\text { „X-fache }{ }^{\prime \prime} \\
\text { Expression }\end{array}$ & p-Wert \\
\hline CTNNB1* & beta 1 Catenin & -1.40 & 2,64 - fach $\downarrow$ & 0.01 \\
\hline SFRP1* & $\begin{array}{l}\text { secreted frizzled-related } \\
\text { protein-1 }\end{array}$ & -1.80 & $3,49-$ fach $\downarrow$ & 0.005 \\
\hline FZD6* & frizzled homolog 6 & -1.00 & 2,00 - fach $\downarrow$ & 0.04 \\
\hline WIF1* & WNT inhibitory factor 1 & -1.20 & 2,30 - fach $\downarrow$ & 0.04 \\
\hline GDF8* & Myostatin & -1.50 & 2,83 - fach $\downarrow$ & 0.04 \\
\hline
\end{tabular}

Tab. 35: Die Tabelle zeigt die mRNA-Expression verschiedener zum Wnt-Signalweg zugehöriger Gene in mit Runx2 siRNA im Vergleich zu mit scrambled siRNA transfizierten pHOB. Dargestellt sind Gencode (nach NCBI), Genname (nach NCBI), mRNA Expression in fold change (Verhältnis der Genexpression im Bezug auf die Vergleichsexpression zur Basis 2 logarithmiert) und „-fachen“ - Wert sowie p-Wert. Mit $p<0.05$ signifikante Ergebnisse sind mit * gekennzeichnet.

Interessant stellten sich die Auswirkungen des Runx2-knock-downs auf verschiedene Gene des Wnt-Signalweges dar. Im Microarray zeigte sich eine Suppression der prominenten Vertreter dieses Signaltransduktionsweges $\beta 1$ Catenin und secreted frizzled-related protein1 (SFRP1) um ca. $62 \%$ und ca. $71 \%$.

Weitere Mitglieder des WnT Signalweges wie frizzled homolog 6 (FZD6), WNT inhibitory factor 1 (WIF1) und Myostatin (GDF8) zeigten ebenso eine signifikante Suppression auf vergleichbarem Suppressionsniveau.

\section{Runx2-knock-down: Auswirkungen auf Fettstoffwechsel}

\begin{tabular}{|c|c|c|c|c|}
\hline $\begin{array}{c}\text { Gencode } \\
\text { (NCBI) }\end{array}$ & Genname & $\begin{array}{l}\text { fold change } \\
\left(\log 2^{x}\right)\end{array}$ & $\begin{array}{l}\text { „X-fache" } \\
\text { Expression }\end{array}$ & p-Wert \\
\hline PPARy2 & $\begin{array}{l}\text { Peroxisome } \\
\text { proliferator-activated } \\
\text { receptor } \mathrm{y} 2\end{array}$ & +0.50 & $1,41-$ fach $\uparrow$ & 0.11 \\
\hline HSD11B1* & $\begin{array}{l}\text { 11ß-hydroxysteroid } \\
\text { Dehydrogenase } 1\end{array}$ & -2.20 & 4,59 - fach $\downarrow \downarrow$ & 0.002 \\
\hline HSD11B2 & $\begin{array}{l}11 \beta \text {-hydroxysteroid } \\
\text { Dehydrogenase } 2\end{array}$ & -0.05 & $1,04-$ fach $\leftrightarrow$ & 0.96 \\
\hline PMP2* & $\begin{array}{l}\text { peripheral myelin } \\
\text { protein } 2\end{array}$ & -5.90 & 59,71 - fach $\downarrow \downarrow \downarrow$ & 0,0002 \\
\hline$S C D^{*}$ & $\begin{array}{l}\text { Stearoyl-CoA } \\
\text { Desaturase }\end{array}$ & -1.20 & $2,30-$ fach $\downarrow$ & 0,01 \\
\hline ACSL3* & $\begin{array}{l}\text { acyl-CoA synthetase } \\
\text { long-chain family } \\
\text { member } 3\end{array}$ & -1.00 & 2,00 - fach $\downarrow$ & 0.04 \\
\hline
\end{tabular}

Tab. 36: Die Tabelle zeigt die mRNA-Expression verschiedener zum Fettstoffwechsel zugehöriger Gene in mit Runx2 siRNA im Vergleich zu mit scrambled siRNA transfizierten pHOB. Dargestellt sind Gencode (nach NCBI), Genname (nach NCBI), mRNA Expression in fold change (Verhältnis der Genexpression im Bezug auf die 
Vergleichsexpression zur Basis 2 logarithmiert) und „-fachen“ - Wert sowie p-Wert. Mit $p<0.05$ signifikante Ergebnisse sind mit * gekennzeichnet.

Der Runx2-knock-down hatte überdies multiple Effekte auf den Fettstoffwechsel. Es konnte z.B. gezeigt werden, dass peripheral myelin protein 2 (PMP2), ein Gen für ein fettsäurenbindendes Protein, welches bisher lediglich in myelinproduzierenden Zellen des peripheren Nerven gefunden worden ist, durch den knock-down 59,71-fach supprimiert worden ist, was ca. einer 98-prozentigen Suppression dieses Gens entspricht.

Weitere signifikante Suppressionen konnten für die im Fettstoffwechsel involvierten Transkripte der Enzyme Stearoyl-CoA Desaturase (SCD) und acyl-CoA synthetase longchain family member 3 (ACSL3) detektiert werden.

Interessanterweise konnte für die 11ß-hydroxysteroid-Dehydrogenase-1 (HSD11B1) ebenfalls eine signifikante Suppression um ca. 82\% durch den Runx2-knock-down festgestellt werden. Dieses Enzym katalysiert vornehmlich die Konversion von inaktivem Metaboliten des Kortisons in das aktive Kortisol, bzw. deren reverse Reaktion. Für den Typ 2 dieses Enzyms, welches vornehmlich die reverse Reaktion katalysiert, konnte keine signifikante Modulation im Genxpressionsmuster detektiert werden.

Erwähnenswert ist weiterhin die tendentielle 1,41-fache Induktion des Schlüsseltranskriptionsfaktors der Adipogenese PPAR $\gamma 2$.

\section{Realtime-PCR-Bestätigungsanalysen des Runx2-knock-downs}

Zur Bestätigung der im Microarray gesehenen Folgen des Runx2-knock-downs durch die konventionelle Runx2 siRNA im Vergleich zu der scrambled siRNA wurden Realtime-PCR Analysen derselben RNA angefertigt.

Aufgrund begrenzenter cDNA-Menge wurden lediglich ausgesuchte Gene untersucht.

In der orientierenden Realtime-PCR zeigte sich die mRNA-Expression von Col10A1 um $85 \%$, von SFRP1 um $75 \%$ und von HSD11B1 um $82 \%$ supprimiert. Die Expression von $\beta 1$ Catenin zeigte sich in dieser Analyse nicht so stark supprimiert (tendentielle Suppression um 8\%), wie es im Microarray der Fall gewesen ist.

Auch wenn diese Ergebnisse Signifikanzniveau verfehlten, bestätigten sie doch tendentiell die in dem Microarray gesehenen Effekte des Runx2-knock-downs. 


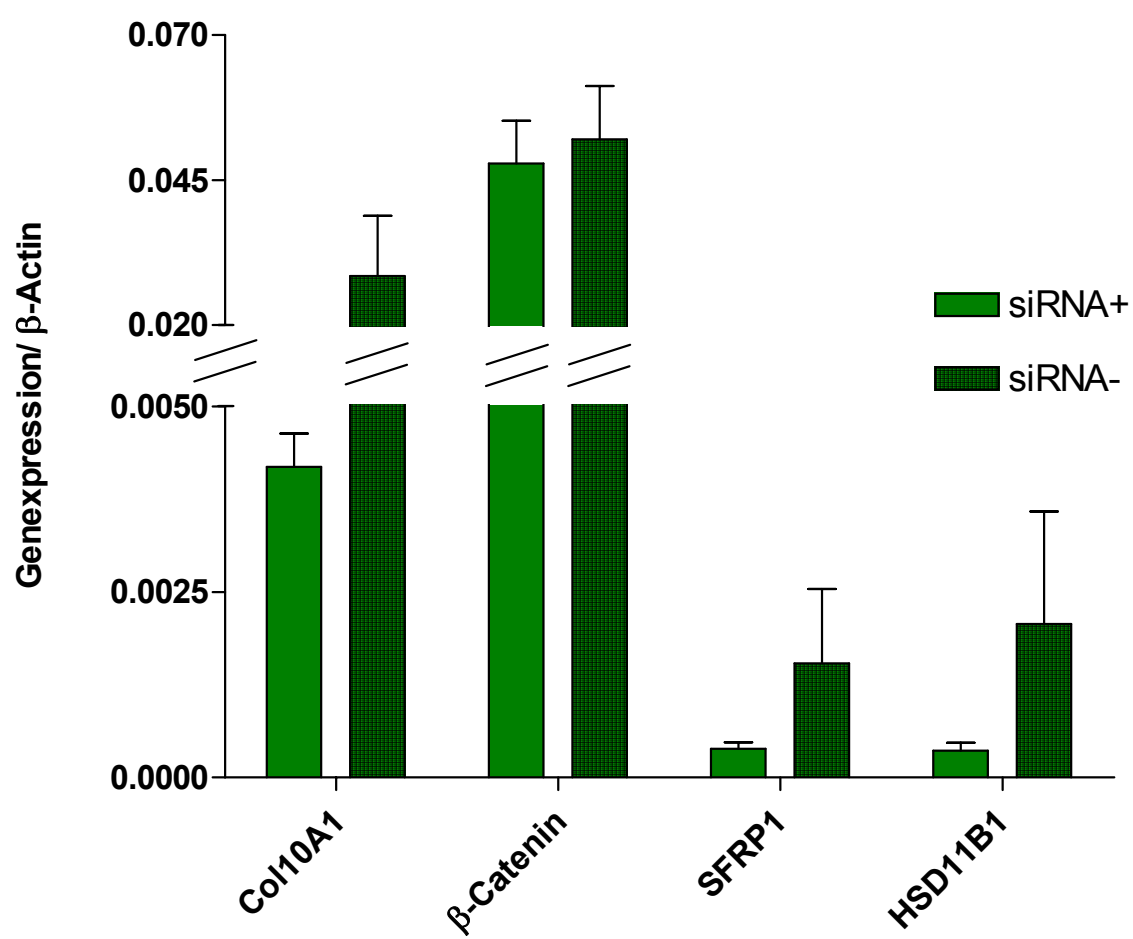

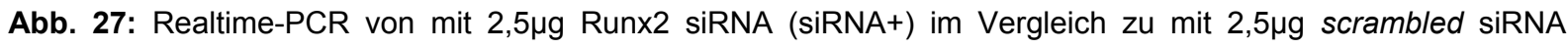
(siRNA-) transfizierten pHOB. Die Darstellung zeigt die Mittelwerte $(n=3)$ und die entsprechenden Standardfehler (SEM). Signifikante Ergebnisse sind mit einem Stern $\left({ }^{*}\right)$ gekennzeichnet

\subsection{Stabile Transfektion pHOB:}

Obwohl in dem vorangegangenen Microarray (Versuch 3.4.9) eine hohe Runx2siRNA-Expression in pHOB-Zellen durch das siRNA-exprimierende-Plasmid pSi+ gezeigt werden konnte, konnte keine Suppression der Runx2 mRNA nachgewiesen werden. Aus der Vorstellung heraus, dass dies z.B. an Kompensationsmechanismen der transfizierten Zellen liegt, stellte sich die Frage, ob einzelne mit pSi+ transfizierte, zu dieser Kompensation aber nicht befähigte Zellen, nicht doch einen Runx2-knock-down aufweisen.

Zur Klärung dieser Frage wurde in diesem Experiment versucht eine mit pSi+ stabil transfizierte klonale Zelllinie auf Basis einer pHOB-Kultur zu etablieren.

Mittels Nukleofektion wurden hierfür $5^{*} 10^{5}$ Zellen einer pHOB-Kultur mit 2,5 $\mathrm{\mu g}$ linearisierten pSi+ transfiziert. Zur Etablierung einer direkten Kontrollzelllinie wurden $5^{\star} 10^{5}$ Zellen

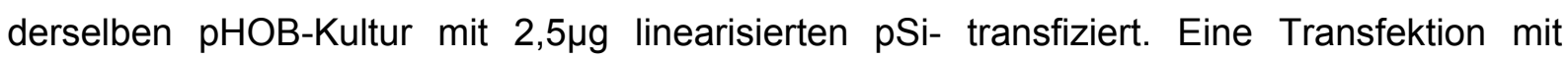
GFP-Plasmid diente zur Kontrolle der Transfektionsrate. Zur Kontrolle der regelrechten Puromycinselektion und der Vitalität der Zellen wurde je ein Kontrollansatz mit $\mathrm{H}_{2} \mathrm{O}$ transfiziert.

Bei einer Transfektionsrate von ca. 90\% (Daten nicht gezeigt) wurden posttransfektionell nach 24-stündiger Inkubation pro Ansatz 1.) ca. 150-300 Zellen/Well in eine 96-Well-Platte, 
2.) ca. 3000 Zellen/Well in eine 24 -Well-Platte 3.) ca 50.000 Zellen/Well in eine 6-Well-Platte gegeben.

Zur Selektion erfolgreich mit pSi transfizierter Zellen wurden nach weiterer 48-stündiger Kultivierung die Zellen (außer den Zellen zur Vitalitätskontrolle) mit 500ng/ml Puromycin (s. Versuch 3.2) antibiotisch behandelt.
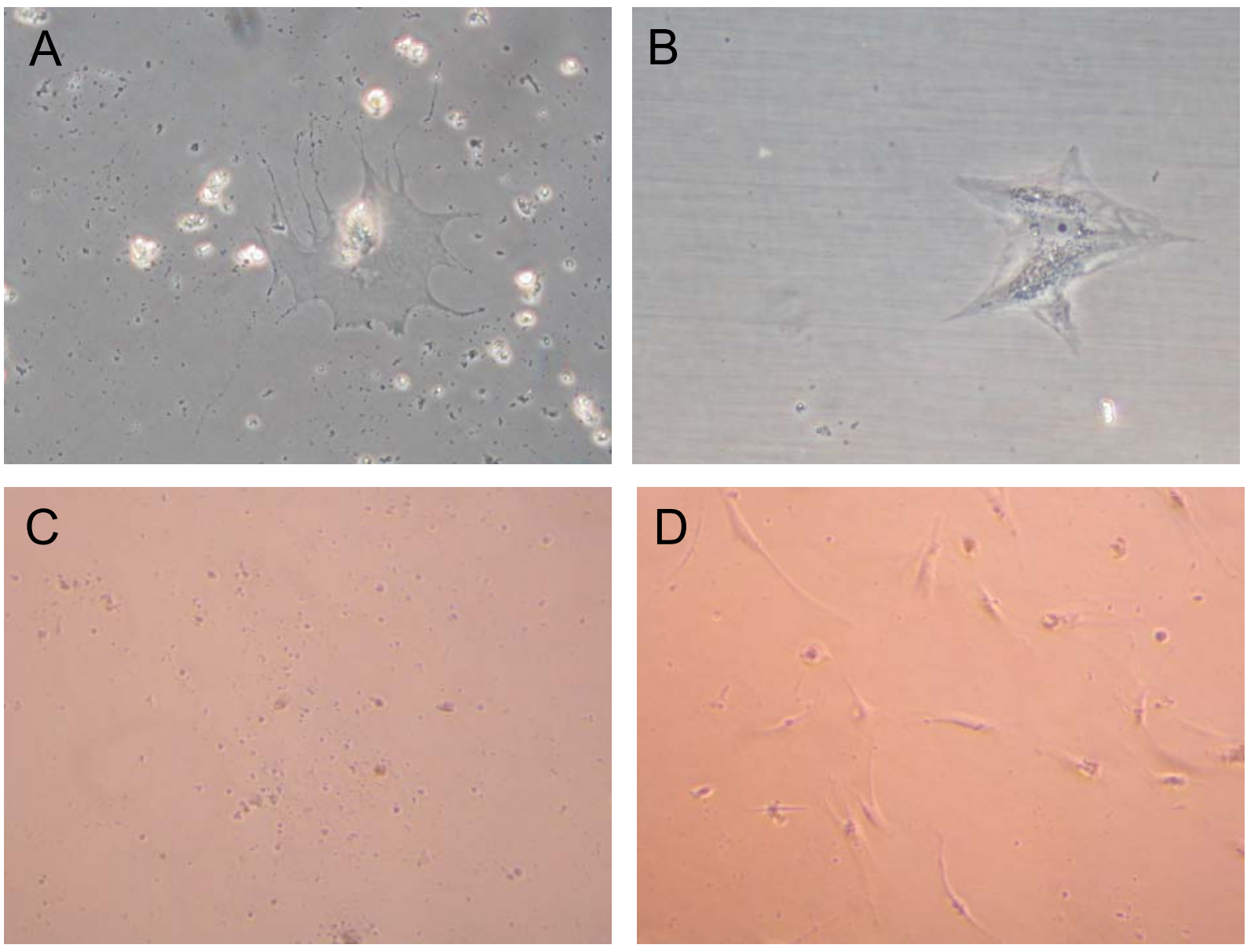

Abb. 28: lichtmikroskopische Bilder von A) einer mit pSi+ transfizierten und mit Puromycin selektierten pHOBZelle; B) einer mit pSi- transfizierten und mit Puromycin selektierten pHOB Zelle; C) Zelldetritus von mit $\mathrm{H}_{2} \mathrm{O}$ transfizierten und mit Puromycin behandelten pHOB-Zellen; D) vitalen mit $\mathrm{H}_{2} \mathrm{O}$ transfizierten ohne Puromycin kultivierten pHOB-Zellen

Nach 144-stündiger Antibiose zeigte die 100-prozentige Mortalität der mit $\mathrm{H}_{2} \mathrm{O}$ transfizierten und anschließend mit Puromycin behandelten Kontrollzellen eine erfolgreiche Puromycinselektion an (s. Abb. 28 C).

Die erfolgreich selektierten mit pSi transfizierten Zellen der 24-Well-Platten wurden abtrypsiniert und so auf 48-Well-Platten verteilt, dass maximal 2-3 Zellen in ein Well gegeben wurde.

Die selektierten Zellen der 96-Well-Platte wurden nicht weiter verteilt, da nach der Antibiose max. 2-3 Zellen/Well überlebt hatten. Die selektierten Zellen der 6-Well-Platte wurden zur Reserve weiter kultiviert. So wurden die mit pSi transfizierten Zellen mit Medium zusätzlich 
$500 \mathrm{ng} / \mathrm{ml}$ Puromycin und die Zellen zur Vitalitätskontrolle mit Medium ohne Puromycin kultiviert und dreimal wöchentlich mikroskopisch kontrolliert.

Während die Zellen zur Vitalitätskontrolle proliferierten (s. Abb. 28 D) und nach zwei Monaten passagiert werden mussten, zeigten die pSi-transfizierten-Zellen keine Proliferation (s. Abb. 28 A und B).

Um einen Proliferationsanreiz zu schaffen, wurden die Zellen zwischenzeitlich mit Medium kultiviert, welches von anderen pHOB-Kulturen abgeschöpft wurde und damit Stoffwechselprodukte und lokale Wachstumsfaktoren dieser Kultur enthielt.

Weder diese Behandlung noch eine Kultivierung ohne Antibiose förderten jedoch eine Proliferation.

So konnten zwar mit pSi transfizierte Zellen für 4 Monate in Kultur gehalten werden, aufgrund fehlender Proliferation der Einzelzellen gelang es jedoch nicht, eine klonale Zelllinie zu etablieren. 


\section{Diskussion}

Der Transkriptionsfaktor Runx2 ist als essentiell für die mesenchymale Kondensation im Rahmen einer adäquaten Ossifikation und für die Differenzierung mesenchymaler Vorläuferzellen in Osteoblasten beschrieben (Komori et al. 1997). Viele Studien in murinen Zellmodellen konnten die Wichtigkeit von Runx2 für die frühe Osteoblastendifferenzierung zeigen, belegten aber auch einen inhibitorischen Effekt von Runx2 für die terminale Osteoblastendifferenzierung (Byers et al. 2002, Ducy et al. 1997, Geoffroy et al. 2002, Liu W et al. 2001). Während zudem eine essentielle Rolle für die terminale Chondrozytendifferenzierung in hypertrophe Chondrozyten gezeigt worden ist, scheint Runx2 gleichsam die Adipogenese zu verhindern (Enomoto et al. 2004, Inada et al. 1999, Takeda et al. 2001).

Allerdings konnten bisher nur wenige detaillierte Studien zeigen, ob diese Erkenntnisse auch im humanen Organismus Gültigkeit besitzen.

So konnte Giesen 2007 in primären humanen Zellen (pHOB) durch einen transienten Runx2knock-down mittels siRNA einen regulierenden Effekt von Runx2 auf die osteoblastentypischen Gene Osteocalcin, alkalische Phophatase und Osterix nachweisen und damit die wichtige Rolle von Runx2 in der Osteogenese auch in humanen Modellen belegen (Giesen 2007).

Intention der vorliegenden Arbeit war es, die Effekte eines Runx2-knock-downs in humanen osteoblastären Zellen näher zu analysieren:

1. Um einen langfristigen knock-down von Runx2 in pHOB-Zellen zu erreichen, sollten diese stabil mit dem siRNA-Expressionsvektor pSilencer transfiziert werden. Mit diesem Vektor konnten z.B. eine aus humanen epithelialen Nierenzellen abstammende Zelllinie erfolgreich gensupprimierend stabil transfiziert werden (Maranchie et Zhan 2005).

2. Die Auswirkungen eines transienten Runx2-knock-downs in pHOB-Zellen sollten mit einer RNA-Microarray-Studie detailliert untersucht werden.

zu 1. Nach der Etablierung eines effizienten Transfektionssystems für die Transfektion von Plasmiden in pHOB konnte eine ausgeprägte Syntheseleistung von shRNA durch pSilencer in pHOB-Zellen mittels RNA-Microarray gemessen werden. Diese shRNA führte jedoch nicht zu einem Runx2-knock-down. Es gelang weiterhin, pHOB-Zellen über 4 Monate stabil mit pSilencer zu transfizieren, aufgrund fehlender Proliferation konnte allerdings keine klonale Zelllinie etabliert werden. 
zu 2. Der durch siRNA vermittelte knock-down von Runx2 zeigte im Microarray einen signifikanten Einfluss auf die Genexpression von 215 verschiedenen Genen. Insbesondere konnte hier eine Rolle von Runx2 in der Regulation osteoblastentypischer Gene, wie z.B. Osteocalcin, belegt werden. Diese Beobachtung konnte bereits in Versuchen an anderern humanen Zellen reproduziert werden (Kishiya et al. 2008)

Interessant stellte sich die Auswirkung dieses knock-downs auf Gene des canonical-WntSignalweges dar, von denen angenommen wird, dass sie in der Regulation der Osteoblastendifferenzierung maßgeblich beteiligt sind (Marie 2008).

Einen Einfluss des knock-downs auf die Expression von Genen, die dem adipogenen Stoffwechsel zugerechnet werden, konnte weiterhin gezeigt werden. So zeigte z.B. die 11ß-hydroxysteroid-Dehydrogenase-1 (HSD11B1) überraschender Weise eine 82- prozentige Gensuppression, was zuvor noch nicht beschrieben worden ist.

\subsection{Plasmidstudien}

Giesen konnte 2007 erfolgreich die Transfektion von Runx2 siRNA in pHOB etablieren. Hierfür benutzte er die Lipofektion mit Lipoefctamine 2000 als Transfektionssystem und konnte dadurch Gensuppressionsraten von über 90\% erreichen (Giesen 2007). Da auch mit dieser Methode bereits erfolgreich Zellinien mit einem siRNA-Expressionsvektor stabil transfiziert werden konnten, wurde in der vorliegenden Arbeit zunächst der Versuch gemacht, diese Methode ebenfalls für die Transfektion von Plasmiden (pSilencer) in pHOB zu etablieren (Yu et al. 2002).

Eine Kontrolle der Transfektionsrate dieses Transfektionssystems mittels GFP-Plasmid zeigte jedoch lediglich eine Synthese von GFP in max. 5\% der transfizierten pHOB-Zellen. Dies lässt darauf schließen, dass entweder eine vergleichbar geringe Anzahl von Zellen das GFP-Plasmid aufgenommen hat oder dass in das Zytosol entlassene Plasmide, die nicht bis in den Nukleus vorgedrungen sind, inaktiv waren und deshalb nicht transkribiert werden konnten (Lin et al. 2003).

Ursächlich für diese, im Vergleich zu der von Giesen 2007 erreichten, sehr niedrigen Transfektionsrate könnte zum einen sein, dass die Zellen lediglich einmal statt wie von Giesen zweimal transfiziert worden sind. Zum anderen könnte aber auch die unterschiedliche Morphologie der entstandenen Lipoplexe als Erklärung dienen. Sowohl die Größe der zu transfizierenden Nukleinsäure als auch der Nukleinsäure/Lipid-Quotient haben einen maßgeblichen Einfluss auf die Höhe der Transfektionsrate (Dass und Su 2000, Kreiss et al. 1999). Demnach könnten die unterschiedliche Größe der von Giesen transfizierten siRNAs (ca.22bp) und der von uns transfizierten Plasmide (ca. 5000bp) sowie die 
unterschiedlichen Nukleinsäure/Lipid-Quotienten der entstandenen Lipoplexe zu diesen stark differierenden Transfektionsraten geführt haben.

Eine Kontrolle der regelrechten pSilencer-Wirkung schien allerdings bei diesen niedrigen Transfektionsraten schwierig, da für die Genexpressionsanalyse mittels Realtime-PCR die RNA aller und damit auch der nicht erfolgreich transfizierten Zellen zugrunde gezogen wurde. Dementsprechend wäre selbst ein maximaler knock-down in den $5 \%$ erfolgreich transfizierten Zellen durch die regelrechte Genexpression in den 95\% nicht erfolgreich transfizierten Zellen maskiert worden.

Durch längere Inkubationszeiten der Zellen mit dem Transfektionsmedium wurde deshalb versucht die Transfektionseffizienz zu verbessern. Hohe Zytotoxizität des Transfektionsansatzes (93\% geringere isolierte RNA-Menge im Vergleich zu mit Wasser transfizierten Zellen bei 24-stündiger Inkubation mit dem Transfektionsmedium) ließ allerdings eine längere Inkubation als in dem vorerst verwendeten Transfektionsprotokoll nicht zu, auch wenn hierdurch höhere Transfektionsraten von bis zu 30\% erreicht werden konnten.

Auch eine zweimalige Transfektion mit den Plasmiden wie von Giesen angewandt verbot sich aufgrund der hohen Zytotoxzität des Versuchsansatzes (Giesen 2007). So konnten bereits nach einer Transfektion nur 6-15\% der RNA-Menge aufgearbeitet werden, die untransfizierte Zellen im selben Versuch erbrachten.

Diese erhöhte Zytotoxizität bei der Transfektion von Plasmiden im Vergleich zu der Transfektion von den strukturell sehr viel kleineren siRNAs, ließe sich ebenfalls durch die Heterogenität der Komplexmorphologie erklären. So zeigen Lipoplexe mit hohem Nukleinsäure/Lipid-Quotienten deutlich höhere zytotoxische Auswirkungen auf die transfizierten Zellen, was sich z.B. in einem Zellschrumpfen, einer verringerten Mitoserate und einer Vakuolisierung des Zytoplasmas auswirkt (Dass et al. 2002, Lappalainen et al. 1994).

Auf der Suche nach einem effizienteren Transfektionssystem wurde als nächstes die Mikroporation von PeqLab getestet. Die Mikroporation wurde kürzlich als sehr effiziente und schonende Methode zur Transfektion von Plasmiden in menschliche Stammzellen beschrieben. Wang et al. konnten eine Transfektionsrate von über 76,1\% erreichen und Zellen über mehr als zwei Wochen stabil transfizieren (Wang et al 2009). Bei der orientierenden Testung dieser Methode in pHOB-Zellen wurde allerdings lediglich eine Transfektionsrate von ca. $10 \%$ erreicht. Eine Erklärung für diese große Differenz in den Transfektionsraten bietet die Tatsache, dass Wang optimale Konditionen für die Transfektion in die Stammzellen ausgetestet hat, was in der vorliegenden Arbeit aufgrund der niedrigen Basistransfektionsrate und der dagegen sehr hohen Transfektionsraten bei der Testung der Nukleofektion als weiteres Transfektionssystem unterblieben ist. 
Die Nukleofektion wurde schon mehrfach erfolgreich in der Transfektion von siRNAs und siRNA-Expressionsvektoren in verschiedenen Zellen eingesetzt (Michel et al. 2005, Reinhold und Naski 2007). Mit dieser modifizierten Methode der Elektroporation konnten GFP-Transfektionsraten in $\mathrm{pHOB}$ von $>90 \%$ erreicht werden, sodass hiermit ein überaus effizientes Transfektionssystem zur Transfektion von Plasmiden in pHOB etabliert worden war. Erst kürzlich konnte ein Vorteil der Nukleofektion gegenüber der Lipofektion hinsichtlich der Transfektionsrate gezeigt werden, was sich auch mit unseren Ergebnissen deckt (Cao et al. 2009). Die hohe Zytotoxizität (transfizierte Zellen erbrachten $20 \%$ der RNA im Vergleich zu nicht transfizierten Zellen) machte allerdings einen hohen Zellmaterialaufwand erforderlich, was aber aufgrund der hohen Transfektionsrate toleriert wurde. Im Unterschied zu der Lipofektion wirkte sich diese Zytotoxizität allerdings auf alle transfizierten Zellen gleichsam aus, egal ob diese mit Wasser, siRNA oder Plasmiden transfiziert worden waren. Dies deutet auf eine globale Zytotoxizität des Systems auf die transfizierten Zellen hin, die nicht von z.B. der Größe der zu transfizierenden Nukleinsäure abhängig ist und bei der Elektroporation ein bekanntes Problem darstellt. Diese Zytotoxizität ist abhängig von der Zellgröße, der Temperatur, der Manipulation an den Zellen nach der Transfektion und der Beschaffenheit der Elektroden sowie des Transfektionsmediums (Gehl 2003).

Auch mit dieser potenten Transfektionsmethode konnte aber kein Runx2-knock-down in transienten Transfektionsversuchen von pSilencer in HOS 58-Zellen und in pHOB-Zellen beobachtet werden. Auch eine Antibiotikaselektion transfizierter Zellen durch Puromycin konnte eine Runx2-Gensuppression nicht demaskieren.

Während sich in HOS 58-Zellen kein Unterschied in der Genexpression von Runx2 gegenüber Kontrollzellen zeigte, konnte in pHOB-Zellen sogar mehrfach eine bis zu 21-fache Induktion von Runx2 durch Realtime-PCR gemessen werden.

Im angefertigten Microarray zeigte sich dann eine 32-fache Induktion des Runx2 Transkriptes durch pSilencer. Während Bone Sialoprotein ebenfalls eine 2,8-fache Induktion zeigte, stellte sich die Genxpression von Osteopontin als 1,45-fach vermindert und die Genxpression von Osteocalcin, Alkalische Phosphatase und Typ-I-Kollagen als nicht verändert dar.

Eine Überexpression von Runx2 konnten in osteoblastären und nichtosteoblastären Zellen erhöhte Expressionen von Osteocalcin, Bone Sialoprotein und der alkalischen Phosphatase bewirken. Widersprüchliche Daten bestehen über die Expression von Typ-I-Kollagen und Osteopontin, die sich in Überexpressionversuchen als nicht beeinflusst oder suppremiert darstellten (Byers et al. 2002, Byers und Garcia 2004, Ducy et al. 1997, Pan et al. 2009, Zhang $X$ et al. 2006).

Demnach könnte die im Microarray gemessene Induktion von Bone Sialoprotein für eine tatsächliche Induktion von Runx2 durch pSilencer sprechen. Während die Suppression von 
Osteopontin und die gleich bleibende Expression von Typ-I-Kollagen im Microarray aufgrund widersprüchlicher Daten in der Literatur nicht grundsätzlich gegen diese These sprechen, stellen die gleichbleibende Expressionen des Osteocalcins und der alkalischen Phosphatase allerdings ein Gegenargument gegen eine mögliche Induktion von Runx2 durch pSilencer dar. Allerdings wurden für die zitierten Daten differierend zu der vorliegen Studie murine Zellmodelle untersucht (Byers et al. 2002, Byers et Garcia 2004, Ducy et al. 1997).

Dass durch pSi+ durchaus eine Induktion des Zielgens bewirkt werden kann, deckt sich mit den Erfahrungen des Herstellers. Demnach kompensieren viele Zellen die Suppression eines für sie wichtigen Genes im Sinne eines Rescue-Effektes durch andere Mechanismen, bzw. dämmen die Synthese der siRNA ein.

Bei näherer Betrachtung des im Microarray detektierenden Oligonukleotids 2 fiel aber auf, dass diese Sequenz komplementär zu einem Abschnitt in der von pSi+ zu synthetisierenden shRNA war (s. Abb. 25).

pSi+ synthetisiert normalerweise in einer transfizierten Zelle als Vorläufermolekül eine shRNA, ein doppelstränges 17 mer mit einem hairpin loop, einem $3^{`}-2$ nt-Nukleotidüberhang und einem poly-A-Schwanz.

Eine Duplikation dieser pSi(+)-Produkte wäre durch deren poly-Schwanz in den RT-PCRReaktionen innerhalb der Microarrayversuchsanordnung durchaus möglich, sodass eine direkte Detektion der von pSi+ synthetisierten shRNA oder eines prozessierten Folgemoleküls im Microarray möglich und sehr wahrscheilnlich ist.

pSi+ wäre demnach in pHOB-Zellen in der Lage, hohe shRNA-Syntheseraten zu erreichen. Weshalb diese shRNA-Moleküle keine gensupprimierende Wirkung zeigen ist aber nicht klar. Eine Erklärung hierfür könnte der oben beschriebene Rescue-Effekt sein. Die Zelle könnte demnach durch Kompensationsmechanismen in der Lage sein, die Expression von Runx2 trotz funktionell aktiver siRNA auszugleichen oder sogar zu erhöhen. Solch eine Induktion konnte tendentiell in 3 verschiedenen Versuchen beobachtet werden. Im vorliegenden Microarray konnte zwar kein direkter Hinweis auf eine Induktion erbracht werden, die direkte Messung der synthetisierten shRNA könnte aber eine wahrhaftige Induktion der Runx2 mRNA maskieren.

pSilencer synthetisiert normalerweise aufgrund seines Pol-II-Promotors ein shRNATranskript, welches der physiologischen pri-microRNA entspricht (Stegmeier et al. 2005). Dieses wird durch ihren 3'-2nt-Nukleotidüberhang von der zelleigenen RNase III Drosha erkannt und prozessiert (Bartel 2004, Dickins et al. 2005, Lee $Y$ et al. 2003). Das korrekt prozessierte shRNA-Produkt wird durch den Transporter Exportin 5 spezifisch ins Zytoplasma geschleust (Yi et al 2003). Hier schneidet Dicer, eine weitere zelleigene RNase III, die hairpin-Struktur aus der shRNA und entlässt ein funktionell aktives siRNA-Molekül, 
welches schließlich in den gensupprimierenden RISC (RNA-induced silencing complex) inkorporiert wird (Bartel 2004, Bernstein et al. 2001).

Wie in der vorliegenden Arbeit gezeigt, synthetisiert pSilencer in unserem Fall ein shRNATranskript, welches keinen knock-down bewirkt, obwohl die Transfektion exogen synthetisierter siRNA mit der gleichen Sequenz diesen erreicht (Giesen 2007). Für den erfolgreichen knock-down muss aber auch die exogen synthetisierte siRNA durch Dicer prozessiert und in RISC inkorporiert werden. Dieses legt nahe, dass die Aktivität von Dicer und RISC in pHOB-Zellen nicht beeinträchtigt ist. In Folge dessen könnte aber die Ursache für die fehlende Aktivität der durch pSilencer synthetisierten shRNA in dem Schritt der Prozessierung durch Drosha oder dem Kernexport durch Exportin 5 liegen.

In Tumorzellen konnte eine stark verminderte Aktivität von Drosha nachgewiesen werden, wodurch in diesen Zellen keine RNA-Interferenz durch miRNAs oder shRNAs möglich war (Thomson et al. 2006). Drosha enthält zudem ein RNA-bindenes Protein mit dem Namen Pasha, welches die pri-miRNA bzw. die shRNA bindet und die Prozessierung initiert. Eine verminderte Expression dieses Proteins führt nachweislich zu einer verminderten RNAInterferenz (Denli et al. 2004).

Auch Exportin 5 konnte 2005 als limitierender Faktor für die RNA-Interferenz identifziert werden (Yi et al. 2005).

Demnach könnte eine verminderte Expression oder Aktivität von sowohl Drosha, Pasha als auch Exportin 5 in pHOB-Zellen verantwortlich für die Inaktivität der von pSilencer synthetisierten shRNA sein.

Sowohl Drosha als auch Dicer erkennen überdies einen 3-'2nt-Nukleotidüberhang an dem zu prozessierenden Molekül (Bartel 2004, Rose et al. 2005).

Demnach könnte auch eine fehlerhafte Transkription dieses Überhanges in der shRNA Synthese durch pSilencer zu einer verminderten Prozessierung durch Drosha und Dicer und damit zu einer verminderten RNA-Interferenz führen, was als weitere Ursache für unsere Beobachtungen möglich wäre. 


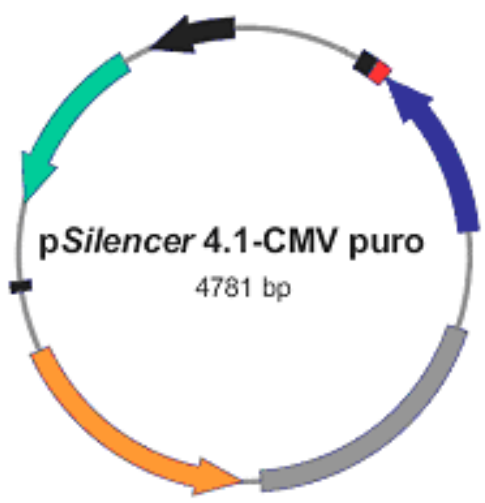

Transfektion

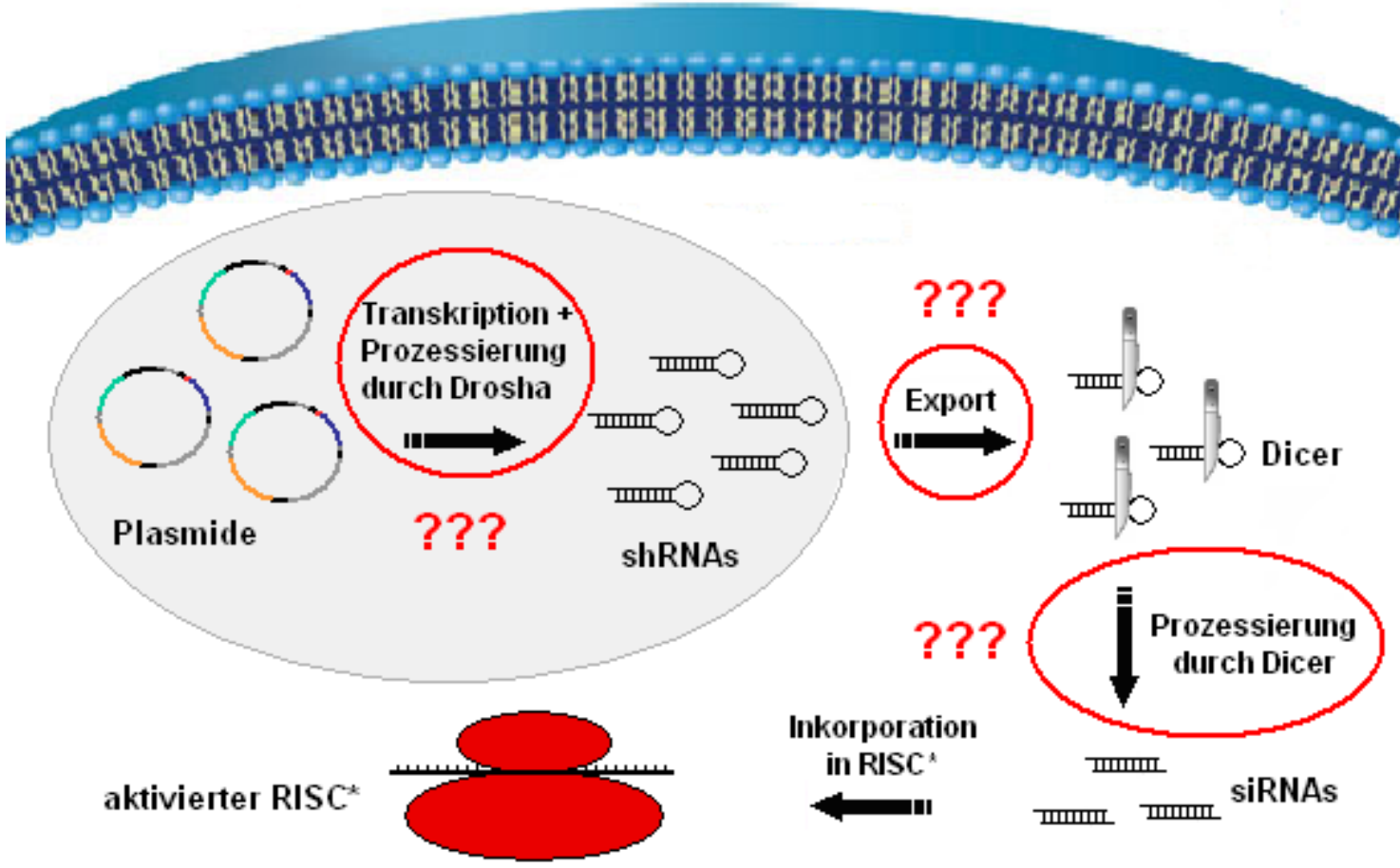

Abb. 29: Darstellung der Plasmidwirkung von pSi in transfizierten Zielzellen und mögliche Fehlerquellen. In Zielzellen transfizierte pSi werden im Nukleus transkribiert und durch Drosha in shRNAs prozessiert. Diese werden aus dem Nukleus durch Exportin 5 ins Zytoplasma exportiert, hier durch Dicer in siRNAs prozessiert und schließlich in den gensupprimierenden RISC* (RNA-induced silencing comlpex) inkorporiert (modifiziert nach http://www.ambion.com/techlib/prot/fm_5775.pdf, Stand 05.06.2011).

In weiteren Studien könnte die Etablierung eines Vektorsystems auf Basis eines Pol-IIIPromotors für einen langfristigen knock-down in $\mathrm{pHOB}$ vorteilhaft sein, da dessen Transkripte nicht die Prozessierung durch Drosha benötigen um RNA-Interferenz zu induzieren (Scheer et Eder 2007). Falls der Grund für die Inaktivität der synthetisierten shRNA allerdings im Kernexport durch Exportin 5 liegt, würde auch dieser Ansatz keinen Vorteil bringen. 


\section{2 siRNA-Studien}

Im Microarray konnte ein Runx2-knock-down in pHOB-Zellen durch Runx2 siRNA nachgewiesen werden. Mit Runx2 siRNA transfizierte Zellen zeigten im Microarray eine Gensuppression um $>80 \%$ (in der Realtime-PCR $87 \%$ ) im Vergleich zu mit scrambled siRNA transfizierten Zellen.

Giesen hatte 2007 mit der gleichen siRNA eine Runx2-Gensuppression von >90\% in pHOBZellen erreicht (Giesen 2007). Weshalb Giesen eine höhere Suppressionsrate erreichen konnte, könnte in mehreren Faktoren begründet sein. Giesen transfizierte die pHOB-Zellen zweimalig mittels Lipofektion. In der vorliegenden Arbeit wurden die pHOB-Zellen allerdings nur einmalig mittels Nukleofektion transfiziert. Obwohl erst kürzlich gezeigt worden ist, dass die Nukleofektion der Lipofektion in der Transfektionsrate überlegen ist, könnten bereits diese Unterschiede in der Transfektionsmethode zu den differierenden Suppressionsraten geführt haben (Cao et al. 2009).

Während der Microarray eine Runx2-Gensuppressionrate von $>80 \%$ gemessen hat, hat die Realtime-PCR-Analyse derselben Proben eine Runx2-Gensuppressionsrate von $87 \%$ erbracht. Demnach zeigt sich schon bei der Genexpressionsmessung derselben Proben mit zwei verschieden Methoden eine Differenz von 7\%. Giesen hat die semiquantitative PCR als weitere Methode zur Genexpressionsmessung angewandt und mit ihr eine Runx2Gensuppression von $>90 \%$ beobachtet. Demnach könnte auch eine methodenabhängige Ungenauigkeit in der Genxpressionmessung unterschiedliche Gensuppressionsraten vortäuschen, obwohl sie evtl. auf gleichem Niveau liegen.

Da jede pHOB-Kultur als primäres Zellmodell von einem Spender abstammt, wäre es weiterhin möglich, dass die unterschiedlichen Gensuppressionsraten auf unterschiedliche Eigenschaften der transfizierten Zellen, bedingt durch unterschiedliche Spender, zurückzuführen sind. So konnte z.B. Siggelkow eine Abhängigkeit der Zelleigenschaften primärer Zellen von den entsprechen Spendern zeigen (Siggelkow et al. 1998).

Weshalb Giesen höhere Gensuppressionsraten erreichen konnte, bleibt also ungeklärt (Giesen 2007). Weitere vergleichende Runx2-siRNA-Transfektionsversuche mit den beiden verwendeten Transfektionssystemen könnten hier weitere Erkenntnisse bringen.

Von dem Runx2-knock-down waren 215 Transkripte signifikant in ihrer Expression verändert. Dies betraf vor allem osteogene, chondrogene, adipogene, sowie Gene des canonical WntSignalweges.

Das Transkript des osteoblastenspezifischen Gens Osteocalcin z.B. zeigte sich durch den Runx2-knock-down um 50\% (2-fach) supprimiert. Auch Giesen konnte einen hemmenden Einfluss des Runx2-knock-downs auf Osteocalcin um mehr als 50\% beobachten (Giesen 2007). In einer weiteren Microarraystudie konnte dieses entsprechend gezeigt werden 
(Kishiya et al. 2008). Dieses lässt vermuten, dass Runx2 als Induktor für die Osteocalcinexpression wirkt. Überexpressionsversuche von Runx2 belegen diese These (Byers et Garcia 2004). Tatsächlich konnte in der Promotorregion des Osteocalcins im Mausmodell ein osteoblastenspezifisches cis-acting-Element gefunden werden, an welches Runx2 binden und seine transkriptionelle Aktivität als Induktor entfalten kann (Ducy et al. 1997, Geoffroy et al. 1995).

Auch das osteblastentypische Gen Osteopontin zeigte sich durch den Runx2-knock-down moduliert. Eine 1,91-fache Suppression legte demnach auch für Osteopontin eine Regulierung durch Runx2 nahe. Runx2-knock-out-Mäuse zeigen keine Osteopontinexpression (Komori et al. 1997). Nachdem schon 1997 eine Bindungsstelle für Runx2 in der Promotorregion von Osteopontin identifiziert worden ist, konnten mehrere Arbeitsgruppen in murinen Zellmodellen eine induzierende Aktivität für Runx2 zeigen (Ducy et al. 1997, Pan et al. 2009, Zhang $X$ et al. 2006). Folglich ist die hier beobachtete Osteopontinsuppression sehr wahrscheinlich eine Folge der verminderten Runx2-Expression und der damit verminderten induktorischen Aktivität.

Die Transkripte der beiden Kollagene Typ I und X zeigten ebenfalls eine Suppression durch den Runx2-knock-down. Während das Transkript des osteoblastentypischen Kollagens Typ I ledigliche eine knapp nicht signifikante $(p=0.06)$ tendentielle Suppression zeigte, war das Transkript des Kollagens Typ X signifikant fast 5-fach supprimiert. Auch für diese beiden Gene konnte eine Promotoraktivität und Regulierung durch Runx2 gezeigt werden (Ducy et al. 1997, Higashikawa et al. 2009, Zheng et al. 2003). Überexpressionsversuche sowie Suppressionsversuche belegen dies (Byers et Garcia 2004, Inada et al. 1999, Kishiya et al. 2008, Pan et al. 2009). Runx2 hat für die terminale Chondrozytendifferenzierung in hypertrophe Chondrozyten essentielle Bedeutung (Enomoto et al. 2004, Inada et al. 1999). Warum das für hypertrophe Chondrozyten charakteristische Kollagen Typ X aber so stark in pHOB durch Runx2 reguliert zu sein scheint, ist ungewiss und bedarf weiterer Forschung.

Bone Sialoprotein zeigte sich 1,72-fach tendentiell supprimiert, diese Beobachtung verfehlte allerdings knapp Signifikanzniveau $(p=0.07)$. Dennoch könnte vermutet werden, dass auch die tendentielle Suppression durch einen regulierenden Effekt durch den Runx2-knock-down verursacht worden ist, da auch für das Gen von Bone Sialoprotein eine regulierende Aktivität durch Runx2 gezeigt werden konnte (Ducy et al. 1997, Roca et al. 2005). Auch Runx2 Suppressionsversuche anderer Arbeitsgruppen konnten einen regulierenden Effekt von Runx2 auf Bone Sialoprotein belegen (Vaes et al. 2006).

Integrin alpha 6 wurde durch den Runx2-knock-down stark moduliert und wies eine 4-fache Suppression auf. Für eine direkte Regulierung von Integrin alpha 6 durch Runx2 gibt es in der gegenwärtigen Literatur aber keinen Hinweis. 
Als Mitglied der Integrin alpha Familie ist es in die Zelladhäsion und in Signalprozessen involviert. Integrin-alpha-knock-out-Mäuse sterben postnatal und weisen Charakteristika der Epidermolysis bullosa auf. Eine Überexpression dieses Proteins konnte in hoch tumorgenen Mamma-Karzinomzellen gefunden werden (Cariata et al. 2008). In einer Microarraystudie konnte Integrin alpha 6 in Zellen aus einem intestinalen Adenom als potentielles Ziel der regulierenden Aktivität des Wnt-Signalweges mit $\beta$-Catenin identifiziert werden (Segditsas et al. 2008). Interessanterweise konnte für ein weiteres Mitglied der Integrin alpha Familie eine Regulation durch Bone Sialoprotein in Mamma- und Prostatakarzinomzellen nachgewiesen werden (Gordon et al. 2009). Ob demnach die Suppression von Integrin alpha 6 ein direktes Produkt der verminderten Aktivität von Runx2 ist oder aber im Zusammenhang mit der verminderten Genexpression von $\beta$-Catenin oder sogar Bone Sialoprotein steht, ist zum jetzigen Zeitpunkt jedoch lediglich spekulativ.

Das osteoblastentypische Gen RANKL, welches für die Regulation der Osteoklastentätigkeit von großer Bedeutung ist, zeigte zwar die Tendenz zur 1,6-fachen Suppression, dies verfehlte jedoch deutlich Signifikanzniveau ( $p=0.18)$ (Enomoto et al. 2003).

Auch die alkalische Phosphatase zeigte sich überraschenderweise vom knock-down unbeeinflusst. Obwohl in mehreren Runx2 Suppressionsstudien und Runx2 Überexpressionsversuchen eine Regulierung durch Runx2 nachgewiesen werden konnte, konnte in unseren Studien keine Modulation der Genexpression gezeigt werden (Byers et al 2002, Byers und Garcia 2004, Kishya et al. 2008, Pan et al. 2009, Vaes et al. 2006, Zhang X et al. 2006). Giesen konnte eine Suppression der alkalischen Phosphatase auch in pHOB durch einen Runx2-knock-down zeigen (Giesen 2007). In Runx2-knock-out-Mäusen konnte zwar weder Osteocalcin noch Osteopontin aber eine schwache Expression der alkalischen Phosphatase nachgewiesen werden (Komori et al. 1997). Demnach ist Runx2 zwar an der Regulation der alkalischen Phosphatase beteiligt, aber nicht als alleiniger Faktor hierfür essentiell. Eventuell war der 80-prozentige knock-down von Runx2 aber auch quantitativ für eine deutliche Suppression der alkalischen Phosphatase nicht ausreichend.

Zusammenfassend konnte also eine regulierende Tätigkeit von Runx2 in pHOB-Zellen auf die osteoblastentypischen Gene Osteocalcin und Osteopontin sowie mit großer Wahrscheinlichkeit auf Bone Sialoprotein und Typ-I-Kollagen belegt werden. Eine signifikante Beeinflussung des für die Osteblastendifferenzierung wichtigen Transkriptionsfaktors $\beta$-Catenin wird weiter unten dargelegt.

Allerdings sind weitere optimierte knock-down-Studien nötig, um die widersprüchlichen Daten über die Expression der alkalischen Phosphatase in pHOB zu klären.

Die deutliche regulative Tätigkeit von Runx2 auf das Kollagen Typ $X$ bietet einen interessanten Ansatzpunkt für weitere Forschung über die Bedeutung dieses Kollagens in 
pHOB-Zellen. Besonders interessant wäre hier die Frage, ob diese Kollagen-X-Suppression tatsächlich auch auf Proteinexpressionsebene nachzuweisen ist.

Auch die Rolle des Integrins alpha 6 in pHOB Zellen und der Osteoblastendifferenzierung bedarf grundlegender Forschung, da zu diesem Zeitpunkt hierüber keine gesicherte Aussage gemacht werden kann.

Die Auswirkungen des Runx2-knock-downs auf Osterix und $\beta$-Catenin, zwei weitere zentrale Transkriptionsfaktoren der Osteoblastendifferenzierung, bieten einen Anhalt für die Eingruppierung der untersuchten Zellen in ein frühes Differenzierungsstadium.

Während $\beta$-Catenin siginifikant 2,64-fach supprimiert gemessen wurde, blieb Osterix durch den Runx2-knock-down unbeeinflusst. Bei näherer Betrachtung der Microarrayrohdaten (Daten nicht gezeigt) fiel sogar auf, dass die Osterix Expression sowohl in den mit Runx2 siRNA transfizierten als auch in den mit scrambled siRNA transfizierten Zellen nahe der Nachweisgrenze lag.

$\beta$-Catenin wirkt nach heutiger Datenlage vermutlich als Transkriptionsfaktor in frühen unreifen Stadien der Osteoblastendifferenzierung (Day et al. 2005, Hill et al. 2005, Hu et al. 2005). Demnach entfaltet $\beta$-Catenin seine transkriptionelle Tätigkeít bei den Differenzierungschritten von der mesenchymalen Stammzelle zum Präosteoblasten und vom Präosteoblasten zum unreifen Osteoblasten (Komori 2010).

Osterix dagegen scheint in der Osteoblastendifferenzierung erstmalig chronologisch später aktiv als Runx2 und $\beta$-Catenin zu sein (Nakashima et al. 2002). So ist Osterix gemeinsam mit $\beta$-Catenin und Runx2 entscheidend für die Differenzierung vom Präosteoblasten zum unreifen Osteoblasten (Komori 2010, Marie 2008).

Die Regulation von $\beta$-Catenin durch den Runx2-knock-down lässt auf eine aktive Rolle von $\beta$-Catenin im Zusammenspiel der Transkriptionsfaktoren in diesen Zellen schließen. Osterix dagegen zeigte sich durch den Runx2-knock-down nicht reguliert und lag in seiner Expression an der Nachweisgrenze. Demnach scheint Osterix in den untersuchten Zellen als Transkriptionsfaktor nicht aktiv zu sein. Nimmt man ein frühes Differenzierungsstadium der untersuchten Zellen an, würde dies eine Erklärung für die gefundene Konstellation dieser Transkriptionsfaktoren bieten. Demnach entsprechen die untersuchten pHOB-Zellen einem Differenzierungsstadium der Osteoblastendifferenzierung, welches dem Präosteoblasten oder dem unreiferer Zellen entspricht, da hier Runx2 und $\beta$-Catenin nicht aber Osterix aktiv sind (s. Abb. 30). 


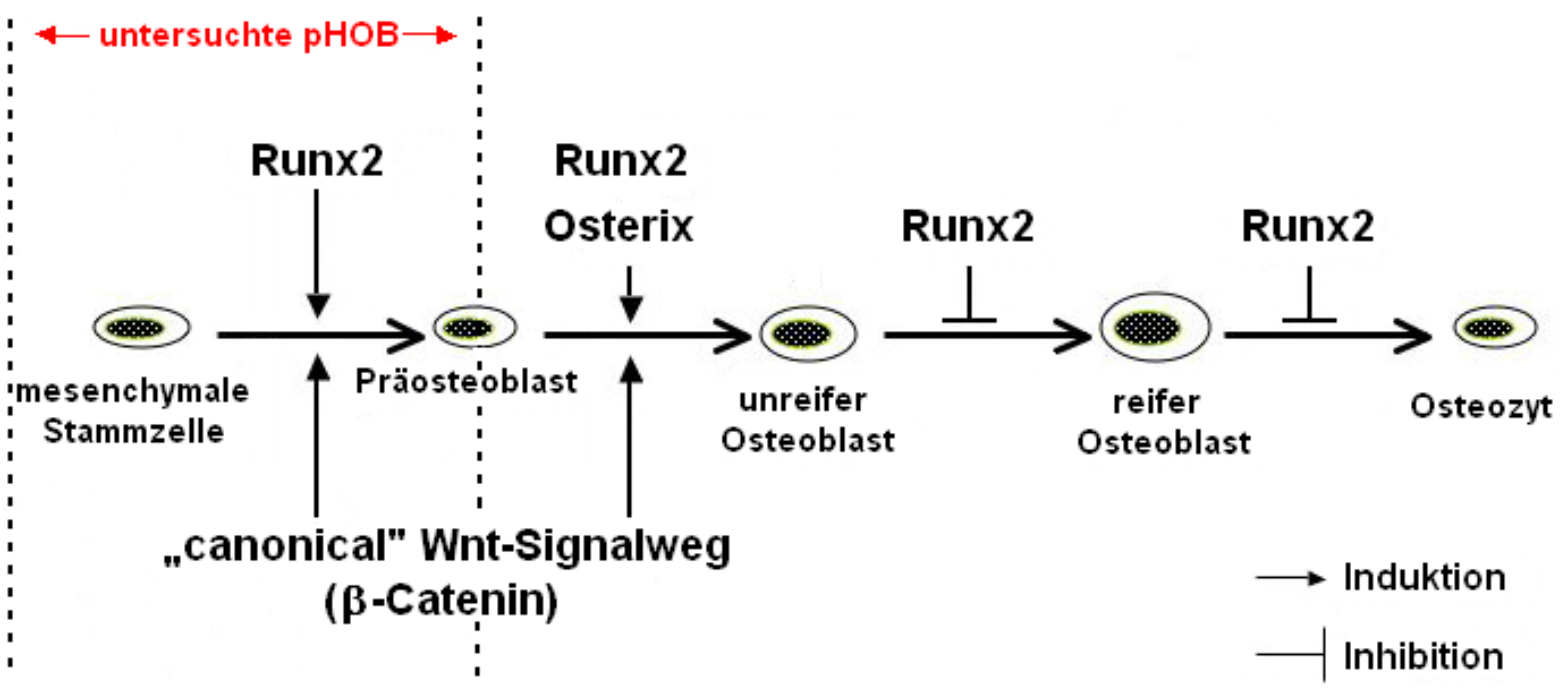

Abb. 30: Transkriptionsfaktorinteraktionen in der Osteoblastendifferenzierung. Dargestellt sind die Interaktionen von Runx2, Osterix und $\beta$-Catenin bei der Osteoblastendifferenzierung, sowie die Einordnung der hier untersuchten Zellen in dieses Differenzierungsschema (modifiziert nach Komori 2010, S. 46).

Im Mausmodell konnte für das zentrale Element des canonical Wnt-Signalweges $\beta$-Catenin eine induzierende Wirkung auf die Promotoraktivität von Runx2 gezeigt werden (Gaur et al. 2005). Eine erhöhte Aktivität von $\beta$-Catenin resultierte so in erhöhten Runx2-Spiegeln und stimulierte die Knochenbildung. Dies konnte gleichsam für den terminalen Differenzierungsschritt der murinen Chondrozyten in hypertrophe Chondrozyten belegt werden. Auch hier zeigten sich erhöhte Runx2-Spiegel und resultierend erhöhte KollagenTyp-X-Expressionen durch die vermehrte Aktivität von $\beta$-Catenin (Dong et al. 2006).

Auch in $\beta$-Catenin-knock-out-Experimenten wurde eine deutlich verminderte Expression von Runx2 gesehen, was die Wichtigkeit von $\beta$-Catenin für die Expression von Runx2 weiter beweist (Day et al. 2005).

Die von uns beobachtete Suppression der $\beta$-Catenin Expression durch den Runx2knock-down könnte allerdings auch ein Hinweis auf eine dazu inverse, bisher nicht beschriebene, Interaktion dieser beiden Transkriptionsfaktoren sein. Demnach ist eine induzierende Wirkung von Runx2 auch auf $\beta$-Catenin in pHOB möglich, sodass eine verminderterte Runx2-Aktivität in einer verminderten Expression von $\beta$-Catenin resultiert. Überexpressionsstudien von Runx2 in pHOB könnten weitere wertvolle Informationen in der Frage bringen, ob Runx2 die Expression von $\beta$-Catenin induziert und so durch einen zusätzlichen, bisher nicht bekannten, Mechanismus auf die Osteoblastendifferenzierung einwirkt. Zudem müsste dieser Zusammenhang natürlich auch auf Proteinexpressionsebene untersucht werden, um die Frage zu beantworten, ob die auf die Expression der mRNA gesehenen Effekte sich auch phänotypisch auswirken. 
In diesem Zusammenhang besonders interessant stellten sich zudem die Auswirkung des Runx2-knock-downs auf andere Mitglieder bzw. in Verbindung stehende Moleküle des canonical Wnt-Signalweges dar. SFRP1 (secreted frizzled-related protein-1), FZD6 (frizzled homolog 6), WIF1 (WNT inhibitory factor 1) und GDF8 (Myostatin) stellten sich ca. 2- bis 3,5fach supprimiert dar.

Das im Knochenstoffwechsel prominente SFRP1 ist ein extrazelluläres Protein, welches an transmembranöse frizzled-Proteine bindet, inhibitorisch auf den canonical Wnt-Signalweg wirkt und somit zur einer verminderten Knochenbildung führt (Bodine et al. 2004, Marie 2008). Knock-out-Experimente von SFRP1 zeigten eine erhöhte Knochenneubildungsrate, eine vermehrte Osteoblastenaktivität, Osteoblastendifferenzierung und Osteoblastenproliferation. In diesen Mäusen wurde zudem eine verstärkte Aktivität von Runx2 gemessen (Gaur et al. 2005). Als Effektorprotein für den geschilderten Sachverhalt wurde $\beta$-Catenin identifizert. In diesen knock-out-Mäusen konnte überdies durch vermehrte Aktivität von phosphorylierten $\beta$-Catenin eine erhöhte Kalzifizierung in hypertrophen Chondrozyten mit erhöhter Runx2- und Kollagen-Typ-X-Expression gemessen werden (Gaur et al. 2006). So korreliert SFRP1 invers mit dem phosphorylierten $\beta$-Catenin (Gaur et al. 2006).

Warum der Runx2-knock-down in pHOB allerdings zu einer fast 3,5-fachen Suppression von SFRP1 führt ist aus heutiger Datenlage lediglich spekulativ. Denkbar wäre aber hier, dass Runx2 physiologischerweise in $\mathrm{pHOB}$ eine induzierende Wirkung auf die Expression von SFRP1 hat und diese in Folge des knock-downs reduziert wird. Solch eine Induktion könnte z.B. als negativer Rückkopplungsmechanismus von Runx2 auf den canonical Wnt-Signalweg und damit auf die eigene Expression und die Osteoblastendifferenzierung verstanden werden. Eventuell ist die verminderte Expression von SFRP1 aber auch Ausdruck eines kompensatorischen Mechanismus der pHOB-Zellen auf die verminderte Aktivität von $\beta$-Catenin, da aus einer verminderten SFRP1 Expression eine erhöhte $\beta$-Catenin Aktivität resultiert.

Die oben beschriebenen Daten zu SFRP1 wurden zudem im murinen Zellmodell beobachtet, während die Beobachtungen dieser Arbeit am humanen Zellmodell vorgenommen worden sind, sodass eventuelle Widersprüche dieser Tatsache geschuldet sein könnten. Entsprechende Daten für die Interaktion von Runx2 und SFRP1 im humanen Modell sind in der gegenwärtigen Literatur jedoch nicht zu finden.

WIF1 bindet an zytoplasmatische Wnt-Proteine und inhibiert hierüber den canonical WntSignalweg und hat so im murinen Zellmodell eine inhibitorische Wirkung auf die Osteoblastogenese (Cho et al. 2009, Hsieh et al. 1999). Auch das transmembranöse FZD6 hat einen inhibitorischen Effekt auf den canonical Wnt-Signalweg und damit auf $\beta$-Catenin (Golan et al. 2004). Beide zeigten sich durch den Runx2-knock-down jedoch supprimiert, 
was wie die Suppression von SFRP1 durch eine verminderte transkriptionelle Aktivität von Runx2 oder als kompensatorischer Mechanismus der pHOB-Zellen auf die verminderte Aktivität von $\beta$-Catenin verstanden werden könnte. Um hierüber gesicherte Aussagen machen zu können ist die heutige Datenlage jedoch nicht ausreichend.

Das bis heute schlecht verstandene Myostatin dagegen scheint induzierend auf die Aktivität von $\beta$-Catenin zu wirken. In humanen mesenchymalen Stammzellen z.B. inhibiert es auch durch Interaktionen mit $\beta$-Catenin die Adipogenese (Guo et al. 2008). Dass der Runx2knock-down zu einer Suppression von diesem Molekül führt, könnte ein Indiz dafür sein, dass Myostatin durch Runx2 induziert wird und dass die nachgewiesene antiadipogenetische Wirkung von Runx2 zumindest zum Teil auch über dieses Molekül vermittelt sein könnte (Enomoto et al. 2004).

Der Runx2-knock-down zeigte zudem multiple Auswirkungen auf den Lipidstoffwechsel. Auch wenn prominente Vertreter der Adipogenese wie z.B. das CCAAT/enhancer-binding protein- $\alpha$ und das LPL unbeeinflusst vom Runx2-knock-down blieben stellten sich die dem Lipidstoffwechsel zugehörigen Gene PMP2, ACSL3 und SCD supprimiert dar. Interessanterweise zeigte sich auch die 11ß-Hydroxysteroid-Dehydrogenase-1 (HSD11B1) 2,2-fach supprimiert, während die Expression der 11 $\beta$-Hydroxysteroid-Dehydrogenase-2 (HSD11B2) unbeeinflusst blieb. Die Expression des Schlüsseltranskriptionsfaktors der Adipogenese PPAR zeigte sich tendentiell indes induziert, was allerdings kein Signifikanzniveau erreichte.

Giesen konnte durch einen Runx2-knock-down in pHOB eine Induktion von PPAR $\gamma$ und eine Erhöhung des adipogenen Markers LPL zeigen (Giesen 2007). Dieser Effekt erschien umso ausgeprägter je länger der knock-down aufrechterhalten wurde.

So wurde eine maximale Induktion von PPAR $\gamma$ (358\%) nach 8 Tagen knock-down erreicht, eine signifikation Induktion von LPL (302\%) konnte erstmalig nach erst 8 Tagen knock-down beobachtet werden. Bei der kürzeren knock-down-Dauer von 4 Tagen zeigte sich PPAR $\gamma$ in zwei Versuchen einmalig um 65\%, einmalig um 252\% erhöht, während LPL nicht signifikant erhöht war. Die in dieser Arbeit erlangten Ergebnisse wurden nach einem 4-tägigen knockdown erlangt. Die hier gesehene tendentielle Induktion von PPAR $\gamma$ könnte demnach auch hier als erstes Zeichen einer möglichen Induktion der Adipogenese gesehen werden. Um dieser Frage weiter nachzugehen, sind weitere knock-down-Versuche über einen längeren Zeitraum als 4 Tage (z.B. über 8 und 16 Tage) erforderlich.

Mit einer fast 60-fachen Suppression wurde das Gen PMP2 massiv von dem Runx2knock-down beeinflusst. Das Gen PMP2 kodiert für ein kleines basisches Protein, das peripheral myelin protein 2, welches Fettsäuren binden kann und v.a. im peripheren Nerven als Bestandteil des Myelins gefunden wird (Kursula 2008). Eine Verbindung zu dem 
osteoblastären Transkriptionsfaktor Runx2 wurde in der gegenwärtigen Literatur jedoch noch nicht beschrieben. Sollten weitere Runx2-Studien zu einem vergleichbaren Ergebnis wie die vorliegende Studie kommen, wäre weitere Forschung hinsichtlich der Verbindung dieser beiden Gene durchaus gerechtfertigt.

Auch die 2-fache Suppression von ACSL3 durch den Runx2-knock-down kann aus der heutigen Datenlage heraus nicht erklärt werden. ACSL3 ist ein Gen, welches für ein Isoenzym der langkettigen Fettsäuren-Coenzym-A-Ligase-Familie kodiert. Es verestert langkettige Fettsäuren und nimmt damit eine Schlüsselrolle in der Lipidbiosynthese und der Fettsäurendegradation ein (Fujino et al. 1996). Im Gehirn ist dieses Protein besonders stark exprimiert.

SCD zeigte sich 2,3-fach supprimiert. Das Gen SCD kodiert für die Stearoyl-CoADesaturase, welche eine Schlüsselreaktion in der Synthese von ungesättigten Fettsäuren katalysiert (Zhang $\mathrm{L}$ et al. 1999). Durch die Produktmenge übt SCD über die Zellmembranfluidität und die Signaltransduktion indirekt einen Einfluss auf die Zellwachstums- und die Zelldifferenzierungsregulation aus.

Ob und wie Runx2 einen Einfluss auf die Expression von SCD ausübt ist allerdings zu diesem Zeitpunkt völlig unklar.

Besonders interessant stellte sich allerdings die ca. 80-prozentige Suppression von HSD11B1 dar. Die 11ß-hydroxysteroid-Dehydrogenase-Typ-1 ist ein intrazelluläres Enzym, welches vorwiegend die Konversion des inaktiven Steroidhormons Kortison in den aktiven Metaboliten Kortisol katalysiert (Seckl und Walker 2001). HSD11B2, welches vorwiegend die inverse Reaktion, vom aktiven Kortisol ins inaktive Kortison katalysiert, wurde vom Runx2knock-down nicht beeinflusst (Odermatt et al. 2001). Demnach führt der Runx2-knock-downzu einer verminderten Expression und wahrscheinlich auch zu einer verminderten Aktivität von HSD11B1, während die Expression von HSD11B2 indes unverändert bleibt. Könnte demnach Runx2 physiologischerweise über diesen Weg einen Einfluss auf das Verhältnis von aktivem Kortisol zu inaktivem Kortison während der Osteoblastendifferenzierung haben? 2005 beobachteten Eijken et al. in einem humanen Osteoblastenzellmodell einen Switch in der Expression und Aktivität von HSD11B1 innerhalb der Osteoblastendifferenzierung, der zu einer erhöhten Kortisolkonzentration und damit zu einer autokrin verstärkten Osteoblastendifferenzierung führte (Eijken et al. 2005). Theoretisch könnte demnach Runx2 über einen bisher unbekannten Mechanismus an diesen Vorgängen innerhalb der Osteoblastendifferenzierung beteiligt sein und so die Kortisolproduktion durch Osteoblasten zumindest zum Teil regulieren. In welcher Weise Runx2 aber die Expression von HSD11B1 beeinflusst ist lediglich spekulativ. Eine direkte induzierende Wirkung von Runx2, vielleicht sogar über direkte Bindung des Transkriptionsfaktors an das HSD11B1-Gen, wäre aber durchaus denkbar. Jüngste Studien konnten in Adipozyten zeigen, dass HSD11B1 durch 
PPAR-Agonisten, wie z.B. Bezafibrate, in ihrer Expression supprimiert wird (Berthiaume et al. 2004, Nakano et al. 2006). Dementsprechend ließe sich auch spekulieren, dass die verminderte HSD11B1-Expression ein Produkt der im Microarray tendentiell vermehrten Expression des adipogenen Transkriptionsfaktors PPAR 2 sein könnte.

Weitere knock-down-Studien von Runx2 in humanen Osteoblasten evtl. sogar in Verbindung mit knock-down-Studien von PPARy2 könnten hier wertvolle neue Erkenntnisse bringen. 


\section{$5 \quad$ Zusammenfassung}

Die Osteoblastendifferenzierung ist ein hoch komplexer physiologischer Prozess, in dem der Transkriptionsfaktor Runx2 essentiell ist und über multiple Mechanismen seine Wirkung entfaltet. Auch wenn in den letzten Jahren und Jahrzehnten viel über seine Funktion erkannt worden ist, scheinen dennoch viele regulative Mechanismen unverstanden bzw. unerkannt zu sein.

Mit dem shRNA-Expressionsvektor p-Silencer wurde deshalb in dieser Arbeit der Versuch gemacht, in einer humanen Osteoblastenzellkultur ein stabiles knock-down-Modell zu generieren, welches helfen sollte, die physiologische Funktion von Runx2 umfassender analysieren zu können.

Die geringe Transfektionsrate von Plasmiden in unserem Zellmodell durch die Lipofektion erbrachte die Notwendigkeit, ein geeigneteres Transfektionssystem für die Transfektion dieser DNA-Komplexe zu etablieren. Dies gelang eindrucksvoll mit der Nukleofektion von Amaxa, mit der eine über 90-prozentige Transfektionsrate erreicht werden konnte.

Resultierend zeigte sich tatsächlich eine enorme Synthese von shRNA durch p-Silencer in unserem Zellmodell, was allerdings nicht in einer Suppression des Zielgens resultierte. Ungenügende oder fehlerhafte enzymatische Reaktionen in der Zielzelle für die shRNAProzessierung (Drosha, Pasha) bzw. der intrazelluläre Transport (Exportin5) scheinen am ehesten dafür verantwortlich zu sein, dass p-Silener in pHOB-Zellen keine Gensuppression von Runx2 erreicht. Mögliche weitere Lösungsansätze zur Etablierung eines stabilen knockdown-Zellsystems wurden aufgezeigt.

Der durch konventionelle siRNA bewirkte transiente knock-down von Runx2 in unserem Osteoblasten-Zellmodell hat viele interessante Einblicke in die Funktion dieses Transkriptionsfaktors erbracht.

Hierdurch konnte die regulative Tätigkeit von Runx2 auf die osteoblastentypischen Gene Osteocalcin, Osteopontin und sehr wahrscheinlich Kollagen Typ 1 und Bone Sialoprotein abermals aufgezeigt und bestätigt werden.

Die Beziehung von Runx2 zu dem Schlüsselmolekül des canionical Wnt-Signalweges $\beta$-Catenin hat sich in unseren Studien verstärkt in den Mittelpunkt des Interesses geschoben. Demnach könnte Runx2 eine direkt induzierende Wirkung auf $\beta$-Catenin haben, welches wiederum selbst als Effektorprotein des canonicals Wnt-Signalweges für die Osteoblastendifferenzierung regulative Funktion besitzt. Zudem konnten andere Faktoren des canonicals Wnt-Signalweges wie das secreted frizzled-related protein-1, das frizzled 
homolog 6 und der WNT inhibitory factor 1 als potentielle Regulatorproteine dieser hochkomplexen Regulationsvorgänge identifiziert werden.

Zudem zeigten unsere Studien, dass Runx2 regulativ auf die Expression der 11ßHydroxisteroid-Dehydrogenase-1 einwirkt. Hiermit könnte Runx2 auch beeinflussend auf hormonelle Regelkreisläufe agieren, indem es die Menge von in Osteoblasten synthetisiertem aktiven Kortisol zumindest zum Teil steuert. 


\section{$6 \quad$ Literaturverzeichnis}

Aguirre JI, Plotkin LI, Stewart SA, Weinstein RS, Parfitt AM, Manolagas SC, Bellido T (2006): Osteocyte apoptosis is induced by weightlessness in mice and precedes osteoclast recruitment and bone loss. J Bone Miner Res 21: 605-615

Arnold I, Caplan PD (2005): Mesenchymal stem cells: Cell-based reconstructive therapy in orthopedics. Tissue Eng 11: 1198-1211

Auf'm Kolk B, Hauschka PV, Schwartz ER (1985): Characterization of human bone cells in culture. Calcif Tissue Int 37: 228-235

Bartel DP (2004): MicroRNAs: genomics, biogenesis, mechanism and function. Cell 116: 281-297

Beck C, Morbach H, Stenzel M, Schneider P, Collmann H, Girschick G, Girschick HJ (2009): Hypophosphatasia. Klin Pädiatr 221: 219-226

Bennett CN, Longo KA, Wright WS, Suva LJ, Lane TF, Hankenson KD, MacDougald OA (2005): Regulation of osteoblastogenesis and bone mass by Wnt10b. Proc Natl Acad Sci USA 102: 3324-3329

Bennett CN, Ouyang $\mathrm{H}$, Ma $\mathrm{YL}$, Zeng $\mathrm{Q}$, Gerin I, Sousa KM, Lane TF, Krishnan V, Hankenson KD, MacDougald OA (2007): Wnt10b increases postnatal bone formation by enhancing Osteoblast differentation. J Bone Miner Res 22: 1924-1932

Beresford JN, Gallagher JA, Poser JW, Russel RG (1984): Production of osteocalcin by human bone cells in vitro. Effects of 1,25(OH)2D3, 24,25(OH)2D3, parathyroid hormone, and glucocorticoids. Metab Bone Dis Relat Res $\underline{5}$ : 229-234

Bernstein E, Caudy AA, Hammond SM, Hannon GJ (2001): Role for a bidentate ribonuclease in the initiation step of RNA interference. Nature $\underline{409}$ : 363-366

Berthiaume M, Sell H, Lalonde J,Ge'linas Y, Tchernof A, Richard D, Deshaies Y (2004): Actions of PPAR $\gamma$ agonism on adipose tissue remodeling, insulin sensitivity, and lipemia in absence of glucocorticoids. Am J Physiol Regul Integr Comp Physiol 287: 1116-1123

Bianco P, Robey GP (2000): Marrow stromal stem cells. J Clin Invest 105: 1663-1668

Bodine PVN, Komm BS (2006): Wnt signaling and osteoblastogenesis. Rev Endocr Metab Disord 7: 33-39

Bodine PVN, Zhao W, Kharode YP, Bex FJ, Lambert A-J, Goad MB, Gaur T, Stein GS, Lian JB, Komm BS (2004): The Wnt Antagonist Secreted Frizzled-Related Protein-1 Is a Negative Regulator of Trabecular Bone Formation in Adult Mice. Mol Endocrinol 18: 1222-1237 
Boskey AL, Posner AS (1984): Bone structure, composition, and mineralization. Orthop Clin North Am 15: 597-612

Boskey AL, Coleman R (2010): Aging an Bone. J Dent Res 89 (12): 1333 - 1348

Brummelkamp TR, Bernards R, Agami R (2002): A system for stable expression of short interfering RNAs in mammalian cells. Science 296: 550-553

Byers BA, Garcia AJ (2004): Exogenous Runx2 expression enhances in vitro osteoblastic differentiation and mineralization in primary bone marrow stromal cells. Tissue Eng 10:1623-1632.

Byers BA, Pavlath GK, Murphy TJ, Karsenty G, Garcia AJ (2002): Cell-type-depend upregulation of in vitro mineralization after overexpression of the osteoblast-spezific transcription factor Runx2/Cbfa1. J Bone Miner Res 17: 1931-1944

Cao F, Xie X, Gollan T, Zhao L, Narsinh K, Lee RJ, Wu JC (2009): Comparison of genetransfer efficiency in human embryonic stem cells. Mol Imaging Biol 12: 15-24

Cariata M, Naderi A, Brown JP, Smalley MJ, Pinder SE, Caldas C, Purushotham AD (2008): Alpha-6 Integrin is necessary fort he tumourigenicity of a stem-cell like subpopulation within the MCF7 breast cancer cell line. Int J Cancer 122: 298-304

Cho SW, Yang JY, Sun HJ, Jung JY, Her SJ, Cho HY, Choi HJ, Kim SW, ChinCS (2009): Wnt inhibitory factor (WIF)-1 inhibits osteoblastic differentation in mouse embryonic mesenchymal cells. Bone 44: 1069-1077

Chow JW, Wilson AJ, Chambers TJ, Fox SW (1998): Mechanical loading stimulates bone formation by reactivation of bone lining cells in 13-week old rats.

J Bone Miner Res 13: 1760-1767

Cullen BR (2005): RNAi the natural way. Nature Gen 37: 1163-1165

Dass CR (2000): Delivery of lipoplexes for genotherapy of solid tumours: role of vascular endothelial cells. J Pharm Pharmacol 52: 1301-1317

Dass CR (2004): Lipoplex-mediated delivery of nucleic acids: factors affecting in vivo transfection. J Mol Med 82: 579-591

Dass CR, Su T (2000): Delivery of lipoplexes for genotherapy of solid tumours: role of vascular endothelial cells. J Pharm Pharmacol 52: 1301-1317

Dass CR, Saravolac EG, Li Y (2002): Cellular uptake, distribution and stability of 10-23 desoxyribozymes. Antisense Nucleic Acid Drug Dev 12: 289-299

Day TF, Guo X, Garrett-Beal L, YangY (2005): Wnt/ $\beta$-Catenin Signaling in Mesenchymal Progenitors controls Osteoblast and Chondrocyte Differentiation during Vertebrate Skeletogenesis. Dev Cell ㅁ: 739-750

De la Luna S, Ortin J (1992): Pac gene as efficient dominant marker and reporter gene in mammalian cells. Methods Enzymol 216:376-385 
Denli AM, Tops BBJ, Plasterk RHA, Ketting RF, Hannon GJ (2004): Processing of primary microRNAsby the Microprocessor complex. Nature 432: 231-235

Dickins RA, Hemann MT, Zilfou JT, Simpson DR, Ibarra I, Hannon GJ, Lowe SW (2005): Probing tumor phenotypes using stable and regulated synthetic microRNA precursors. Nat Gene 37: 1289-1295

Dobnig H, Turner RT (1995): Evidence That Intermittent Treatment with Parathyroid Hormone Increases Bone Formation in Adult Rats by Activation of Bone Lining Cells. Endocrinology 136: 3632-3638

Dong YF, Soung DY, Schwarz EM, O`Keefe RJ, Drissi H (2006): Wnt linduction of chondrozyte hyperthrophy through the Runx2 transcription factor. J Cell Physiol 208: $77-86$

Doty SB (1981): Morphological Evidence of Gap Junctions Between Bone Cells. Calcif Tissue Int 33: 509-512

Drissi H, Pouliot A, Koolloos C, Stein JL, Lian JB, Stein GS, van Wijnen AJ (2002): 1,25$(\mathrm{OH}) 2-$ Vitamin D3 suppresses the bone-related Runx2/Cbfa1 gene promoter. Exp Cell Res 274: 323-333

Ducy P, Desbois C, Boyce B, Pinero G, Story B, Dunstan C, Smith E, Bonadio J, Goldstein S, Grundberg C (1996): Increased bone formation in osteocalcin-deficient mice. Nature 382: 448-452

Ducy P, Zhang R, Geoffroy V, Ridall AL, Karsenty G (1997): Osf2/Cbfa1: a transcriptional activator of osteoblast differentiation. Cell 89: 747-754

Ducy P, Schinke T, Karsenty G (2000): The osteoblast: a sophisticated fibroblast under central surveillance. Science 289: 1501-1504

Duncan RL, Turner CH (1995): Mechanotransduction and the Functional Response of Bone to Mechanical Strain. Calcif Tissue Int $\underline{57}$ : 344-358

Eijken M, Hewison M, Cooper MS, de Jong FH, Chiba H, Stewart PM, Uitterlinden AG, Pols HA, van Leeuwen JP (2005): 11 -hydroxysteroid dehydrogenase expression and Glucocorticoid synthesis are directed by a molecular switch during Osteoblast Differentiation. Mol Endocrinol 19: 621-631

Elbashir SM, Harborth J, Lendeckel W, Yalcin A, Weber K, Tuschl T (2001): Duplexes of 21 nucleotide RNAs mediate RNA interference in cultured mammalian cells. Nature 411 : 494-498

Enomoto H, Shiojiri S, Hoshi K, Furuichi T, Fukuyama R, Yoshida CA, Kanatani N, Nakamura R, Mizuno A, Zanma A (2003): Induction of osteoclast differentiation by Runx2 through receptor activator of nuclear faktor- $\kappa B$ ligand (RANKL) and osteoprotegerin regulation and partial rescue of osteoclastogenesis in Runx $2^{-/-}$mice by RANKL transgene. J Biol Chem 278: 23971-23977 
Enomoto H, Furuichi T, Zanma A, Yamana K, Yoshida C, Somitani S, Yamamoto H, Enomoto-Iwamoto M, Iwamoto M, Komori T (2004): Runx2 deficiency in chondrocytes causes adipogenic changes in vitro. J Cell Sci 117: 417-425

Everts V, Delaisse JM, Korper W, Jansen DC, Tigchelaar-Gutter W, Saftig P, Beertsen W (2002): The bone linig cells: Its role in cleaning Howship's lacunae and initiating bone formation. J Bone Miner Res 17: 77-90

Felgner JH, Gadek TR, Holm M, Roman R, Chan HW, Wenz M, Northrop JP, Ringold GM, Danielsen M (1987): Lipofection: A highly efficient, lipid-mediated DNA-transfection procedure. Proc Natl Acad Sci USA 84: 7413-7417

Fire A, Xu SQ, Montgomery MK, Kostas SA, Driver SE, Mello CC (1998): Potent and specific genetic interference by double-stranded RNA in Caenorhabditis elegans. Nature $\underline{391}$ : 806-811

Franzen A, Hultenby K, Reinholt FP, Onnerfjord P, Heinegard D (2008): Altered Osteoclast Development and Function in Osteopontin Deficient Mice. J Orthop Res 26:721-728

Frohman MA, Dush MK, Martin GR (1988): Rapid production of full-length cDNAs from rare transcripts: Amplification using a single gene-spezific oligonucleotide primer. Proc Natl Acad Sci 85:8998-9002

Fujino T, Kang MJ, Suzuki H, lijima H, Yamamoto T (1996): Molecular characterization and expression of rat Acyl-CoA Synthetase 3. J Biol Chem 28: 16748-16752

Gartland A, Buckley KA, Dillon JP, Curran JM, Hunt JA, Gallagher JA (2004): Isolation and culture of human osteoblasts. Methods Mol Med 107: 29-54

Gaur T, Lengner CJ, Hovhannisyan H, Bhat RA, Bodine PVN, Komm BS, Javed A, van Wijnen AJ, Stein JL, Stein GS (2005): Canonical WNT Signaling Promotes Osteogenesis by Directly Stimulating Runx2 Gene Expression. J Biol Chem 280: 33132-33140

Gaur T, Rich L, Lengner CJ, Hussain S, Trevant B, Ayers D, Stein JL, Bodine PVN, Komm BS, Stein GS (2006): Secreted frizzled related protein 1 regulates Wnt signaling for BMP2 induced chondrozyte differentation. J Cell Physiol 208: 87-96

Gehl J (2003): Electroporation: theory and methods, perspectives for drug delivery, gene therapy and research. Acta Physiol Scand 177: 437-447

Geoffroy V, Kneissel M, Fournier B, Boyde A, Matthias P (2002): High bone resorption in adult aging transgenic mice overexpressing cbfa1/runx2 in cells of the osteoblastic lineage. Mol Cell Biol 22: 6222-6233

Giesen, M: Die Rolle der Transkriptionsfaktoren "runt-related transcription factor-2" (RUNX2) und Osterix in humanen Osteoblasten. In-vitro-Untersuchung zu Differenzierung und Einfluss der Hemmung von RUNX2 mittels siRNA. Med. Diss. Göttingen 2007 
Golan T, Yaniv A, Bafico A, Liu G, Gazit A (2004): The Human Frizzled 6 (HFz6) Acts as a Negative Regulator of the Canonical Wnt $\beta$-Catenin Signaling Cascade. Biochem Mol Biol 15: 14879-14888

Gordon JAR, Sodek J, Hunter GK, Goldberg HA (2009): Bone Sialoprotein stimulates focal adhesion-related signalling pathways: role in migration and survival of breast and prostate cancer cells. J Cell Biochem 107: 1118-1128

Gori F, Thomas T, Hicok KC, Spelsberg TC, Riggs BL (1999): Differentiation of human marrow stromal precursor cells: bone morphogenetic protein-2 increases OSF2/CBFA1, enhances osteoblast commitment, and inhibits late adipocyte maturation. J Bone Miner Res 14: 1522-1535

Gori F, Hofbauer LC, Dunstan CR, Spelsberg TC, Khosla S, Riggs BL (2000): The expression of Osteoprotegerin and RANK ligand and the support of osteoclast formation by stromal-osteoblast lineage cells is developmentally regulated. Endocrinology 141: 4768-4776

Guo W, Flanagan J, Jasuja R, Kirkland J, Jiang L, Bhasins S (2008): The effects of Myostatin on adipogenic differentation of human bone marrow-derived Mesenchymal Stem Cells are mediated through cross-communication betwenn Smad3 and Wnt/ $\beta$-catenin signaling pathways. J Biol Chem 283: 9136-9145

Hafez IM, Maurer N, Cullis PR (2001): On the mechanism whereby cationic lipids promote intracellular delivery of polynucleic acids. Gene Ther $\underline{8}$ : 1188-1196

Hamilton AJ, Baulcombe DC (1999): A species of small antisense RNA in posttranscriptional gene silencing in plants. Science 286: 950-952

Harada S-I, Rodan GA (2003): Control of osteoblast function and regulation of bone mass. Nature 423: 349-355

Hauge EM, Qvesel D, Eriksen EF, Mosekilde L, Melsen F (2001): Cancellous Bone Remodeling Occurs in Specialized Compartments Lined by Cells Expressing Osteoblastic Markers. J Bone Miner Res 16: 1575-1582

Hauschka PV, Lian JB, Cole DEC, Grundberg CM (1989): Osteocalcin and matrix Gla protein: vitamin K-dependent proteins in bone. Physiol Rev 69: 990-1007

Haylock DN, Nilsson SK (2006): Osteopontin: a bridge between bone and blood $\mathrm{Br} \mathrm{J}$ Haematol 134: 467-474

Hessle L, Johnson KA, Anderson HC, Narisawa S, Sali A, Goding JW, Terkeltaub R, Millan JL (2002): Tissue-nonspecific alkaline phosphatase and plasma cell membrane glycoprotein-1 are central antgonistic regulators of bone mineralization. Proc Natl Acad Sci USA 99(14): 9445-9449 
Higashikawa A, Saito T, Ikeda T, Kamekura S, Kawamura N, Kan A, Oshima, Ohba S, Ogata N, Takeshita K (2009): Identification of the Core Element Responsive to Runt-Related Transcription Factor 2 in the Promoter of Human Type X Collagen Gene. Arthritis Rheum 60: 166-178

Hill TP, Später D, Taketo MM, Birchmeier W, Hartmann C (2005): Canonical Wnt/ $\beta$-Catenin Signaling Prevents Osteoblasts from Differentiating into Chondrocytes. Dev Cell $\underline{8}$ : 727-738

Hsieh J-C, Kodjabachian L, Rebbert ML, Rattner A, Smallwood PM, Samosk CH, Nussek R, Dawid IB, Nathans J (1999): A new secreted protein that binds to Wnt proteins and inhibits their activites. Nature 398: 431-436

Huber W, Heydebreck A, Sultmann H, Poustka A, Vingron M (2002): Variance stablization applied to microarray data calibration and to quantifcation of differentialexpression. Bioinformatics 18:96-104

Hu H, Hilton MJ, Tu X, Yu K, Ornitz DM, Long F (2005): Sequential roles of Hedgehog and Wnt signaling in osteoblast development. Development 132: 49-60

Inada M, Yasui T, Nomura S, Miyake S, Deguchi K, Himeno M, Sato M, Yamagiwa H, Kimura T, Yasui N (1999): Maturation disturbance of chondrocytes in Cbfa1-deficient mice. Dev Dyn 214: 279-290

Jaiswal N, Haynesworth SE, Caplan PD, Bruder SP (1997): Osteogenic Differentiation of Purified, Culture-Expanded Human Mesenchymal Stem Cells In Vitro. J Cell Biochem 64: 295-312

Jeon MJ, Kim JA, Kwon SH, Kim SW, Park KS, Park SW, Kim SY, Shin CS (2003): Activation of peroxisome proliferators-activated-receptor gamma inhibits the Runx2mediated transcription of osteocalcin in osteoblasts. J Biol Chem 278: 23270-23277

Kang JS, Alliston T, Delston R, Derynck R (2005): Repression of Runx2 function by recruitment of class II histone deacetylases by Smad3. EMBO J 24: 2543-2555

Kang S, Bennett CN, Gerin I, Rapp LA, Hankenson KD, MacDougald OA (2007): Wnt Signaling Stimulates Osteoblastogenesis of Mesenchymal Precursors by Suppressing CCAAT/Enhancer-binding Protein $\gamma$ and Peroxisome Proliferator-activated Receptor $\gamma$. J Biol Chem 282: 14515-14524

Kern A, Jundt G, Vonderheid B, Groscurth P, Schulz A, (1990): Establishment and functional characterization of a human osteosarcoma cell line (HOS 58). Calcif Tissue Int $\underline{46}$ : 208

Kishiya M, Sawada T, Kanemaru K, Kudo H, Numasawa T, Yokoyama T, Tanaka S, Motomura S, Ueyama K, Harata S (2008): A functional RNAi screen for Runx2regulated genes associated with ectopic bone formation in human spinal ligaments. $J$ Pharmacol Sci 106: 404-414 
Kocher MS, Shapiro F (1998): Osteogenesis imperfecta. J Am Acad Orthop Surg ㅁ: 225-236

Koga T, Matsui Y, Asagiri M, Kodama T, de Crombrugghe B, Nakashima K, Takayanagi H (2005): NFAT and Osterix cooperatively regulate bone formation. Nature Med 11: 880-885

Komori T (2005): Regulation of skeletal development by the RUNX2 family of transcription factors. J Cell Biochem 95: 445-453

Komori T (2010): Regulation of osteoblast differentation by Runx2. Adv Exp Med Biol $\underline{658}$ : $43-49$

Komori T, Yagi H, Nomura S, Yamaguchi A, Sasaki K, Deguchi K, Shimizu Y, Bronson RT, Gao YH, Inada M (1997): Targeted disruption of CBFA1 results in a complete lack of formation owing to maturational arrest of osteoblasts. Cell 89: 755-764

Kreiss P, Cameron B, Rangara R (1999): Plasmid DNA size does not affect the physicochemical properties of lipoplexes but modulates gene transfer efficiency. Nucleic Acids Res 27: 3792-3798

Kursula P (2008): Structural properties of proteinsspecific to the myelin sheath. Amino Acids 34: $175-185$

Lacey DL, Timms E, Tan HL, Kelley MJ, Dunstan CR, Burgess T, Elliott R, Colombero A, Elliott G, Scully S (1998): Osteoprotegerin ligand is a cytokine that regulates osteoclast differentiation and activation. Cell 93: 165-176

Lappalainen K, Jskeläinen I, Syrjänen J (1994): Comparison of cell proliferation and toxicity assay using two cationic liposomes. Pharm Res 11: 1127-1131

Lee R, Feinbaum R, Ambrost V (1993): The C. elegans heterochronic Gene lin-4 encodes small RNAs with antisense complementarity to lin-14. Cell 75: 843-854

Lee S-K, Lorenzo JA (1999): Parathyroid hormone stimulates TRANCE and inhibits Osteoprotegerin messenger ribonucleic acid expression in murine bone marrow cultures: Correlation with osteoclast-like cell formation. Endocrinology 140: 35523561

Lee Y, Ahn C, Han J, Choi H, Kim J, Yim J, Lee J, Provost P, Radmark O, Kim S (2003):The nuclear RNase III Drosha initiates microRNA processing. Nature 425: 415-419

Levanon D, Groner Y (2004): Structure and regulated expression of mammalian RUNX genes. Oncogene 23: 4211-4219.

Levanon D, Bettoun D, Harris-Cerruti C, et al. (2002): The Runx3 transcription factor regulates development and survival of TrkC dorsal root ganglia neurons. EMBO J 21: 3454-3463.

Li QL, Ito K, Sakakura C, Fukamachi H, Inoue K, Chi XZ, Lee KY, Nomura S, Lee CW, Han SB (2002): Causal relationship between the loss of RUNX3 expression and gastric cancer. Cell 109:113-24 
Lin AJ, Slack NL, Ahmad A (2003): Three-dimensional imaging of lipid gene-carriers: membrane charge density controls universal transfection behavior in lamellar cationic liposome-DNA complexes. Biophys J $\underline{84}$ : 3307-3316

Liu J, Carmell MA, Rivas FV, Marsden CG, Thomson JM, Song J, Hammond SM, Tor L, Hannon GJ (2004): Argonaute2 is the catalytic engine of mammalian RNAi. Science 305: 1437-1441

Liu W, Toyosawa S, Furuichi T, Kanatani N, Yoshida C, Liu Y, Himeno M, Narai S, Yamaguchi A, Komori T (2001): Overexpression of Cbfa1 in osteoblasts inhibits osteoblast maturation and causes osteopenia with multiple fractures. J Cell Biol 155: 157-166

Livak KJ, Schmittgen TD (2001): Analysis of relative gene expression data using Real-Time Quantitative PCR and the $2^{-\Delta \Delta C t}$ method. Methods $\underline{25}$ : 402-408

Lüllmann-Rauch R: Histologie. Georg Thieme Verlag, Stuttgart 2003

Maranchie JK, Zhan Y (2005): Nox4 is critical for Hypoxia-Inducible Factor 2-A transcriptional activity in von Hippel-Lindau-Deficient Renal Cell Carcinoma. Cancer Res 20: $9190-9193$

Marie PJ (2008): Transcription factors controlling osteoblastogenesis. Arch Biochem Biophys 473: 98-105

Marks SC Jr, Popoff SN (1988): Bone cell biology: the regulation of development, structure and function in the skeleton. Am J Anat 183: 1-44

Martin SE, Caplen NJ (2007): Applications of RNA interference in Mammalian Systems. Annu Rev Genom Human Genet $\underline{\text { : }}$ 81-108

Meister G, Landthaler M, Patkaniowska A, Dorsett Y, Teng G, Tuschl T (2004): Human Argonaute2 mediates RNA cleavage targeted by miRNAs and siRNAs. Mol Cell $\underline{15}$ : 185-197

Michel D, Arsanto J, Massey-Harroche D, Béclin C, Wijnholds J, Le Bivic A (2005) : PATJ connects and stabilizes apical and lateral components of tight junctions in human intestinal cells. J Cell Sci 118: 4049-4057

Millan JL (2006): Alkaline Phosphatases: Structure, substrate specifity and functional relatedness to other members of a large superfamily of enzymes. Purinergic Signal. 2: $335-341$

Miller SC, Jee WSS (1987): The bone lining cells: A distinct phenotype? Calcif Tissue Int $\underline{41}$ : $1-5$

Morava E, Karteszi J, Weisenbach J, Caliebe A, Mundlos S, Mehes K (2002): Cleidocranial dysplasia with decreased bone density and biochemical findings of hypophosphatasia. Eur J Pediatr 161: 619-622

Moss DW (1992): Perspectives in alkaline phosphatase research. Clin Chem 38: 2486-2492 
Motyl KJ, McCabe LR, Schwartz AV (2010): Bone and glucose metabolism: a two-way street. Arch Biochem Biophys 503: 2-10

Mui B, Ahkong QF, Chow L, Hope MJ (2000): Membrane perturbation and the mechanism of lipid-mediated transfer of DNA into cells. Biochem Biophys Acta 1467: 281-292

Mundlos S, Otto F, Mundlos C, Mulliken JB, Aylsworth AS, Albright S, Lindhout D, Cole WG, Henn W, Knoll JH (1997): Mutations involving the transkriptionfactor CBFA1 cause cleidocranial dysplasia. Cell 89: 773-779

Nakano S, Inada Y, Masuzaki H, Tanaka T, Yasue S, Ishii T, Arai N, Ebihara K, Hosoda K, Maruyama K (2006): Bezafibrate regulates the expression and enzyme activity of 11 $\beta$-hydroxysteroid dehydrogenase type 1 in murine adipose tissue and 3T3-L1 adipocytes. Am J Physiol Endocrinol Metab 292: 1213-1222

Nakashima K, Zhou X, Kunkel G, Zhang Z, Deng JM, Behringer RR, Crombrugghe B (2002): The novel zinc finger-containing transcription factor osterix is required for osteoblast differentiation and bone formation. Cell 108: 17-29

Neumann E, Schaefer-Ridder M, Wang Y, Hofschneider PH (1982): Gene transfer into mouse lyoma cells by electroporation in high electric fields. EMBO J 1:841-845

Nöth U, Osyczka AM, Tuli R, Hickok NJ, Danielson KG, Tuan RS (2002): Multilineage mesenchymal differentiation potential of human trabecular bone derived cells. $\mathrm{J}$ Orthop Res 20: 1060-1069

Nuttall ME, Patton AJ, Olivera DL, Nadeau DP, Gowen M (1998): Human trabecular bone cells are able to express both osteoblastic and adipocytic phenotype: implications for osteopenic disorders. J Bone Miner Res 13: 371-381

Nuytinck L, Freund M, Lagae L, Pierard GE, Hermanns-Le T, De Paepe A (2000): Classical Ehlers-Danlos Syndrome Caused by a Mutation in Type I Collagen. Am J Hum Genet $\underline{66}: 1398-1402$

Odermatt A, Arnold P, Frey FJ (2001): The intracellular localization of the mineralocorticoid receptor is regulated by $11 \beta$-Hydroxysteroid Dehydrogenase type 2 . J Biol Chem 276 : 28484-28492

Okada H, Watanabe T, Niki M (1998): AML1(-l-) embryos do not express certain hematopoiesis- related gene transcripts including those of the PU.1 gene. Oncogene 17: 2287-2293.

Orimo H, Girschick HJ, Goseki-Sone M, Ito M, Oda K, Shimada T (2001): Mutational Analysis and functional correlation with phenotype in German patients with childhoodtype Hypophophatasia. J Bone Miner Res 16: 2313-2319 
Otto F, Thornell AP, Crompton T, Denzel A, Gilmour KC, Rosewell IR, Stamp GWH, Beddington RSP, Mundlos S, Olsen BR (1997): Cbfa1, a candidate gene for Cleidocranial Dysplasia Syndrome, is essential for osteoblast differentiation and bone development. Cell 89: 747-754

Owen TA, Aronow M, Shalhoub V, Barone LM, Wilming L, Tassinari MS, Kennedy MB, Pockwinse S, Lian JB, Stein GS (1990): Progressive development of rat osteoblast phenotype in vitro: reciprocal relationships in expression of genes associated with osteoblast proliferation and differentiation during formation of the bone extracellular matrix. J Cell Physiol 143: 420-430

Paddison PJ, Caudy AA, Bernstein E, Hannon GJ, Conklin DS (2002): Short hairpin RNAs (shRNAs) induce sequence-specific silencing in mammalian cells. Genes Dev 16: 948-958

Palumbo C (1986):A three-dimensional ultrastructural study of osteoid-osteocytes in the tibia of chick embryos. Cell Tissue Res 246:125-131

Pan K, Yan S, Ge S, Li S, Zhao Y, Yang P (2009): Effects of core binding factora1 or bone morphogenic protein-2 overexpression on osteoblast/cementoblast-related gene expression in NIH3T3 mouse cells and dental follicle cells. Cell Prolif $\underline{42}$ : 364-372

Parfitt AM (1977): The Cellular Basis of Bone Turnover and bone loss. Clin Orthop Rel Res 127: $236-247$

Parfitt AM (1994): Osteonal and hemi-osteonal remodelling: the spatial and temporal framework for signal traffic in adult bone. J Cell Biochem 55: 273-286

Paul CP, Good PD, Winer I, Engelke DR (2002): Effective expression of small interfering RNA in human cells. Nat Biotechnol 20: 505-508

Pixley FJ, Stanley ER (2004): CSF-1 regulation of the wandering macrophage: complexity in action. Trends Cell Biol 14:-628-638

Quarles DL, Yohay DA, Lever LW, Caton R, Wenstrup RJ (1992): Distinct proliferative and differentiated stages of murine MC3T3-E1 cells in culture: an in vitro model of osteoblasts development. J Bone Miner Res 7: 639-650

Raggatt LJ, Partridge NC (2010): Cellular and molecular mechanisms of bone remodelling. J Biol Chem 285 (33): 25103 - 25108

Reinhold MI, Naski MC (2007): Direct interactions of Runx2 and canonical Wnt signaling induce FGF18. J Biol Chem 282: 3653-3663

Robling AG, Castillo AB, Turner CH (2006): Biomechanical and molecular regulation of bone remodelling. Annu Rev Biomed Eng ㅁ: 455-498 
Roca H, Phimphilai M, Gopalakrishnan R, Xiao G, Franceschi RT (2005): Cooperative interactions between Runx2 and Homeodomain Protein-binding sites are critical for the osteoblast-specific expression of the Bone Sialoprotein gene. J Biol Chem $\underline{280}$ : 30845-30855

Rodan GA (1995): Osteopontin Overview. Ann NY Acad Sci 760:1-5

Rodan GA, Martin TJ (1981): Role of osteoblasts in hormonal control of bone resorption- a hypothesis. Calcif Tissue Int $\underline{33}$ : 349-351

Rose SD, Kim DH, Amarzguioui M, Heidel JD, Collingwood MA, Davis ME, Rossi JJ, Behlke MA (2005): Functional polarityis introduced by Dicer processing of short substrate RNAs. Nucleic Acids Res 33: 4140-4156

Ross FP, Christiano AM (2006): Nothing but skin and bone. J Clin Invest 116: 1140-1149

Russel RG (1965): Excretion of inorganic Pyrophosphate in Hypophosphatasia. Lancet 286: 461-464

Saiki RK, Scharf S, Falcoona F, Mullis KB, Horn GT, Erlich HA, Arnheim N (1985): Enzymatic amplification of beta-globin genomic sequences and restriction site analysis for diagnosis of sickle cell anemia. Biotechnology 24: 467-480

Salingcarnboriboon R, Tsuji K, Komori T, Nakashima K, Ezura Y, Noda M (2006): Runx2 is a target of mechanical unloading to alter osteoblastic activity and bone formation in vivo. Endocrinology 147: 2296-2305

Sanger F, Nicklen S, Coulson AR (1977): DNA sequencing with chain-terminating inhibitors. Proc Nat Acad Sci USA 74: 5463-5467

Scheer M, Eder M (2007): Gene silencing by small regulatory RNAs in mammlian cells. Cell Cycle $\underline{6}$ : 444-449

Schröder TM, Jensen ED, Westendorf JJ (2005): Runx2: a master organizer of gene transcription in developing and maturing osteoblasts. Birth Defects Res C Embryo Today $\underline{75}$ : 213-225

Schulz A, Battmann A, Heinrichs CM, Kern A, Tiedemann A, Bürger H, Fohr B, Hani N, Pietruck C, Busk H (1993): Properties and reactivity of a new human osteosarcoma cell line (HOS 58). Calcif Tissue Int (Suppl 1) $\underline{52}$ : S8 (30)

Seckl JR, Walker BR (2001): Minireview: 11ß-Hydroxysteroid Dehydrogenase type 1-a tissue-specific amplifier of glucocorticoid action. Endocrinology 142: 1371-1376

Segditsas S, Sieber O, Deheragoda M, East P, Rowan A, Jeffery R, Nye E, Clark S, Spencer-Dene B, Stamp G (2008): Putative direct and indirect Wnt targets identified through consistent gene expression changes in APC-mutant intestinal adenomas from humans and mice. Hum Mol Gene 24: 3864-3875

Seibel MJ (2005): Biochemical Markers of Bone Turnover Part I: Biochemistry and Variability Clin Biochem Rev 26: 97-122 
Shen V, Hruska K, Avioli LV (1988): Characterization of a (Ca2+ + Mg2+) - ATPase System in the Osteoblast Plasma Membrane. Bone 9: 325-329

Siggelkow H, Niedhart C, Kurre W, Ihbe A, Schulz A, Atkinson MJ, Hüfner M (1998a): In vitro differentiation potential of a new human osteosarcoma cell line (HOS 58). Differentiation $\underline{62}:$ 81-91

Siggelkow H, Neubauer K, Schulz H, Krüger M, Ramadori G, Hüfner M (1998b): Einfluß von Ascorbat auf das Kollagenprozessing und die Sekretion von Procollagen-I-Peptid in primären humanen Osteoblasten. Osteologie 7: 31

Siggelkow H, Rebenstorff K, Kurre W, Niedhart C, Engel I, Schulz H, Atkinson MJ, Hüfner M (1999): Development of the osteoblast phenotype in primary human osteblasts in culture: Comparison with rat calvarial cells in osteoblast differentiation. J Cell Biochem 75: 22-35

Siggelkow H, Schenck RM, Rohde M, Viereck V, Tauber S, Atkinson MJ, Hüfner M (2002):

Prolonged culture of HOS 58 human osteosarcoma cells with 1,25(OH)2-d3, TGFbeta, and dexamethason reveals physiological regulation of alkaline phosphatase, dissociated osteocalcin gene expression, and protein synthesis and lack of mineralization. J Cell Biochem 85: 279-294

Siggelkow H, Schmidt E, Hennies B, Hüfner M (2004): Evidence of downregulation of matrix extracellular phosphoglycoprotein during terminal differentiation in human osteoblasts. Bone $\underline{35}$ : 570-576

Simonet WS, Lacey DL, Dunstan CR, Kelley M, Chang M-S, Luthy R, Nguyen HQ, Wooden S, Bennett L, Boone T (1997): Osteoprotegerin: A novel secreted proteininvolved in the regulation of bone density. Cell $\underline{89}$ : 309-319

Smyth GK: Linear models for Microarray data; in: Bioinformatics and Computational Biology Solutions using R and Bioconductor; hrsg. v. Gentleman R, Carey V, Dudoit S, Irizarry R, Huber W; Springer, New York (2005): 397-420

Song L, Tuan RS (2004): Transdifferentiation potential of human mesenchymal stem cells derived from bone marrow. FASEB J 18: 980-982

Spencer GJ, Utting JC, Etheridge SL, Arnett TR, Genever PG (2006): Wnt signalling in osteoblasts regulates expression ofthe receptor activator of NFKB ligand and inhibits osteoclastogenesis in vitro. J Cell Sci 119: 1283-1296

Stegmeier F, Hu G, Rickles RJ, Hannon GJ, Elledge SJ (2005): A lentiviral microRNAsbased system for single-copy polymerase II-regulated RNA Interference in mammalian cells. Proc Natl Acad 102: 13212-13217

Tai G, Polak JM, Bishop AE, Christodoulou I, Buttery LD (2004): Differentiation of osteoblasts from murine embryonic stem cells by overexpression of transcriptional factor Osterix. Tissue Eng 10: 1456-1466 
Takeda S, Bonnamy JP, Owen MJ, Ducy P, Karsenty G (2001): Continuous expression of Cbfa1 in nonhypertrophic chondrocytes uncovers its ability to induce hypertrophic chondrocyte differentiation and partially rescues Cbfa1-deficient mice. Genes Dev $\underline{15}$ : 467-481

Teitelbaum SL (2000): Bone resorption by osteoclasts. Science 289: 1504-1508

Tezukat K-I, Sate T, Kamiokas H, Nijweide PJ, Tanaka K, Matsuos T, Ohtas M, Kuriharaz N, Hakedat Y, Kumegawal M (1992): Identification of Osteopontin in isolated Rabbit Osteoclasts. Biochem Biophys Res Commun 186: 911-917

Thomson JM, Newman M, Parker JS, Morin-Kensicki EM, Wright T, Hammond SM (2006): Extensive post-transcriptional regulation of microRNAs and its implications for cancer. Genes Dev 20: 2202-2207

Udagawa N, Takahashi N, Akatsu T, Tanaka H, Sasaki T, Nishihara T, Koga T, Martins TJ, Suda T (1990): Origin of osteoclasts: Mature monocytes and macrophages are capable of differentiating into osteoclasts under a suitable microenvironment prepared by bone marrow-derived stromal cells. Proc Natl Acad Sci USA 87: 7260-7264

Vaes BL, Ducy P, Sijbers AM, Hendriks JM, van Someren EP, de Jong NG, van den Heuvel ER, Olijve W, van Zoelen EJ, Dechering KJ (2006): Microarray analysis on Runx2deficient mouse embryos reveals novel Runx2 functions and target genes during intramembranouse and endochondral bone formation. Bone 39:724-738

Valverde P, Zhang J, Fix A, Zhu J, Ma W, Tu Qisheng, Chen J (2008): Overexpression of Bone Sialoprotein Leads to an Uncoupling of Bone Formation and Bone Resorption in Mice. J Bone Miner Res 23: 1775-1788

Wang YH, Ho ML, Chang JK, Chu HC, Lai SC, Wang GJ (2009): Microporation is a valuable transfection method for gene expression in human adipose tissue-derived stem cells. Mol Ther 17: 302-308

Wennberg C, Hessle L, Lundberg P, Mauro S, Narisawa S, Lerner UH, Millan JL (2000): Functional characterization of osteoblasts and osteoclasts from alkaline phosphate knock out mice. J Bone Miner Res 15: 1879-1888

Wetterwald A, Hofstetter W, Cecchini MG, Lanske B, Wagner C, Fleisch H, Atkinson M (1996): Characterization and Cloning of the E11 Antigen, a Marker Expressed by Rat Osteoblasts and Osteocytes. Bone 18: 125-132

Xia H, Mao Q, Paulson H, Davidson B (2002): siRNA-mediated gene silencing in vitro and in vivo. Nat Biotech 20: 1006-1010.

Yi R, Doehle BP, Qin Y, Macara IG, Cullen BR (2005): Overexpression of Exportin 5 enhances RNA Interference mediated by short hairpin RNAs and microRNAs. RNA 11: $220-226$ 
Yoshida CA, Yamamoto H, Fujita T (2004): Runx2 and Runx3 are essential for chondrocyte maturation, and Runx2 regulates limb growth through induction of Indian hedgehog. Genes Dev 18: 952-963

You LD, Weinbaum S, Cowin SC, Schaffler MB (2004): Ultrastructure of the ostoecyte process and its pericellular matrix. Anat $\operatorname{Rec} \underline{278}$ : 505-513

Yu JY, DeRuiter SL, Turner DL (2002): RNAinterference by expression of short-interfering RNAs and hairpin RNAs in mammalian cells. Proc Natl Acad Sci USA 108 (9): 60476052

Zhang L, Ge L, Parimoo S, Stenn K, Prouty SM (1999): Human steraoyl CoA desaturase: alternative transcripts generated from a single gene by usage of tandem polyadenylation sites. J Biochem 340: 255-264

Zhang X, Yang M, Lin L, Chen P, Ma KT, Zhou CY, Ao YF (2006): Runx2 overexpression enhances osteoblastic differentation and mineralization in adipose-derived stem cells in vitro and in vivo. Calcif Tissue Int 79: 169-178

Zheng Q, Zhou G, Morello R, Chen Y, Garcia-Rojas X, Lee B (2003): Type X collagen gene regulation by Runx2 contributes directly to its hypertrophic chondrozyte-specific expression in vivo. J Cell Biol 162: 833-842

Zuidam NJ, Barenholz Y (1998): Electrostatic and structural properties of complexes involving plasmid DNA and cationic lipids commonly used for gene delivery. Biochem Biophys Acta 1368: 115-128 


\section{Danksagung}

Bei den nachfolgend genannten Personen möchte ich mich ganz herzlich bedanken:

Herrn Professor Dr. med. Dr. h.c. G. Ramadori möchte ich für die Möglichkeit der Durchführung meiner Promotion in der Abteilung Gastroenterologie und Endokrinologie des Universtätsklinkums Göttingen danken.

Frau Professor Dr. med. Heide Siggelkow gilt mein ganz besonderer Dank. Durch die Kreierung einer innovativen und freundlichen Arbeitsatmosphäre fühlte ich mich in ihrer Arbeitsgruppe ausgesprochen gut aufgehoben und unterstützt. Durch immerwährende Ansprechbarkeit, Hilfsbereitschaft, zielführenden Anregungen und konstruktiver Kritik gelang es Frau Professor Siggelkow auch in schwierigen Phasen der Dissertationsentstehung erneute Motivationen zu schaffen.

Frau Dr. rer. nat. Martina Blaschke kann an dieser Stelle nicht genügend gedankt werden. Ohne ihre Unterstüzung bei der Planung, der Durchführung und der Auswertung der gemachten Experimente wäre die Durchführung dieser Dissertation nicht im Asatz realisierbar gewesen.

Frau Regine Köpp und Frau Doris Krause danke ich für die Einführung in die entsprechenden Methoden der Zellkultur und der Molekularbiologie und für die stets vorhandene Hilfsbereitschaft im Laboralltag.

Herrn Professor Dr. med. Nicolai Miosge danke ich für die Möglichkeit, die Nukleofektion als Transfektionsmethode in pHOB etablieren zu können.

Frau Vera Ritz und Herrn Dr. rer. nat. Mladen Tzvetkov danke ich für die Hilfe bei der Planung, Klonierung, Sequenzierung und Präparation der benutzten siRNAExpressionsvektoren.

Frau Dr. rer. nat. Gabriela Salinas-Riester und Herrn Dipl. Bioinf. Lennart Opitz danke ich für die Hilfe bei der Anfertigung des RNA-Microarrays.

Meinen Kollegen Markus Giesen, Philipp Braun und Thomas Janyga danke ich für die kollegiale und nette Zusammenarbeit im Forschungslabor. 


\section{Curriculum vitae}

Ich, Kai-Henrik Peiffer, wurde am 01.12.1982 in Bad Harzburg als Sohn des Internisten Dr. med. Wolfgang Peiffer und der Allgemeinmedizinerin Dr. med. Dorothee Peiffer geboren. Meine schulische Laufbahn absolvierte ich von 1989-1994 in der Brakenhoffschule, von 1994-1996 in der Robert-Danemann-Schule und von 1996-2002 in dem Gymnasium in Westerstede und erlangte hier die Allgemeine Hochschulreife.

Meinen Zivildienst leistete ich von 2002-2003 auf einer kinderchirurgischen Station im Altonaer Kinderkrankenhaus in Hamburg ab.

Im Wintersemsester 2003/ 2004 durfte ich mein Studium der Humanmedizin an der GeorgAugust-Universität in Göttingen beginnen, woraufhin ich im Sommer 2005 den ersten Abschnitt der ärztlichen Prüfung bestand.

In den folgenden Jahren hatte ich die Möglichkeit in Hamburg, Westerstede, Göttingen und Kapstadt (Südafrika) zu famulieren. Mein Praktisches Jahr absolvierte ich in Stoke-on-Trent (England), Oldenburg und Bremen.

Den zweiten Abschnitt der ärztlichen Prüfung bestand ich im Herbst 2009. Am 23.11.2009 erhielt ich die Approbation als Arzt.

Seit dem 01.02.2010 darf ich nun als Assistenzarzt unter der Direktion von Professor Dr. med. Zeuzem in der Medizinischen Klinik 1 des Klinikums der Johann Wolfgang GoetheUniversität in Frankfurt tätig sein. 